\title{
Physiotherapy for pain and disability in adults with complex regional pain syndrome (CRPS) types I and II \\ Review information
}

\section{Review number: 283}

\section{Authors}

Keith M Smart ${ }^{1}$, Benedict M Wand ${ }^{2}$, Neil E O'Connell ${ }^{3}$

${ }^{1}$ Physiotherapy Department, St Vincent's University Hospital, Dublin, Ireland

${ }^{2}$ School of Physiotherapy, The University of Notre Dame Australia, Fremantle, Australia

${ }^{3}$ Department of Clinical Sciences/Health Economics Research Group, Institute of Environment, Health and Societies, Brunel University, Uxbridge, UK

Citation example: Smart KM, Wand BM, O'Connell NE. Physiotherapy for pain and disability in adults with complex regional pain syndrome (CRPS) types I and II. Cochrane Database of Systematic Reviews 2016, Issue 2. Art. No.: CD010853. DOI: 10.1002/14651858.CD010853.pub2.

\section{Contact person}

\section{Keith M Smart}

Physiotherapy Department

St Vincent's University Hospital

Elm Park

4 Dublin

Ireland

E-mail:k.smart@svuh.ie

\section{Dates}

$\begin{array}{ll}\text { Assessed as Up-to-date: } & 15 \text { February } 2015 \\ \text { Date of Search: } & 15 \text { February } 2015 \\ \text { Next Stage Expected: } & 01 \text { March } 2018 \\ \text { Protocol First Published: } & \text { Issue 11, } 2013 \\ \text { Review First Published: } & \text { Issue 2, 2016 } \\ \text { Last Citation Issue: } & \text { Issue 2, } 2016\end{array}$

What's new

Date / Event Description

History 


\section{Abstract}

\section{Background}

Complex regional pain syndrome (CRPS) is a painful and disabling condition that usually manifests in response to trauma or surgery. When it occurs, it is associated with significant pain and disability. It is thought to arise and persist as a consequence of a maladaptive pro-inflammatory response and disturbances in sympathetically-mediated vasomotor control, together with maladaptive peripheral and central neuronal plasticity. CRPS can be classified into two types: type I (CRPS I) in which a specific nerve lesion has not been identified, and type II (CRPS II) where there is an identifiable nerve lesion. Guidelines recommend the inclusion of a variety of physiotherapy interventions as part of the multimodal treatment of people with CRPS, although their effectiveness is not known.

\section{Objectives}

To determine the effectiveness of physiotherapy interventions for treating the pain and disability associated with CRPS types I and II.

\section{Search methods}

We searched the following databases from inception up to 12 February 2015: CENTRAL (the Cochrane Library), MEDLINE, EMBASE, CINAHL, PsycINFO, LILACS, PEDro, Web of Science, DARE and Health Technology Assessments, without language restrictions, for randomised controlled trials (RCTs) of physiotherapy interventions for treating pain and disability in people CRPS. We also searched additional online sources for unpublished trials and trials in progress.

\section{Selection criteria}

We included RCTs of physiotherapy interventions (including manual therapy, therapeutic exercise, electrotherapy, physiotherapist-administered education and cortically directed sensory-motor rehabilitation strategies) employed in either a stand-alone fashion or in combination, compared with placebo, no treatment, another intervention or usual care, or of varying physiotherapy interventions compared with each other in adults with CRPS I and II. Our primary outcomes of interest were patient-centred outcomes of pain intensity and functional disability.

\section{Data collection and analysis}

Two review authors independently evaluated those studies identified through the electronic searches for eligibility and subsequently extracted all relevant data from the included RCTs. Two review authors independently performed 'Risk of bias' assessments and rated the quality of the body of evidence for the main outcomes using the Grading of Recommendations Assessment, Development and Evaluation (GRADE) approach.

\section{Main results}

We included 18 RCTs (739 participants) that tested the effectiveness of a broad range of physiotherapy-based interventions. Overall, there was a paucity of high quality evidence concerning physiotherapy treatment for pain and disability in people with CRPS I. Most included trials were at 'high' risk of bias (15 trials) and the remainder were at 'unclear' risk of bias (three trials). The quality of the evidence was very low or low for all comparisons, according to the GRADE approach.

We found very low quality evidence that graded motor imagery (GMl; two trials, 49 participants) may be useful for improving pain (0 to 100 VAS) (mean difference (MD) $-21.00,95 \% \mathrm{Cl}-31.17$ to -10.83 ) and functional disability (11-point numerical rating scale) (MD 2.30, 95\% $\mathrm{Cl} 1.12$ to 3.48), at long-term (six months) follow-up, in people with CRPS I compared to usual care plus physiotherapy; very low quality evidence that multimodal physiotherapy (one trial, 135 participants) may be useful for improving 'impairment' at long-term (12 month) 
follow-up compared to a minimal 'social work' intervention; and very low quality evidence that mirror therapy (two trials, 72 participants) provides clinically meaningful improvements in pain (0 to $10 \mathrm{VAS}$ ) (MD $3.4,95 \% \mathrm{Cl}$ -4.71 to -2.09 ) and function ( 0 to 5 functional ability subscale of the Wolf Motor Function Test) (MD - 2.3, $95 \% \mathrm{Cl}-2.88$ to -1.72 ) at long-term (six month) follow-up in people with CRPS I post stroke compared to placebo (covered mirror).

There was low to very low quality evidence that tactile discrimination training, stellate ganglion block via ultrasound and pulsed electromagnetic field therapy compared to placebo, and manual lymphatic drainage combined with and compared to either anti-inflammatories and physical therapy or exercise are not effective for treating pain in the short-term in people with CRPS I. Laser therapy may provide small clinically insignificant, short-term, improvements in pain compared to interferential current therapy in people with CRPS I.

Adverse events were only rarely reported in the included trials. No trials including participants with CRPS II met the inclusion criteria of this review.

\section{Authors' conclusions}

The best available data show that GMI and mirror therapy may provide clinically meaningful improvements in pain and function in people with CRPS I although the quality of the supporting evidence is very low. Evidence of the effectiveness of multimodal physiotherapy, electrotherapy and manual lymphatic drainage for treating people with CRPS types I and II is generally absent or unclear. Large scale, high quality RCTs are required to test the effectiveness of physiotherapy-based interventions for treating pain and disability of people with CRPS I and II. Implications for clinical practice and future research are considered.

\section{Plain language summary}

\section{Physiotherapy for pain and disability in adults with complex regional pain syndrome (CRPS) types I and II}

\section{Background}

Complex regional pain syndrome (CRPS) is a painful and disabling condition. Most commonly it affects a person's arm and hand or leg and foot and may occur after a traumatic injury. There are two types of CRPS: CRPS I in which there is no nerve injury, and CRPS II in which there is a nerve injury. Guidelines recommend physiotherapy, which could include different kinds of exercise therapy or electrotherapy for instance, along with other medical treatments for treating the pain and disability associated with CRPS. However, we do not know how well these treatments work.

\section{Review question}

Which types of physiotherapy treatment are effective for reducing the pain and disability associated with CRPS in adults?

\section{Study characteristics}

We searched for clinical trials of physiotherapy up to 12 February 2015. We included 18 trials that had 739 participants with CRPS I. In most of these trials the participants had CRPS I of the arm and hand. We did not find any clinical trials that included participants with CRPS II.

\section{Key results}

Overall we did not find any good quality clinical trials of physiotherapy aimed at reducing the pain and disability of CRPS I in adults. Most included trials were not well designed and contained only small numbers of patients. We did find some low quality trials suggesting that two broadly similar types of rehabilitation training, known as 'graded motor imagery' (GMI) and 'mirror therapy', might be useful for reducing the pain and disability 
associated with CRPS I after traumatic events or surgery or a stroke. From the limited evidence available it appears that some types of electrotherapy, such as ultrasound and pulsed electromagnetic field therapy, as well as a type of massage therapy known as manual lymphatic drainage, are not effective. Most studies did not report on adverse events and so we do not know if these treatments have any harmful side-effects.

On the whole, because of the limited number and low quality of available trials for the various physiotherapy treatments, we cannot be sure if any of the physiotherapy treatments we evaluated are effective for treating the pain and disability of CRPS I in adults. It is possible that some treatments, such as GMI or mirror therapy, might be effective. Further high quality clinical trials of physiotherapy are needed in order to find out if any of the different types of physiotherapy treatment are effective at improving pain and disability in people with CRPS.

\section{Background}

\section{Description of the condition}

Complex regional pain syndrome (CRPS) is a persistent, painful and disabling condition that usually, but not exclusively, manifests in response to acute trauma or surgery (Goebel 2011; Shipton 2009). The International Association for the Study of Pain (IASP) introduced the diagnostic label 'CRPS' in the 1990s in order to standardise inconsistencies in terminology and diagnostic criteria (Merskey 1994). Two sub-categories of CRPS have been described: CRPS type I (CRPS I) (formerly and variously referred to as reflex sympathetic dystrophy (RSD), algodystrophy, Sudek's atrophy) in which no nerve lesion is present and CRPS type II (CRPS II) (formerly referred to as causalgia, algoneurodystrophy), in which a co-existing nerve lesion (as determined by nerve conduction studies or surgical inspection for example) is present (Coderre 2011; Todorova 2013).

CRPS is characterised by symptoms and signs typically confined to a body region or limb, but which may become more widespread (van Rijn 2011). The diagnostic criteria for CRPS originally proposed by the IASP (Merskey 1994) have since been revised in response to their low specificity and potential to over-diagnose cases of CRPS. The Budapest criteria proposed by Harden 2010 have enhanced diagnostic accuracy and are now widely accepted (Goebel 2011). The diagnosis of CRPS is clinical (Goebel 2011) and the cardinal features include:

1. continuing pain disproportionate to any inciting event;

2. the presence of clusters of various symptoms and signs reflecting sensory (e.g. hyperaesthesia, allodynia), vasomotor (e.g. asymmetries of temperature or skin colour, or both), sudomotor (e.g. oedema or altered sweating or both), motor (e.g. reduced range of motion, tremor) or trophic (e.g. altered hair or nails, or both) disturbances; and

3. the absence of any other medical diagnosis that might better account for an individual's symptoms and signs.

The pathophysiological mechanisms underlying CRPS are not fully understood (Harden 2010). Current understanding implicates multiple mechanisms including complex contributions from a maladaptive pro-inflammatory response and a disturbance in sympathetically mediated vasomotor control, together with maladaptive peripheral and central neuronal plasticity (Bruehl 2010; Bruehl 2015; Marinus 2011; Parkitny 2013). Furthermore, mechanisms, and in consequence symptoms and signs, may vary between individuals and within individuals over the time course of the disorder, thus heightening the complexity (Marinus 2011).

The incidence of CRPS is not accurately known but population estimates indicate an incidence of somewhere between five and 26 cases per 100,000 person-years (Marinus 2011). A likely conservative 11-year period prevalence rate for CRPS of 20.57 per 100,000 people has been reported (Sandroni 2003). CRPS is three to 
four times more likely to occur in women than in men, and although it may occur at any time throughout the lifespan it tends to occur more frequently with increasing age (Shipton 2009). Genetic susceptibility may serve as an aetiological risk factor for the development of CRPS (de Rooij 2009). In individuals who develop CRPS after a fracture, intra-articular fracture, fracture-dislocation, pre-existing rheumatoid arthritis, pre-existing musculoskeletal co-morbidities (e.g. low-back pain, arthrosis) (Beerthuizen 2012) and limb immobilisation (Marinus 2011) may increase the risk of its development. Psychological traits, such as depression, anxiety, neuroticism and anger, have so far been discounted as risk factors for the development of CRPS (Beerthuizen 2009: Lohnberg 2013), although further prospective studies are required to substantiate this assertion (Harden 2013).

People with CRPS experience significant suffering and disability (Bruehl 2010; Lohnberg 2013). Preliminary data suggest that interference with activities of daily living, sleep, work and recreation is common and further contributes to a diminished quality of life (Galer 2000; Geertzen 1998; Kemler 2000; Sharma 2009).

Studies into the course of CRPS present contradictory findings. Whilst some studies have reported complete and partial symptom resolution within one year (Sandroni 2003; Zyluk 1998), other studies have indicated more protracted symptoms and impairments lasting from three to nine years (de Mos 2009; Geertzen 1998; Vaneker 2006). In addition, emerging evidence suggests that people with CRPS of an upper limb (which develops less often in response to a fracture) and whose affected limb is colder than the contralateral limb, may experience significantly longer disease duration than people with CRPS of a lower limb (which occurs more commonly after fracture) and whose affected limb is warmer than the contralateral limb (de Mos 2009).

Although guidelines for the treatment of CRPS recommend an interdisciplinary multimodal approach, comprising pharmacological and interventional pain management strategies together with rehabilitation, psychological therapy and educational strategies (Goebel 2012; Harden 2013; Perez 2010;

Stanton-Hicks 2002), determining the optimal approach to therapy remains clinically challenging (Cossins 2013; O'Connell 2013).

\section{Description of the intervention}

Guidelines recommend the inclusion of a variety of physiotherapy interventions as part of the multimodal treatment of CRPS (Goebel 2012; Perez 2010; Stanton-Hicks 2002) but their effectiveness is not known. Physiotherapy has been defined as "the treatment of disorders with physical agents and methods" (Anderson 2002) and for CRPS could include any of the following interventions employed either as stand-alone interventions or in combination: manual therapy (e.g. mobilisation, manipulation, massage, desensitisation); therapeutic exercise and progressive loading regimens (including hydrotherapy); electrotherapy (e.g. transcutaneous electrical nerve stimulation (TENS), therapeutic ultrasound, interferential, shortwave diathermy, laser); physiotherapist-administered education (e.g. pain neuroscience education); as well as cortically directed sensory-motor rehabilitation strategies (e.g. graded motor imagery (GMI), mirror therapy, sensory motor retuning, tactile discrimination training).

\section{How the intervention might work}

The precise mechanisms of action through which various physiotherapy interventions are purported to relieve the pain and disability associated with CRPS are not fully understood. Theories underpinning the use of manual therapies to relieve pain include the induction of peripheral or central nervous system-mediated analgesia, or both (Bialosky 2009; Goats 1994). Therapeutic exercise may induce analgesia, via endorphin-mediated inhibition (Nijs 2012), and improve function, and by extension disability, by restoring range of movement at affected joints and improving neuromuscular function (Kisner 2002). Theories underlying the use of electrotherapy modalities for pain relief variously include spinal cord-mediated electro-analgesia, heat- or cold-mediated analgesia and anti-inflammatory effects (Atamaz 2012; Robertson 2006). Pain neuroscience education may reduce pain and disability by helping individuals to better understand the biological processes underlying their pain in a way that positively changes pain perceptions and attitudes (Louw 2011). Other rehabilitation strategies, such GMI or mirror therapy, may provide pain relief or increase 
mobility, or both, by ameliorating maladaptive somatosensory and motor cortex reorganisation (Moseley 2005; Moseley 2012).

\section{Why it is important to do this review}

A number of systematic reviews suggest that physiotherapy interventions (e.g. exercise, GMI, TENS) employed in combination with medical management may be beneficial in reducing the pain and disability associated with CRPS (Daly 2009; Smith 2005). However, the inclusion of non-randomised clinical trials and case series designs, together with the exclusion of studies involving people with CRPS type II as well as those published in a language other than English, may have biased these conclusions. Furthermore, the methodologies used for conducting systematic reviews have been substantially revised in recent years, such as those recommended within the Grading of Recommendations Assessment, Development and Evaluation (GRADE) approach for describing the strength of the evidence (Balshem 2011), which has not been utilised in previous reviews. Given the limitations of existing systematic reviews, together with the availability of potentially numerous physiotherapy treatment strategies for CRPS, an up-to-date systematic review of the evidence from randomised clinical trials for the effectiveness of these interventions may assist clinicians in their treatment choices and inform future clinical guidelines that may be of use to policymakers and those who commission health care for people with CRPS.

\section{Objectives}

To determine the effectiveness of physiotherapy interventions for treating pain and disability associated with CRPS types I and II.

\section{Methods}

\section{Criteria for considering studies for this review}

\section{Types of studies}

We included randomised controlled trials (RCTs) (including those of parallel, cluster-randomised and cross-over design) published in any language. Translators identified by the Managing Editor of the Cochrane Pain, Palliative and Supportive Care Group evaluated studies published in a language other than English. We excluded studies in which participants were not randomised to intervention groups.

\section{Types of participants}

We included trials of adults, aged 18 years or older, diagnosed with CRPS I or II, or with an alternative diagnostic label for these conditions (e.g. RSD, causalgia). We grouped trials according to diagnosis (i.e. CRPS types I and II, or mixed). Since the use of formal diagnostic criteria for CRPS is inconsistent across studies (Reinders 2002), we included trials that used established or validated diagnostic criteria, including the Veldman criteria (Veldman 1993), the International Association for the Study of Pain (IASP) criteria (Merskey 1994), Bruehl criteria (Bruehl 1999), Budapest criteria (Harden 2010) and Atkins criteria (Atkins 2010), as well as studies that either predate these criteria or use non-standard diagnostic criteria.

\section{Types of interventions}

We included all randomised controlled comparisons of physiotherapy interventions, employed in either a stand-alone fashion or in combination, compared with placebo, no treatment, another intervention or usual care, or of varying physiotherapy interventions compared with each other, which were aimed at treating pain or disability, or both, associated with CRPS. We included trials in which non-physiotherapists (e.g. occupational therapists) delivered such physiotherapy interventions, as defined in 'Description of the intervention', and reported the professional discipline of the clinician delivering the intervention. After the publication of our Cochrane protocol, (Smart 2013) we decided to exclude studies that evaluated non-physiotherapy based interventions (e.g. pharmacological) in which all arms received the same physiotherapy intervention (differing 
only in the application of the non-physiotherapy component) as they are unlikely to offer any insight into the value of physiotherapy management (see Differences between protocol and review).

\section{Types of outcome measures}

\section{Primary outcomes}

1. Changes in pain severity/intensity as measured using a visual analogue scale (VAS), numerical rating scale (NRS), verbal rating scale or Likert scale;

2. changes in disability as measured by validated self-report questionnaires/scales or functional testing protocols.

We presented and analysed primary outcomes as change on a continuous scale or in a dichotomised format as the proportion of participants in each group who attained a predetermined threshold of improvement. For example, we judged cut-points from which to interpret the likely clinical importance of (pooled) effect sizes according to provisional criteria proposed in the Initiative on Methods, Measurement, and Pain Assessment in Clinical Trials (IMMPACT) consensus statement (Dworkin 2008). Specifically, reductions in pain intensity compared with baseline were judged as follows:

1. less than $15 \%$ : 'no important change';

2. $15 \%$ or more: 'minimally important change';

3. $30 \%$ or more: 'moderately important change';

4. $50 \%$ or more: 'substantially important change'.

We planned to use the cut-points for 'minimally', 'moderately' and 'substantially' important changes to generate dichotomous outcomes, the effect size for which we would have expressed as the risk ratio (or relative risk $(\mathrm{RR}))$ but a lack of data did not permit any such analyses.

\section{Secondary outcomes}

We planned to analyse the following secondary outcome measures where such data were available:

1. changes in composite scores for CRPS symptoms;

2. changes in health-related quality of life (HRQoL) using any validated tool;

3. changes in patient global impression of change (PGIC) scales;

4. incidence/nature of adverse effects.

We planned to analyse and present secondary outcomes as change on a continuous scale or in a dichotomised format but a lack of data did not permit any such analyses. For example, equivalent measures of treatment effect with respect to PGIC have been defined as: 'much' or 'very much' improved (moderate benefit) and very much' improved (substantial benefit) (Dworkin 2008). Future updates may allow such analyses where relevant data are available.

\section{Search methods for identification of studies}

\section{Electronic searches}

We identified relevant RCTs by electronically searching the following databases:

1. Cochrane Central Register of Controlled Trials (CENTRAL) in the Cochrane Library, Issue 1 of 12, 2015;

2. Database of Abstracts of Reviews of Effects in the Cochrane Library, Issue 1 of 4 2015;

3. Health Technology Assessments in the Cochrane Library, Issue 1 of 4 2015;

4. MEDLINE (OVID) (1966 to 11 February 2015); 
5. EMBASE (OVID) (1974 to 11 February 2015);

6. CINAHL (EBSCO) (1982 to 11 February 2015);

7. PsycINFO (OVID) (1806 to 11 February 2015);

8. LILACS; (1982 to 15 February 2015);

9. PEDro; (1929 to 15 February 2015);

10. Web of Science (ISI);(1945 to 15 February 2015).

The Trials Search Co-ordinator of the Cochrane Pain, Palliative and Supportive Care Group devised the search strategies. She and the review authors ran these searches. We used a combination of controlled vocabulary, i.e. medical subject headings (MeSH) and free-text terms. The search strategies are in Appendix 1 .

\section{Searching other resources}

\section{Reference lists}

On completion of the electronic searches we searched the reference lists of all eligible studies in order to identify additional relevant studies. In addition we screened the reference lists of key physiotherapy textbooks and previous systematic reviews.

\section{External experts}

We sent the list of included trials to a content expert to help identify any additional relevant studies.

\section{Unpublished data}

In order to minimise the impact of publication bias we searched the following registers and databases to identify unpublished research as well as research in progress:

1. OpenGrey (System for Information on Grey Literature in Europe);

2. Dissertation Abstracts (ProQuest);

3. National Research Register Archive;

4. Health Services Research Projects in Progress;

5. Current Controlled Trials Register (incorporating the meta-register of controlled trials and the International Standard Randomised Controlled Trial Number);

6. ClinicalTrials.gov;

7. International Clinical Trials Registry Platform;

8. Pan African Clinical Trials Registry;

9. EU Clinical Trials Register.

\section{Data collection and analysis}

\section{Selection of studies}

Two review authors (KMS and BMW) independently assessed the titles and abstracts of studies we identified by the search strategy for eligibility. If the eligibility of a trial was unclear from the title and abstract, we assessed the full-text article. We excluded trials that did not match the inclusion criteria (see the 'Criteria for considering studies for this review' section). We resolved any disagreements between review authors regarding a study's inclusion by discussion. If we could not resolve disagreements, a third review author (NEO) assessed relevant studies and we made a majority decision. Trials were not anonymised prior to assessment. We obtained potentially relevant studies identified in the first round of screening in full text and independently assessed these for inclusion using the same process outlined above. We did not apply any language restrictions. 


\section{Data extraction and management}

Two review authors (KMS and BMW) independently extracted data from all included trials. We extracted data using a standardised and piloted form. We resolved any discrepancies and disagreements by consensus. In cases where we could not achieve consensus, a third review author (NEO) assessed the trial and we took a majority decision. We extracted the following data from each included trial:

1. country of origin;

2. study design;

3. study population (including diagnosis, diagnostic criteria used, symptom duration, age range, gender split);

4. type of noxious initiating event: surgery, fracture, crush injury, projectile, stab injury, other or no event;

5. type of tissue injured: nerve, soft tissue, bone;

6. presence of medicolegal factors (that may influence the experience of pain and the outcomes of therapeutic interventions);

7. concomitant treatments that may affect outcome: medication, procedures etc.;

8. sample size: active and control/comparator groups;

9. intervention (including type, parameters (e.g. frequency, dose, duration), setting and professional discipline of the clinician delivering the therapy);

10. type of placebo/comparator intervention;

11. outcomes (primary and secondary) and time points assessed;

12. adverse effects;

13. author conflict of interest statements;

14. assessment of risk of bias.

\section{Assessment of risk of bias in included studies}

We assessed the overall risk of bias for each included trial on the basis of an evaluation of key domains using a modified version of the Cochrane 'Risk of bias' assessment tool. We classified risk of bias as either 'low' (low risk of bias for all key domains), 'unclear' (unclear risk of bias for one or more key domains) or 'high' (high risk of bias for one or more key domains), as outlined in the Cochrane Handbook for Systematic Reviews of Interventions (Higgins 2011a). We also considered experimental design-specific (e.g. cross-over study designs) 'Risk of bias' issues where appropriate (Higgins 2011b). We assessed the following key domains of risks of bias for each included trial using either 'yes', 'no' or 'unclear' judgements:

1. random sequence generation (checking for possible selection bias). We assessed the method used to generate the allocation sequence as either: low risk of bias (any truly random process, e.g. random number table; computer random number generator); unclear risk of bias (method used to generate sequence not clearly stated); or high risk of bias (studies using a quasi/non-random process (e.g. odd or even date of birth; hospital or clinic record number);

2. allocation concealment (checking for possible selection bias). The method used to conceal allocation to group prior to assignment determines whether intervention allocation could have been foreseen in advance of, or during recruitment, or changed after assignment. We assessed the methods used as: low risk of bias (e.g. telephone or central randomisation; consecutively numbered sealed opaque envelopes); unclear risk of bias (method not clearly stated); or high risk of bias (studies that do not conceal allocation (e.g. open list));

3. blinding of study participants and personnel (checking for possible performance bias). We assessed the methods used to blind participants and care providers as either: low risk of bias (participants and care providers blinded to allocated intervention and unlikely that blinding broken; or no/incomplete blinding but judged that both intervention arms reflect active interventions of relatively equal credibility delivered with equal enthusiasm); unclear risk of bias (insufficient information provided to permit a judgement of low/high risk of bias); or high risk of bias (participants and care providers not blinded to the allocated intervention and interventions are clearly identifiable as control and experimental; or participants and care 
providers blinded to the allocated intervention but likely that blinding was broken);

4. blinding of outcome assessment (self reported outcomes) (checking for possible detection bias). We assessed the methods used to blind study participants self-reporting outcomes (e.g. pain severity) from knowledge of which intervention a participant received. We assessed the methods as either: low risk of bias (participants blinded to allocated intervention and unlikely that blinding broken; or no/incomplete blinding but judged that both intervention arms reflect active interventions of relatively equal credibility delivered with equal enthusiasm); unclear risk of bias (insufficient information provided to permit a judgement of low/high risk of bias); or high risk of bias (participants not blinded to the allocated intervention and interventions are clearly identifiable as control and experimental; or participants blinded to the allocated intervention but likely that blinding was broken);

5. blinding of outcome assessment (investigator-administered outcomes) (checking for possible detection bias). We assessed the methods used to blind researchers undertaking outcome assessments (e.g. functional testing protocols) from knowledge of which intervention a participant received. We assessed the methods as at either: low risk of bias (researchers blinded to allocated intervention and unlikely that blinding broken); unclear risk of bias (insufficient information provided to permit a judgement of low/high risk of bias); high risk of bias (researchers not blinded to the allocated intervention; or researcher blinded to the allocated intervention but likely that blinding was broken);

6. incomplete outcome data (drop out) (checking for possible attrition bias). We first assessed for risk of attrition bias by evaluating participant drop out rates according to judgements based on the following criteria: low risk of bias (less than $20 \%$ drop out and appears not to be systematic, with numbers for each group and reasons for drop out reported); unclear risk of bias (less than $20 \%$ drop out but appears to be systematic or numbers per group and reasons for drop out not reported); high risk of bias (greater than or equal to $20 \%$ drop out);

7. incomplete outcome data (method of analysis) (participants analysed in the group to which they were allocated) (checking for possible attrition bias). We further assessed for risk of attrition bias by separately evaluating the appropriateness of the method of analysis employed, using the following criteria: low risk of bias (participants analysed in the group to which they were allocated (intention-to-treat (ITT) or as an available case analysis); unclear risk of bias (insufficient information provided to determine if analysis was based on the principle of ITT or per protocol); or high risk of bias (if per protocol analysis used or where available data is not analysed or participant's data were included in group to which they were not originally assigned to);

8. selective reporting (checking for possible reporting bias). We assessed studies for selective outcome reporting using the following judgements: low risk of bias (study protocol available and all pre-specified primary outcomes of interest adequately reported or study protocol not available but all expected primary outcomes of interest adequately reported or all primary outcomes numerically reported with point estimates and measures of variance for all time points); unclear risk of bias (insufficient information provided to permit a judgement of low/high risk of bias); or high risk of bias (incomplete reporting of pre-specified primary outcomes or point estimates and measures of variance for one or more primary outcome not reported numerically (e.g. graphically only) or one or more primary outcomes reported using measurements, analysis methods or subsets of data that were not pre-specified or one or more reported primary outcomes were not pre-specified or results for a primary outcome expected to have been reported were excluded);

9. other bias. We assessed studies for other potential sources of bias. We determined judgements regarding low/unclear/high risk of bias according to the potential confounding influence of identified factors, for example: low risk of bias (appears free of other potentially serious sources of bias e.g. no serious study protocol violations identified); unclear risk of bias (other sources of bias may be present but there is either insufficient information to assess whether an important risk of bias exists or insufficient rationale or evidence regarding whether an identified problem will introduce bias); or high risk of bias (results may have been confounded by at least one potentially serious risk of bias, e.g. a significant baseline imbalance between groups; a serious protocol violation; use of 'last observation carried forward' when dealing with missing data). 
We also evaluated included trials for the additional sources of bias associated with:

1. sample size; and

2. duration of follow-up, as recommended by Moore 2010.

Small studies are more prone to bias because of their inherent imprecision and due to the effects of publication biases (Dechartres 2013; Moore 2012; Nüesch 2010). Inadequate length of follow-up may produce an overly positive view of the true clinical effectiveness of interventions, particularly in persistent conditions (Moore 2010). These additional criteria were not considered 'key domains' and therefore did not inform judgements of a trial's overall risk of bias. We assessed these trials according to the following criteria:

1. sample size (checking for possible biases confounded by small sample size): we assessed trials as being at low risk of bias (greater than or equal to 200 participants per treatment arm); unclear risk of bias (50 to 199 participants per treatment arm); high risk of bias (less than 50 participants per treatment arm);

2. duration of follow-up (checking for possible biases confounded by a short duration of follow-up): we assessed trials as being at low risk of bias (follow-up of greater than or equal to eight weeks); unclear risk of bias (follow-up of two to seven weeks); or high risk of bias (follow-up of less than two weeks).

Two review authors (KMS and BMW) independently undertook the 'Risk of bias' assessments, and resolved any disagreements by discussion. If they could not reach an agreement, a third review author (NEO) undertook a 'Risk of bias' assessment and we took a majority decision.

\section{Measures of treatment effect}

We presented treatment effect sizes using appropriate metrics. We calculated the risk ratio (RR) with $95 \%$ confidence intervals (Cls) for dichotomised outcome measures, and the number needed to treat (NNT) as an absolute measure of treatment effect where possible.

We expressed the size of treatment effect on pain intensity, as measured with a VAS or NRS, using the mean difference (MD) (where all studies utilised the same measurement scale) or the standardised mean difference (SMD) (where studies used different scales). In order to aid interpretation of the pooled effect size we planned to back-transform the SMD value to a 0 to $100 \mathrm{~mm}$ VAS format on the basis of the mean standard deviation (SD) from trials using a 0 to $100 \mathrm{~mm}$ VAS where possible.

We analysed the data using Review Manager (RevMan) (RevMan 2014). We plotted the results of each RCT with available data as point estimates with corresponding $95 \% \mathrm{Cls}$ and displayed them using forest plots. If included trials demonstrated clinical homogeneity we performed a meta-analysis to quantify the pooled treatment effect sizes using a random-effects model. We did not perform a meta-analysis when clinical heterogeneity was present. Similarly we presented secondary outcomes, though we did not consider them for meta-analysis.

\section{Unit of analysis issues}

All included trials randomised participants at the individual participant level. We planned to meta-analyse estimates of treatment effect (and their standard errors (SE)) from cluster-RCTs employing appropriate statistical analyses using the generic inverse-variance method in RevMan (RevMan

2014), as suggested in the Cochrane Handbook for Systematic Reviews of Interventions (Higgins 2011b). Where we considered such trials to have employed inappropriate analyses, we planned to utilise methods for 'approximately correct analysis' where possible (Higgins 2011b). In addition, we planned to enter cross-over trials into a meta-analysis when it was clear that data were free from carry-over effects, and to combine the results of cross-over trials with those of parallel trials by imputing the post-treatment between-condition correlation coefficient from an included trial that presented individual participant data and use this to calculate the SE of the SMD. These data may be entered into a meta-analysis using the generic inverse-variance method (Higgins 2011b). Issues concerning cluster-RCTs and crossover trials did not arise as we did not identify any cluster-RCTs that met the inclusion criteria of this review and we did not conduct any quantitative 
analyses on the one included crossover trial. We may include such analyses where relevant data are available in future updates of this Cochrane review.

\section{Dealing with missing data}

We attempted to contact the authors of included trials when numerical data were unreported or incomplete. If trial authors only presented data in graphical form, we did not attempt to extract the data from the figures. If SD values were missing from follow-up assessments but were available at baseline, we used these values as estimates of variance in the follow-up analyses.

\section{Assessment of heterogeneity}

We evaluated the included trials for clinical homogeneity regarding study population, treatment procedure, control intervention, timing of follow-up and outcome measurement. For trials that were sufficiently clinically homogenous to pool, we formally explored heterogeneity using the $\mathrm{Chi}^{2}$ test to investigate the statistical significance of any heterogeneity, and the $\mathrm{I}^{2}$ statistic to estimate the amount of heterogeneity. Where significant heterogeneity ( $P$ value $<0.1$ ) was present, we planned to explore subgroup analyses (see the 'Differences between protocol and review' section).

\section{Assessment of reporting biases}

We planned to test for the possible influence of publication bias on trials that utilised dichotomised outcomes by estimating the number of participants in trials with zero effect required to change the NNT to an unacceptably high level (defined as an NNT of 10), as outlined by Moore 2008. An absence of relevant data meant that we did not undertake any analyses. Instead, we considered the possible influence of small study/publication biases on review findings as part of our 'Risk of bias' assessment (see the 'Assessment of risk of bias in included studies' section) and as part of our Grading of Recommendations Assessment, Development and Evaluation (GRADE) assessments (Guyatt 2011a) of the quality of evidence (see the 'Data synthesis' section). We may include such analyses in future updates of this Cochrane review where relevant data are available.

\section{Data synthesis}

Where possible, we grouped extracted data according to diagnosis (CRPS types I or II, or mixed), intervention, outcome (i.e. pain, disability) and duration of follow-up (short-term: zero to less than two weeks postintervention; mid-term: two to seven weeks postintervention; and long-term: eight or more weeks postintervention). Regarding intervention, we planned to pool data from trials that investigated the same single therapy separately for each therapy. We planned to pool trials of multimodal physiotherapy programmes together.

For all analyses, we report the outcome of the 'Risk of bias' assessments. Where we found inadequate data to support statistical pooling, we performed a narrative synthesis of the evidence. We were only able to combine trials through meta-analysis for one type of intervention (graded motor imagery (GMI)) because of insufficient data and clinical heterogeneity. We conducted a qualitative analysis of all trial findings and used the GRADE approach to assess the quality of evidence (Guyatt 2011a; Guyatt 2011b).

To ensure consistency of GRADE judgements we applied the following criteria to each domain equally for all key comparisons of the primary outcome:

1. limitations of studies: we downgraded once if more than $25 \%$ of the participants were from trials we classified as being at high risk of bias;

2. inconsistency: we downgraded once if heterogeneity was statistically significant and the $I^{2}$ statistic value was greater than $40 \%$. When a meta-analysis was not performed we downgraded once if the trials did not show effects in the same direction; 
3. indirectness: we downgraded once if more than $50 \%$ of the participants were outside the target group;

4. imprecision: we downgraded once if there were fewer than 400 participants for continuous data and fewer than 300 events for dichotomous data;

5. publication bias: we downgraded once where there was direct evidence of publication bias or if estimates of effect based on small scale, industry sponsored studies raised a high index of suspicion of publication bias.

Two review authors (KS and NO) made the judgement of whether these factors were present or not. We considered single trials to be inconsistent and imprecise, unless more than 400 participants were randomised for continuous outcomes or more than 300 for dichotomous outcomes. We applied the following definitions of the quality of the evidence (Balshem 2011):

1. high quality: we are very confident that the true effect lies close to that of the estimate of the effect;

2. moderate quality: we are moderately confident in the effect estimate. The true effect is likely to be close to the estimate of the effect, but there is a possibility that it is substantially different;

3. low quality: our confidence in the effect estimate is limited. The true effect may be substantially different from the estimate of the effect;

4. very low quality: we have very little confidence in the effect estimate. The true effect is likely to be substantially different from the estimate of effect.

\section{Subgroup analysis and investigation of heterogeneity}

We planned to perform subgroup analyses based on the type of CRPS (i.e. I, II or mixed) and its temporal characteristics (i.e. acute (defined as symptoms and signs of CRPS of zero to 12 weeks duration) and chronic (symptoms and signs of CRPS lasting 13 weeks). However, we did not undertake them due to the insufficient number of included trials.

\section{Sensitivity analysis}

We planned to perform sensitivity analyses on risk of bias (investigating the influence of excluding studies classified at high risk of bias) and choice of meta-analysis model (investigating the influence of using a fixed-effect analysis). We did not perform them as insufficient data were available (see the 'Differences between protocol and review' section).

\section{Results}

\section{Description of studies}

See the 'Characteristics of included studies' and 'Characteristics of excluded studies' sections.

\section{Results of the search}

We conducted the literature search up to 12 February 2015 and identified 990 papers that comprised original research studies, reviews and poster abstracts, of which 744 remained after we removed duplicates. After we screened titles and abstracts, we discarded 702 records because they did not meet the inclusion criteria of this Cochrane review. We retrieved 42 records for full-text screening. We deemed 21 trial reports from 18 original trials for inclusion (Askin 2014; Aydemir 2006; Cacchio 2009a; Cacchio 2009b; Dimitrijevic 2014; Duman 2009; Durmus 2004; Hazneci 2005; Jeon 2014; Li 2012; Moseley 2004; Moseley 2005; Moseley 2006; Moseley 2009; Mucha 1992; Oerlemans 1999; Schreuders 2014; Severens 1999; Uher 2000). Four published trial manuscripts reported data pertaining to a single included trial (Oerlemans 1999).

One additional trial is awaiting submission for publication (ISRCTN39729827), one trial is available only as a conference abstract (Mete-Topcuoglu 2010) and we were unable to contact the authors of one registered trial (NCT00625976). These three trials are awaiting classification (see the 'Characteristics of studies awaiting classification' table). 
In addition, we identified five ongoing trials (see the 'Characteristics of ongoing studies' section). We have presented a flow diagram outlining the trial screening and selection process (Figure 1). Two review authors (KMS and BMW) reported study details in the 'Characteristics of included studies' and 'Risk of bias' tables for two papers published in the Turkish language (Aydemir 2006; Hazneci 2005) based on an English translation of the original trial report; and one review author (BMW) reported study details in the 'Characteristics of included studies' and 'Risk of bias' tables for two papers published in the German language (Mucha 1992; Uher 2000).

\section{Included studies}

We have provided the details of all included trials in the 'Characteristics of included studies' tables. We extracted relevant data from eight included trials (Askin 2014; Aydemir 2006; Cacchio 2009a; Dimitrijevic 2014; Duman 2009; Durmus 2004; Hazneci 2005; Li 2012). We contacted or attempted to contact the corresponding authors of 10 trials on three occasions in order to obtain missing outcomes data (Cacchio 2009b; Jeon 2014; Moseley 2004; Moseley 2005; Moseley 2006; Moseley 2009; Mucha 1992; Oerlemans 1999; Schreuders 2014; Uher 2000). One trial author responded and supplied data for an outcome measure of 'impairment' but we were unable to extract outcome data linked to 'pain intensity' from the supplied data (Oerlemans 1999); one trial author responded stating that they were unable to supply the relevant data (Schreuders 2014); and there was no response from the other trial authors we had contacted.

\section{Design}

All included trials were RCTs, and 17 essentially used a parallel-group design. Whilst the selected participants in three trials crossed over from comparator to intervention groups (Cacchio 2009b; Moseley 2004;

Mucha 1992), none employed a true randomised crossover design and we analysed them up to the point of crossover as parallel group-designs. One trial employed a within-subject randomised crossover design (Moseley 2009). Twelve trials included two intervention arms (Cacchio 2009a; Dimitrijevic 2014; Duman 2009; Durmus 2004; Hazneci 2005; Jeon 2014; Li 2012; Moseley 2004; Moseley 2006; Mucha 1992; Schreuders 2014; Uher 2000), five trials included three arms (Askin 2014; Aydemir 2006; Cacchio 2009b; Moseley 2005; Oerlemans 1999) and one study used four arms (Moseley 2009). No cluster-RCTs met the inclusion criteria of this Cochrane review.

\section{Participants}

The 18 trials included a total of 739 participants and the total number of participants per trial ranged from 10 to 135. All 18 trials included participants with CRPS I using a range of diagnostic criteria, most commonly using those of Bruehl 1999. There were no trials that included participants with CRPS II. Fourteen trials included participants with CRPS I of the upper limb (Askin 2014; Aydemir 2006; Cacchio 2009a; Cacchio 2009b; Duman 2009; Durmus 2004; Hazneci 2005; Li 2012; Moseley 2004; Moseley 2005; Moseley 2009; Mucha 1992; Oerlemans 1999; Schreuders 2014), two with either upper or lower limb CRPS I (Dimitrijevic 2014; Moseley 2006), one with CRPS I of the lower limb (Uher 2000) and one trial included participants with either upper, lower, multi-limb or whole body CRPS I (Jeon 2014). Participants developed CRPS I linked to a range of aetiologies including onset post fracture, soft-tissue injuries, stroke, surgery, carpal tunnel syndrome as well as of idiopathic onset. Participants had acute symptoms (less than or equal to three months) of CRPS I in six trials (Cacchio 2009a; Dimitrijevic 2014; Durmus 2004; Hazneci 2005; Li 2012; Mucha 1992), chronic symptoms (greater than three months) in seven trials (Duman 2009; Jeon 2014; Moseley 2004; Moseley 2005; Moseley 2006; Moseley 2009; Schreuders 2014), a mix of acute and chronic symptoms in two trials (Askin 2014; Oerlemans 1999), and three trials did not report the duration of symptoms (Aydemir 2006; Cacchio 2009b; Uher 2000). Trials were undertaken across a range of geographical locations including: Turkey $(N=5)$; Australia $(N=4)$; Italy, Germany, the Netherlands $(N=2$ each); China, Serbia, and South Korea $(\mathrm{N}=1$ each $)$. 


\section{Interventions}

We have provided a detailed description of the interventions delivered in each included trial in the 'Characteristics of included studies' table. The types of physiotherapy interventions delivered were heterogenous across the included trials and included various electrotherapy modalities (ultrasound, TENS, laser, interferential therapy, pulsed electromagnetic field therapy), cortically-directed sensory-motor rehabilitation strategies (GMI, mirror therapy, virtual body swapping, tactile sensory discrimination training), exercise (active, active-assisted, passive, stretching, strengthening, mobilising, functional; supervised and unsupervised), manual lymphatic drainage (MLD) and pain management advice. Five trials directly compared an active and placebo intervention (Askin 2014; Aydemir 2006; Cacchio 2009a; Cacchio 2009b; Durmus 2004). Six trials evaluated electrotherapy modalities (Askin 2014; Aydemir 2006; Dimitrijevic 2014; Durmus 2004; Hazneci 2005; Mucha 1992), eight trials evaluated cortically-directed sensory-motor rehabilitation strategies (Cacchio 2009a; Cacchio 2009b; Jeon 2014; Moseley 2004; Moseley 2005; Moseley 2006; Moseley 2009; Schreuders 2014), two trials evaluated MLD (Duman 2009; Uher 2000) and two trials evaluated general rehabilitation therapies (Li 2012; Oerlemans 1999).

\section{Excluded studies}

We have listed the details regarding the 13 trial reports that we excluded in the 'Characteristics of excluded studies' table. The main reasons for exclusion were that the studies were either not RCTs $(N=8)$, investigated clinically irrelevant outcome measures $(N=2)$, tested interventions that fell outside the scope of physiotherapy $(\mathrm{N}=2)$ or included participants with mixed aetiologies with only one participant with CRPS I in each of the two arms of the trial $(\mathrm{N}=1)$.

\section{Risk of bias in included studies}

We presented a summary of the 'Risk of bias' assessments for all included trials in Figure 2 and Figure 3 . We judged the overall risk of bias as being 'high' for 15 trials (Askin 2014; Cacchio 2009a; Cacchio 2009b; Dimitrijevic 2014; Duman 2009; Jeon 2014; Li 2012; Moseley 2004; Moseley 2005; Moseley 2006; Moseley 2009; Mucha 1992; Oerlemans 1999; Schreuders 2014; Uher 2000) and 'unclear' for three trials (Aydemir 2006; Durmus 2004; Hazneci 2005). We did not judge any of the included trials as having an overall 'low' risk of bias.

\section{Allocation (selection bias)}

Only seven out of the 18 trials reported using, or were judged to have used, adequate methods to generate a random sequence and conceal allocation (Aydemir 2006; Dimitrijevic 2014; Li 2012; Moseley 2004; Moseley 2005; Moseley 2006; Schreuders 2014) and as such we judged them as being of 'low' risk of selection bias. The risk of selection bias was 'unclear' in 10 trials (Cacchio 2009a; Cacchio 2009b; Duman 2009; Durmus 2004; Hazneci 2005; Jeon 2014; Moseley 2009; Mucha 1992; Oerlemans 1999; Uher 2000) where the methods used to generate the allocation sequence or where the method of allocation concealment were not adequately reported enough in order to allow a judgement of 'high' or 'low' risk of bias. One trial, Askin 2014, used a quasi-randomisation method and we judged it as having a 'high' risk of selection bias.

\section{Blinding (performance bias and detection bias)}

We judged six trials to have a 'low' risk of performance bias (Askin 2014; Aydemir 2006; Dimitrijevic 2014; Durmus 2004; Hazneci 2005; Moseley 2005), where participants were adequately blinded to their intervention or where we considered a lack of blinding to have been unlikely to have biased trial outcomes. Eight trials were at 'high' risk of performance bias and consequently detection biases because of inadequate or a lack of blinding (Duman 2009; Li 2012; Moseley 2004; Moseley 2006; Mucha 1992; Oerlemans 1999; Schreuders 2014; Uher 2000). We judged three trials, all of which tested the efficacy of electrotherapy-based modalities, as at 'low' risk of detection bias because they successfully blinded participants and outcome assessors (Askin 2014; Aydemir 2006; Durmus 2004). 


\section{Incomplete outcome data (attrition bias)}

Twelve trials either had no drop-outs or a drop-out rate of less than $20 \%$ and as such we judged them as having a 'low' risk of attrition bias secondary to drop-outs (Askin 2014; Cacchio 2009b; Duman 2009; Durmus 2004; Jeon 2014; Li 2012; Moseley 2004; Moseley 2005; Moseley 2006; Moseley 2009; Mucha 1992; Uher 2000). In five trials the risk of attrition bias was 'unclear' either because the drop-out rate was not reported (Aydemir 2006; Hazneci 2005) or the drop-out rate between groups was unequal and the effect of which was uncertain (Cacchio 2009a; Dimitrijevic 2014; Oerlemans 1999). One trial, with an overall drop-out rate of 44\%, had a 'high' risk of attrition bias (Schreuders 2014). We judged 11 trials (Cacchio 2009a; Cacchio 2009b; Duman 2009; Durmus 2004; Jeon 2014; Li 2012; Moseley 2004; Moseley 2006; Moseley 2009; Mucha 1992; Oerlemans 1999), two trials (Aydemir 2006; Hazneci 2005) and five trials (Askin 2014; Dimitrijevic 2014; Moseley 2005; Schreuders 2014; Uher 2000) respectively as being at 'low', 'unclear' and 'high' risk of attrition bias as a consequence of their adopted method of analysis.

\section{Selective reporting (reporting bias)}

We judged a total of nine trials as being of 'high' risk of reporting bias; three trials because of inadequate or incomplete reporting of primary outcomes, or both (Jeon 2014; Oerlemans 1999; Uher 2000) and six trials because the trial authors presented data in graphical format only, i.e. point estimates with measures of variation were not reported (Cacchio 2009b; Moseley 2004; Moseley 2005; Moseley 2009; Mucha 1992; Schreuders 2014). The other nine trials adequately reported outcome data and we judged them as being at 'low' risk of reporting bias (Askin 2014; Aydemir 2006; Cacchio 2009a; Dimitrijevic 2014; Duman 2009; Durmus 2004; Hazneci 2005; Li 2012; Moseley 2006).

\section{Other potential sources of bias}

We considered three trials to be at 'high' risk of other potential sources of bias; one trial because it was published as a 'Letter to the Editor' and not as a full trial report (Cacchio 2009b); one trial because violations of the random sequence generation were permitted (Oerlemans 1999); and one trial because it did not report the baseline data of three participants excluded from the analysis and because of a likely highly significant baseline imbalance in duration of symptoms between groups (Schreuders 2014). The 15 other trials appeared to be free of other potential sources of bias.

\section{Sample size}

None of the included trials had intervention arms with 200 or more participants per treatment arm. One trial randomised 60 participants to each trial arm and we judged it as being at 'unclear' risk of bias (Li 2012). The remaining 17 trials had less than 50 participants per trial arm and we judged them as being at 'high' risk of bias based on this criterion.

\section{Duration of follow-up}

Nine trials employed a follow-up period of less than two weeks and we judged them as being at 'high' risk of bias based on this criterion (Askin 2014; Cacchio 2009b; Dimitrijevic 2014; Durmus 2004; Hazneci 2005; Jeon 2014; Moseley 2009; Mucha 1992; Uher 2000). Six trials employed a follow-up period of eight or more weeks and we judged them as being at 'low' risk of bias (Cacchio 2009a; Duman 2009; Li 2012; Moseley 2005; Moseley 2006; Oerlemans 1999). Three trials reported a follow-up period of two to seven weeks and we judged them as being at 'unclear' risk of bias (Aydemir 2006; Moseley 2004; Schreuders 2014).

\section{Effects of interventions}

\section{Multimodal physiotherapy}

One three-arm trial, Oerlemans 1999, (135 participants), which we judged as being at 'high' risk of bias based on a number of criteria, compared a physiotherapy programme (pain management advice, relaxation 
exercises, connective tissue massage, TENS and exercise) plus medical treatment according to a fixed pre-established protocol, to an occupational therapy (OT) programme (splinting, de-sensitisation, functional rehabilitation) plus medical management and to a control intervention, described as 'social work' (SW), (attention, advice) plus medical management in participants with CRPS I of the upper limb secondary to mixed aetiologies. The trial authors did not adequately report details regarding the nature of the interventions and did not standardise the number of treatment sessions given with the intensity and frequency of treatment adjusted to the individual needs of participants. The trial authors did not report the overall duration of the treatment periods for each trial group.

According to the trial authors, adjuvant physiotherapy, and to a lesser extent, OT were superior to SW for reducing pain according to all four measures of pain intensity at three months post-recruitment, and for reducing pain from effort of use of the affected extremity at six months. However, there were no significant between-group differences for any measure of pain intensity at 12 months follow-up. Numerical data (i.e. group means and standard deviations (SD) for each time-point) for the four self-reported measures of pain intensity (current pain, pain from effort of use of the affected extremity, least and worst pain experienced in the preceding week) were not reported, and the trial authors have not provided these data. Consequently, no further analyses of these measures were possible and we could not determine effect sizes.

Physiotherapy demonstrated a small but statistically significant between-group improvement in impairment at 12 months compared to SW (impairment level sum score, five to 50 scale; mean difference (MD) 3.7, 95\% (Cl) -7.13 to $-0.27, \mathrm{P}=0.03$; but not OT.

The trial authors did not report numerical data from other outcomes of interest, including measures of function (Radboud Skills Questionnaire, modified Greentest, Radboud Dexterity Test), HRQoL (Sickness Impact Profile) and adverse events although Oerlemans 1999 state that there were no between-group differences in function or well-being at 12 months follow-up.

\section{Quality of the evidence}

There is very low quality evidence (RCT evidence: high, downgraded once for methodological limitations, once for imprecision and once for inconsistency) that physiotherapy plus medical treatment may be more effective at reducing pain at short- (three months) but not long-term follow-up (12 months) compared to a control intervention of SW and that physiotherapy plus medical treatment may be more effective at reducing impairment compared to SW at long-term follow-up in the treatment of CRPS I of the upper limb.

\section{Cortically directed sensory-motor rehabilitation strategies}

\section{Graded Motor Imagery}

We included four separate trials of GMI, all of which were small trials (13 to 37 participants) judged to be at 'high' risk of bias. Two trials compared the same GMI protocol to control interventions of standard care (Moseley 2004; Moseley 2006); one compared a different GMI protocol plus conventional treatment (occupational and therapy physiotherapy) to conventional treatment alone (Schreuders 2014); and one compared three different GMI protocols to each another (Moseley 2005).

Moseley $2004(\mathrm{~N}=13)$ compared a six-week GMI programme (consisting of two weeks of limb laterality recognition followed by two weeks of imagined movements followed by two weeks of mirror-box therapy) to 12 weeks of ongoing medical management (predominantly physiotherapy) in participants with longstanding CRPS I of the upper limb post wrist fracture. Moseley 2006 compared the same GMI programme to physical therapy and usual care in a combined cohort of 14 participants with phantom-limb pain and 37 participants with CRPS I of the upper or lower limb of mixed aetiologies. Schreuders $2014(\mathrm{~N}=18)$ compared a six-week GMI programme (consisting of one week of limb laterality recognition, followed by one week of imagined movements, followed by four weeks of mirror-box therapy) plus conventional care (physiotherapy and OT) to conventional care alone in participants with longstanding CRPS I of the upper limb (aetiology not reported). 
Moseley 2004 reported a statistically significant improvement in pain, as measured by the Neuropathic Pain Scale (NPS) at six weeks post-treatment, in participants that received GMI compared to ongoing medical management. Moseley 2004 reported a NNT to obtain a 50\% reduction in the NPS (total score) of three $(95 \%$ $\mathrm{Cl} 1.4$ to 10.1). Moseley 2006 reported statistically significant improvements in pain, as measured by a 0 to 100 VAS, and function, as measured by an 11-point NRS, immediately postintervention and at six months post-treatment for the combined cohort of participants with CRPS I and phantom limb pain. At six weeks post-treatment Schreuders 2014 found no statistically significant differences between groups on any measure of pain intensity or function. None of these trials reported any data about adverse events and did not measure other outcomes of interest, such as composite scoring of symptoms, HRQoL and PGIC.

Moseley 2004, Moseley 2006 and Schreuders 2014 presented data for changes in pain and function in participants specifically with CRPS I graphically only and did not report numerical data (i.e. group means and SD values at each time-point) for measures of pain intensity or function, or both. However, 0 to 100 VAS pain and function data were available from Moseley 2004 and the CRPS I participants in Moseley 2006 from a previous overview of systematic reviews of interventions for CRPS (O'Connell 2013). We used these data in this Cochrane review with the authors' permission. Pooling of these results gave an effect size (weighted mean difference $)$ of $-14.45(95 \% \mathrm{Cl}-23.02$ to $-5.87, \mathrm{P}=0.001$, 49 participants, two trials; Analysis 1.1$)$ with no significant heterogeneity. We expressed this data as a percentage of the mean baseline pain levels in the larger trial (58 out of 100$)$, which equated to a $25 \%(95 \% \mathrm{Cl} 10$ to 40$)$ reduction in pain intensity at the end of the treatment period. Moseley 2004 presented outcomes at medium-term follow-up (six weeks post-treatment, $\mathrm{N}=13, \mathrm{MD}-20.00,95 \% \mathrm{Cl}-7.97$ to $-32.13, \mathrm{P}=0.001)$. This equated to an improvement of $34 \%(95 \% \mathrm{Cl} 14$ to 55) of the baseline VAS pain level in the Moseley 2006 trial (average baseline data for pain VAS was not available from the Moseley 2004 trial report). At long-term follow-up (six months post-treatment $(\mathrm{N}=36)$ ) in Moseley 2006, the MD was $-21.00,95 \% \mathrm{Cl}-10.83$ to $-31.17, \mathrm{P}<0.001$, which equates to an improvement of $36 \%(95 \% \mathrm{Cl} 19 \%$ to $54 \%)$. The immediate post-treatment effect was below the threshold for a moderately clinically important difference but exceeded the threshold for a minimally clinically important difference. The medium- and long-term effects met the threshold for a moderately important benefit. We were unable to obtain numerical data from Schreuders 2014.

We pooled the data on function from two trials (Moseley 2004 and Moseley 2006; data on CRPS I participants only), which returned a MD of: $1.87(95 \% \mathrm{Cl} 1.03$ to 2.71 , 49 participants, two trials; $\mathrm{P}<0.001$; Analysis 1.2$)$ at the end of treatment; $2.26(95 \% \mathrm{Cl} 1.42$ to $3.10, \mathrm{P}<0.001)$ at medium-term follow-up (Moseley 2004, $\mathrm{N}=13$ ); and $2.30(95 \% \mathrm{Cl} 1.12$ to $3.48, \mathrm{P}<0.001)$ at long-term follow-up (Moseley 2006, $\mathrm{N}=36)$. This represented a large improvement in function from the baseline function score $(0.5)$ in the control group of the larger trial (Moseley 2006).

In a three-arm trial, Moseley 2005 ( $N=20)$ compared a six-week GMI programme with its three components delivered in the 'correct' order (i.e. two weeks of laterality recognition followed by two weeks of imagined movements followed by two weeks of mirror-box therapy) to two other GMI programmes with selected components delivered in different orders at odds with its hypothesised mechanism of action, in participants with longstanding CRPS I of the upper limb post wrist fracture. We found statistically significant improvements in pain and function in the correctly ordered GMI group compared to both comparison groups, as measured by the NPS and an 11-point NRS respectively at 12 weeks post-treatment. Moseley 2005 reported that at 12-week follow-up, the mean reduction in NPS score for the correctly ordered GMI group was approximately seven and 18 points greater than the mean reductions in the other two groups respectively. The trial did not report numerical data for measures of pain intensity and function, and we have been unable to obtain these data from the trial author. Consequently we were unable to perform any further analyses of these measures and we could not determine the effect sizes. The trial did not report any data concerning adverse events and did not measure other outcomes of interest, such as composite scoring of symptoms, HRQoL and PGIC.

\section{Quality of the evidence}

There is very low quality evidence (RCT evidence: high, downgraded once for methodological limitations, once 
for imprecision and once for inconsistency) that GMI plus medical management may be more effective at reducing pain and improving function than conventional physiotherapy plus medical management in the treatment of CRPS I of the upper limb. There is very low quality evidence (RCT evidence: high, downgraded once for methodological limitations, once for imprecision and once for inconsistency) that appropriately ordered GMI was more effective at reducing pain and improving function than inappropriately ordered GMI.

\section{Mirror therapy}

We included two trials of mirror therapy (Cacchio 2009a; Cacchio 2009b). Cacchio 2009a $(\mathrm{N}=48)$ compared four weeks of mirror therapy plus conventional stroke rehabilitation to placebo mirror therapy (covered mirror) plus conventional stroke rehabilitation in participants with CRPS I of the upper limb post-stroke. In a trial judged to be at 'unclear' risk of bias, Cacchio 2009a reported statistically significant improvements in pain and function, at all post-treatment time-points, in the mirror therapy group compared to the placebo group.

Specifically, Cacchio 2009a reported a mean between-group difference following treatment in pain at rest (0 to $10 \mathrm{VAS})$ of $-2.9(95 \% \mathrm{Cl}-4.23$ to $-1.57, \mathrm{P}<0.001)$ and in pain on movement (shoulder flexion) of -3.10 $(95 \% \mathrm{Cl}-4.28$ to $-1.92, \mathrm{P}<0.001)$. At six-month follow-up the differences were still present, $-3.4(95 \% \mathrm{Cl}$ -4.71 to $-2.09, \mathrm{P}<0.001)$ for pain at rest, and $-3.8(95 \% \mathrm{Cl}-4.96$ to $-2.64, \mathrm{P}<0.001)$ for pain on movement. The post-treatment and six-months follow-up mean differences for pain at rest equated to a $38 \%$ (95\% $\mathrm{Cl} 21$ to $56 \%)$ and $45 \%(95 \% \mathrm{Cl} 28$ to $62 \%)$ reduction in the average baseline pain level respectively, whist the post-treatment and six-months follow-up mean differences for pain on movement equated to a $36 \%$ $(95 \% \mathrm{Cl} 23$ to $50 \%)$ and $45 \%(95 \% \mathrm{Cl} 31$ to $58 \%)$ reduction in the average baseline pain level respectively, consistent with a moderately important benefit.

Regarding disability, Cacchio 2009a also reported significant mean between-group differences in functional limitation, as measured by the functional ability subscale of the Wolf Motor Function Test (WMFT, zero to five score range $)$ of $-1.9(95 \% \mathrm{Cl}-2.36$ to $-1.44, \mathrm{P}<0.001)$ at the end of treatment and of $-2.3(95 \% \mathrm{Cl}-2.88$ to $-1.72, P<0.001$ ) at six-months follow-up.

In a separate three-arm trial, judged to be at 'high' risk of bias, Cacchio 2009b ( $N=24)$ compared four weeks of mirror therapy to either placebo mirror therapy (covered mirror) or mental imagery training in participants with CRPS I of the upper limb post stroke. Cacchio 2009b reported that seven out of eight participants in the mirror therapy group reported reduced pain (median change in zero to $100 \mathrm{VAS}$ of $-51 \mathrm{~mm}$, range -70 to -18) compared with one of eight participants in the covered mirror therapy group and two of eight participants in the mental imagery group; the median change was not reported for either the covered mirror or mental imagery groups. At the end of the treatment period, pain scores were significantly lower in the mirror therapy group compared to the other two groups. However, the trial authors did not report any further between-group data and we have been unable to obtain these data from the trial authors. Consequently we were unable to perform any further analyses of these measures and we could not determine the effect size. The trial authors did not report data from other outcomes of interest, including measures of function and adverse events, while they did not measure outcomes, such as composite scoring of symptoms, HRQoL and PGIC.

\section{Quality of the evidence}

There was very low quality evidence (RCT evidence: high, downgraded once for methodological limitations, once for imprecision, once for indirectness) that mirror therapy reduced pain and improved upper limb function in participants with post stroke CRPS I of the upper limb compared with covered mirror therapy.

\section{Virtual body swapping}

We included one trial of virtual body swapping with mental rehearsal compared to virtual body swapping alone ( Jeon 2014) $(\mathrm{N}=10)$ in participants with CRPS I of either the upper or lower limbs, multiple limbs or the whole body, the aetiology of which was not reported. Participants underwent a single session of their allocated intervention with follow-up immediately post-treatment only. Jeon 2014 reported that there was no difference between the groups regarding pain intensity, as measured by an 11-point Likert rating scale ranging from zero 
(no pain) to 10 (severe pain) immediately post-treatment. The trial authors did not report numerical data for measures of pain intensity, and we have been unable to obtain these data from the trial authors. As a result, we could not conduct any further analyses and we could not determine the effect size. We rated the trial as at 'unclear' risk of bias for random sequence generation and allocation concealment, and at 'high' risk of bias for selective outcome reporting. The trial authors did not report any data concerning adverse events and did not measure other outcomes of interest, such as measures of function, composite scoring of symptoms, HRQL and PGIC.

\section{Quality of the evidence}

There was very low quality evidence (RCT evidence: high, downgraded once for methodological limitations, once for imprecision and once for inconsistency) that virtual body swapping with mental rehearsal does not reduce pain in people with CRPS I in the short-term.

\section{Tactile discrimination training}

We included one trial, Moseley 2009, that compared four tactile discrimination training (TDT) protocols with one another $(\mathrm{N}=10)$ in participants with CRPS I of the upper limb from mixed aetiologies. Moseley 2009 reported no significant differences in self-reported pain intensity (0 to $100 \mathrm{VAS}$ ) at two day follow-up. The trial authors did not report numerical data for measures of pain intensity, and they have not supplied us with these data. Thus we were unable to perform any further analyses and we could not determine the effect size. We rated the trial at 'high' risk of bias for selective outcome reporting, sample size and duration of follow-up. Regarding adverse events, three participants reported that the pressure stimuli associated with the TDT occasionally hurt but that this was not enough to necessitate modification or cessation of the TDT training. The trial authors did not measure other outcomes of interest, such as function, composite scoring of symptoms, HRQoL and PGIC.

\section{Quality of the evidence}

There was very low quality evidence (RCT evidence: high, downgraded once for methodological limitations, once for imprecision and once for inconsistency) that TDT does not reduce the pain associated with CRPS I at short-term follow-up.

\section{Electrotherapy interventions}

\section{Ultrasound of the stellate ganglion versus placebo}

Two trials, Askin 2014 and Aydemir 2006, investigated the effectiveness of applying ultrasound directed to the stellate ganglion versus placebo. Both trials were small, with fewer than 50 participants, and were at 'high' or 'unclear' risk of bias based on a number of criteria. Askin $2014(\mathrm{~N}=45)$ compared two doses (3.0 watts and 0.5 watts intensity) of high frequency ultrasound to placebo ultrasound. All trial groups also received multimodal conventional treatment that included a course of medication (including vitamin $\mathrm{C}$, gabapentin and prednisolone) and physiotherapy (including TENS, contrast baths, active and passive range of motion exercises and stretching, resistance and mirror box exercises). The participants received treatments daily for 20 days. Aydemir $2006(\mathrm{~N}=25)$ compared stellate ganglion block with ultrasound to blocks with lidocaine and placebo conditions for both interventions. All trial groups received exercises, TENS, contrast baths, compression and oral paracetamol. While only one trial, Aydemir 2006, provided data in an extractable format for meta-analysis, both trials demonstrated no statistically significant difference of ultrasound over placebo for pain. Regarding assessment of function, Askin 2014 used the DASH score to measure function. While Askin $\underline{2014}$ did not present data in a format extractable for meta-analysis, they reported no statistically significant effect of ultrasound. Aydemir 2006 measured hand function using a Functional Hand Scale (0 to 19 scale, with lower scores indicating better function) and reported statistically significant improvements in all three trial groups post-treatment and at one month follow-up. According to our analyses there were significantly greater improvements in the placebo group post-treatment (MD 7.86, 95\% $\mathrm{Cl} 1.93$ to $13.79, \mathrm{P}=0.009$ ) and at one month follow-up (MD 6.79, $95 \% \mathrm{Cl} 0.85$ to $12.73, \mathrm{P}=0.02$ ). The trial authors did not present any data 
concerning adverse events and did not measure other outcomes of interest, such as composite scoring of symptoms, HRQoL and PGIC.

\section{Quality of the evidence}

There is low quality evidence (RCT evidence: downgrade once for methodological limitations and once for imprecision) that stellate ganglion block via ultrasound is not effective for the treatment of pain or loss of hand function in people with CRPS I.

\section{Ultrasound of the stellate ganglion versus TENS.}

One trial with 30 participants compared ultrasound of the stellate ganglion to TENS in military recruits with acute (mean duration of symptoms: 44 days) CRPS I of the upper limb secondary to mixed aetiologies (Hazneci 2005). Both groups also received contrast baths and physiotherapist prescribed exercises. In this trial the ultrasound group demonstrated inferior post-treatment pain scores (0 to $10 \mathrm{VAS}$; MD 2.13, 95\% Cl 1.47 to $2.79, \mathrm{P}<0.001)$ which equates to a potentially clinically important difference of $27 \%(95 \% \mathrm{Cl} 19$ to 36$)$ of the average baseline pain score. The trial authors measured pain severity at the end of the three-week intervention period only without longer-term follow-up. We rated the trial at 'unclear' risk of bias for random sequence generation and allocation concealment. They did not report any data concerning adverse events and did not measure other outcomes of interest, such as function, composite scoring of symptoms, HRQoL and PGIC.

\section{Quality of the evidence}

There is low quality evidence (RCT evidence: high, downgraded once for imprecision and once for inconsistency) that ultrasound to the stellate ganglion is inferior to TENS for the treatment of pain in people with CRPS I in the short-term.

\section{Pulsed electromagnetic field therapy}

One trial with 40 participants, Durmus 2004, compared pulsed electromagnetic field (PEMF) treatment (100 Gauss, $50 \mathrm{~Hz}$, five times weekly for six weeks) plus calcitonin and a stretching exercise routine to placebo EMF plus calcitonin and stretching in participants with acute (mean duration of symptoms: 52 days) CRPS I of the upper limb following Colles fracture. At the end of treatment, Durmus 2004 found no statistically significant between-group difference in pain at rest (VAS), pain on activity, or range of motion. We rated the trial at 'high' risk of bias for study size and duration of follow-up and at 'unclear' risk of bias for allocation concealment. The trial authors did not report any data concerning adverse events and did not measure other outcomes of interest, such as function, composite scoring of symptoms, HRQoL and PGIC.

\section{Quality of the evidence}

There is low quality evidence (RCT evidence: high, downgraded once for imprecision and once for inconsistency) that PEMF is not superior to placebo for the treatment of pain or range of motion in people with CRPS I.

\section{Laser therapy versus Interferential therapy}

One trial with 50 participants compared 20 sessions of low-level laser therapy with interferential current therapy in participants with post-traumatic CRPS I of the upper or lower limb (Dimitrijevic 2014). Both trial groups also received kinesitherapy that consisted of individualised active and active assisted exercises, strictly dosed up to pain threshold. We rated the trial at 'high' risk of bias for incomplete outcome data, trial size and duration of follow-up. Post-therapy the results demonstrated a statistically significant between-group mean difference for pain at rest ( 0 to $100 \mathrm{VAS})$ of $-8.6(95 \% \mathrm{Cl}-16.27$ to $-0.93, \mathrm{P}=0.03)$ in favour of laser therapy. This equates to a difference of $14 \%(95 \% \mathrm{Cl} 1.5$ to 26$)$ from the mean baseline pain score of the two groups, which falls below our criteria for a minimal clinically important difference. There was no statistically significant post-treatment between-group difference with respect to pain with movement of the affected wrist or 
ankle according to our analysis $(P=0.07)$. The trial authors reported that there were no negative effects of therapy recorded. The trial authors did not measure other outcomes of interest, such as function, composite scoring of symptoms, HRQoL and PGIC.

\section{Quality of the evidence}

There is very low quality evidence (RCT evidence: high, downgraded once for methodological limitations, once for imprecision and once for inconsistency) that low level laser therapy does not result in a clinically important reduction in pain when compared to interferential therapy when added to exercise therapy.

\section{$\mathrm{CO}_{2}$ Bath therapy}

One trial, Mucha 1992, with 40 participants compared carbon dioxide $\left(\mathrm{CO}_{2}\right)$ baths in addition to exercise therapy with exercise therapy alone in participants with post-traumatic CRPS I of the hand. Neither intervention is clearly described in the paper though the baths were administered in 12-minute sessions five times a week for four weeks. Mucha 1992 reported that there was a statistically significant between-group difference in pain at rest, pain with movement and night pain in favour of the $\mathrm{CO}_{2}$ bath group. The trial authors did not report numerical data, and we have been unable to obtain these data from the trial authors. Consequently, we were unable to perform any further analyses of these measures and could not determine an effect size. We rated the study at 'high' risk of bias on five separate criteria. The trial authors did not report any data concerning adverse events and did not measure other outcomes of interest, such as function, composite scoring of symptoms, HRQoL and PGIC.

\section{Quality of the evidence}

There is very low quality evidence (RCT evidence: high, downgraded once for methodological limitations, once for imprecision and once for inconsistency) that $\mathrm{CO}_{2}$ baths combined with exercise therapy are more effective for relieving the pain associated with CRPS I than exercise alone.

\section{Electro-acupuncture and massage versus rehabilitation}

One trial, Li 2012, with 120 participants compared 30 sessions of electro-acupuncture combined with upper limb massage therapy to 30 sessions of rehabilitation in participants with post stroke shoulder-hand syndrome. Rehabilitation consisted of active-assisted scapular movements, Bobath exercises to clench the fist, functional transfer training and proprioceptive neuromuscular facilitation (PNF) exercise. It is unclear if the primary aim of the rehabilitation offered was to manage the shoulder-hand syndrome explicitly or if it was a general rehabilitation programme aimed at addressing the motor impairments related to the stroke. This trial measured pain in the shoulder when it was taken passively to $90^{\circ}$ of elevation but did not include any other measure of upper limb or hand pain. We rated the trial at 'high' risk of bias for blinding of participants and at 'unclear' risk of bias for sample size. Li 2012 reported greater reductions on the outcome pain (in the shoulder when taken passively to $\left.90^{\circ}\right)$ in favour of the electro-acupuncture and massage group at the end of the six-week treatment period (MD $-1.70,95 \% \mathrm{Cl}-2.09$ to $-1.31, \mathrm{P}=0.01$ ) which were sustained at 12-weeks follow-up (MD -1.40 , $95 \% \mathrm{Cl}-1.78$ to $-1.02, \mathrm{P}<0.001)$. The post-treatment and 12 -week follow-up MD values equated to a $21 \%$ $(95 \% \mathrm{Cl} 16$ to $26 \%)$ and $18 \%(95 \% \mathrm{Cl} 13$ to $22 \%)$ reduction in the average baseline pain level respectively. These were below the threshold for a moderately clinically important difference but exceeded the IMMPACT threshold (15\%) for a minimally important benefit. Li 2012 reported no statistically significant difference in hand function between the two trial groups, but a statistically significant difference in upper limb function in favour of the electro-acupuncture and massage group at the end of treatment (MD 4.5, 95\% Cl 0.85 to 8.15, $\mathrm{P}=0.05$ ) which was no longer significant at 12-weeks follow-up. The trial authors reported that there were no adverse reactions to intervention in either trial group. They did not measure other outcomes of interest, such as composite scoring of symptoms, HRQoL and PGIC. Notably, we also have some concerns regarding the diagnostic equivalence of 'shoulder-hand syndrome' and CRPS I and whether the control intervention was directed towards the management of the shoulder-hand syndrome or the upper limb functional stroke problem, 
both of which may have implications for the generalisability of this trial's findings.

\section{Quality of the evidence}

There is very low quality evidence (RCT evidence: high, downgraded once for methodological limitations, once for imprecision and once for indirectness) that a course of electro-acupuncture and massage is superior to rehabilitation therapy for pain on passive shoulder elevation in participants with post stroke shoulder-hand syndrome, but not hand-specific function. Also, the magnitude of effect on pain severity was clinically minimal.

\section{Other interventions}

\section{Manual Lymphatic Drainage therapy}

Two included trials, Duman 2009 and Uher 2000, investigated the effectiveness of adding MLD therapy to rehabilitation. Duman 2009 ( $N=34)$ compared the addition of MLD massage to conventional care (nonsteroidal anti-inflammatory drugs and physical therapy) to conventional care alone in participants with CRPS I of the upper limb of mixed aetiology. Uher $2000(\mathrm{~N}=40)$ compared the addition of MLD in addition to exercise therapy to exercise therapy alone in participants with CRPS I of the lower limb of mixed aetiology. We rated both trials as being at 'high' risk of bias on multiple criteria. We were only able to extract data on relevant outcomes from Duman 2009, but both trials demonstrated no statistically significant effect of the addition of MLD on pain. The trial authors did not report any data on adverse events and did not measure other outcomes of interest, such as function, composite scoring of symptoms, HRQoL and PGIC.

\section{Quality of the evidence}

There is low quality evidence (RCT evidence: high, downgraded once for methodological limitations and once for imprecision) that the addition of MLD to rehabilitation does not improve pain in people with CRPS I.

\section{Discussion}

\section{Summary of main results}

Given the paucity of high quality of evidence derived from our analyses of the 18 included randomised controlled trials (RCTs) (739 participants), we cannot draw any firm conclusions regarding the effectiveness or harmfulness of a broad range of physiotherapy-based interventions for treating the pain and disability associated with complex regional pain syndrome (CRPS) I in adults.

The results of one included trial, Oerlemans 1999, provided very low quality evidence that a multimodal physiotherapy programme may provide a small, long-term improvement in impairment, as measured by a composite scoring method, compared to a minimal intervention of 'social work', but the magnitude of this effect is of questionable clinical significance. We could not determine its effect on a range of pain-related outcomes.

Evidence that supports the use of cortically-directed sensory-motor rehabilitation strategies was mixed. Our findings suggest that graded motor imagery (GMI) may provide clinically meaningful medium- and long-term improvements in both pain and disability in people with CRPS I, although the results from these trials were from very low quality studies and were inconsistent. While our meta-analysis of two trials, Moseley 2004 and Moseley 2006, provided evidence of such benefits, we were unable to obtain and include data from one, as yet unpublished, clinical trial with contradictory results (Schreuders 2014); these results should therefore be treated with caution.

Based on two included trials we found very low quality evidence that mirror therapy provides long-term clinically meaningful improvements in pain and function in people with CRPS I following stroke (Cacchio 2009a; Cacchio 2009b). The effectiveness of mirror therapy in broader participant populations with CRPS I (e.g. post-trauma) is unknown. We also found very low quality evidence that the more novel interventions of virtual body swapping \pm mental rehearsal (Jeon 2014) and tactile discrimination training (TDT) (Moseley 2009) 
do not provide any short-term benefits for pain in people with CRPS I.

Evidence that supported the use of electrotherapy-based interventions was mixed. There was low to very low quality evidence that:

1. stellate ganglion block via ultrasound combined with a conventional treatment programme was not superior to placebo ultrasound for pain and hand function at medium-term follow-up (Askin 2014; Aydemir 2006);

2. stellate ganglion block via ultrasound combined with contrast baths and exercise was inferior to TENS combined with contrast baths and exercise for pain and short-term follow-up (Hazneci 2005);

3. PEMF therapy was not superior to placebo PEMF for pain at short-term follow-up (Durmus 2004);

4. laser therapy combined with exercise may provide a small, probably clinically insignificant, benefit in pain compared to interferential current therapy and exercise at short-term follow-up (Dimitrijevic 2014); and

5. $\mathrm{CO}_{2}$ bath therapy combined with exercise may improve pain compared to exercise therapy alone although the effect size could not be determined (Mucha 1992) and the interventions were inadequately described.

Two RCTs provided low quality evidence that manual lymphatic drainage (MLD) combined with and compared to either non-steroidal anti-inflammatories and physical therapy (Duman 2009) or exercise therapy (느er 2000) is not beneficial for pain in people with CRPS I.

We found very low quality evidence from one trial, Li 2012, that electro-acupuncture and massage were superior to a stroke rehabilitation programme for pain on passive shoulder movement in shoulder-hand syndrome post stroke at longer-term follow-up. However, the magnitude of this effect was unlikely to be clinically important and both the reliability and validity of the outcome measure used are questionable.

Only two trial reports, one related to laser and interferential therapies, Dimitrijevic 2014, and one to TDT, Moseley 2009, commented on the presence or absence of adverse events and reported no serious events.

We did not find any clinical trials that included participants with CRPS II that met the inclusion criteria of this Cochrane review.

Overall, we identified a lack of high or moderate quality evidence with which to inform or guide rehabilitation practice in people with CRPS I or II. Based on the current body of evidence, we cannot draw any accurate or firm conclusions regarding the effectiveness or safety of any of the specific physiotherapy-based interventions we identified in this Cochrane review.

\section{Overall completeness and applicability of evidence}

The evidence base for the use of physiotherapy interventions in CRPS is incomplete, although this reflects a broader problem for all intervention research in CRPS (O'Connell 2013). Most included trials (16/18) used established diagnostic criteria to identify participants with CRPS I. However, as might be expected given the development history of such criteria in CRPS, there was some variation in the criteria used between included trials. Beyond various issues relating to risk of bias and study size (see Quality of the evidence) there are very few instances where more than one included trial tested a specific intervention. Two trials, Duman 2009 and Hazneci 2005, specifically recruited participants from military populations. As such, it is possible that contextual factors specific to that participant group and environment may limit the applicability of those results to civilian clinical practice. Eight trials only measured outcomes immediately at the end of treatment with no longer-term follow-up. Such trials offer limited information about the genuine clinical utility of interventions for a condition that is commonly persistent. The broad heterogeneity of interventions assessed in the included trials afforded us limited opportunities to pool data. However, it is possible that advances in meta-analytical statistics may permit such analyses in the future (Melendez-Torres 2015).

The aim of this Cochrane review was to investlgate the effectiveness of physiotherapy interventions for people with CRPS I or II. We used a deliberately inclusive definition to attempt to include evidence on any intervention 
that might reasonably be delivered within a physiotherapy context for people with CRPS. As a result the included trials varied considerably but most were designed to test the specific effectiveness of individual modalities either alone, when added to other treatments or compared to other treatments. While these trials offered information about the specific or additional clinical benefits of those modalities, they are less informative about the effectiveness of physiotherapy programmes that incorporate multiple treatment modalities, but are more likely to reflect physiotherapy as it is delivered in clinical practice. Only one included trial, Oerlemans 1999, took the pragmatic approach of testing a multimodal physiotherapy programme against a minimal treatment control group. Notably, this trial pre-dates substantial developments in the pathophysiological models of CRPS and it is possible that a modern multimodal physiotherapy programme might differ substantially. In addition, the included trials rarely reported on adverse events (two out of 18 trials) and it is unclear whether or not this represents an absence of adverse events or a failure to report them.

While we categorised these interventions under the label "physiotherapy" in this Cochrane review, we recognise that rehabilitation therapies may be delivered by a range of different professionals, including occupational therapists and nurses.

\section{Quality of the evidence}

As reflected by the Grading of Recommendations Assessment, Development and Evaluation (GRADE) ratings, the overall quality of the evidence in this Cochrane review was low or very low. This reflects the fact that most included trials were at unclear or high risk of bias for criteria included under the standard domains of the Cochrane 'Risk of bias' tool, and under the additional 'Risk of bias' criteria of study size and duration included in this review. The included trials studied a broad heterogeneity of interventions, which afforded us limited opportunity to pool data and that, coupled with study size, led to issues of imprecision and inconsistency.

It is likely that small study effects, wherein there is a propensity for negative studies to not be published, might lead to an overly positive picture for some interventions, particularly in a field with such a limited evidence base. Evidence from the wider literature indicates that this might lead to an overly positive picture for some interventions (Dechartres 2013; Moore 2012; Nüesch 2010). In a review of meta-analyses, Dechartres 2013 demonstrated that trials with fewer than 50 participants, which reflects most trials (17/18) included in this Cochrane review, returned effect estimates that were on average $48 \%$ larger than the largest trials and $23 \%$ larger than estimates from studies with sample sizes of more than 50 participants. We did not downgrade any of the GRADE judgements on the basis of publication bias, as there can be no direct evidence with so few trials for any given intervention. Moreover, it is accepted that existing approaches to detecting publication bias are unsatisfactory. To an extent our GRADE judgements reflect this risk through the assessment of imprecision and the limitations of included trials. Conversely, the issue of small study size with few included trials available for any single comparison raises the possibility of false negatives through lack of statistical power (Button 2013). Many of the comparisons we included in this review did not demonstrate a statistically significant difference. However, it is possible that we may have missed real effects on this basis.

The quality of reporting in many included trials was problematic. There was a lack of detailed descriptions of some interventions and a number of included trials did not present key numerical outcome data for all time-points (9/18 trials) or insufficiently reported the scoring properties of their outcome measures for pain intensity (7/18 trials). The quality of reporting of pain-related outcomes measures in clinical trials and

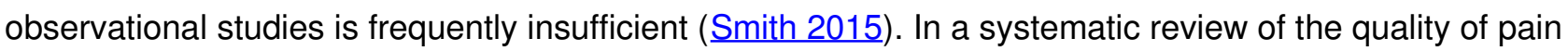
intensity reporting in three prominent pain journals, Smith 2015 found that nearly one quarter of published studies inadequately reported the type of pain intensity measure employed.

\section{Potential biases in the review process}

We conducted extensive and sensitive literature searches and included trials regardless of the language of publication. As such this Cochrane review probably represents the totality of currently available evidence. The choice to use the IMMPACT thresholds to determine the clinical importance of effect sizes is potentially controversial. What exactly constitutes an important difference on any given outcome measure remains 
contentious as the construct of a generic importance thresholds for a variety of interventions fails to reflect that patient satisfaction might differ substantially between interventions given their risks, costs and inconvenience, the point in the care pathway at which the participant arrives, and a range of other possible factors. Moreover, the IMMPACT thresholds are based on estimates of the degree of within-person change from baseline that participants might consider to be clinically important, whereas the effect sizes focused on in this review reflect the average change between intervention-groups following the interventions. For some pharmacological interventions the distribution of participant outcomes is bimodal (Moore 2013; Moore 2014a; Moore 2014b). That is, some participants experience a substantial reduction in symptoms, some minimal to no improvement and very few experience intermediate (moderate) improvements. In this instance, and if the distribution of participant outcomes reflects the distribution of treatment effects, then the average effect may be the effect that the fewest participants actually demonstrate (Moore 2013). It is therefore possible that a small average between-group effect size might reflect that a proportion of participants responded very well to the intervention tested. The common solution to this problem is to conduct a 'responder analysis', which compares the proportion of participants achieving a clinically important improvement from baseline in the treatment and control groups. However responder analysis is very rare in rehabilitation therapies and there is no evidence to date to establish whether outcomes are commonly bimodal in rehabilitation trials. It therefore remains equally possible that a very small average between-group effect might accurately represent the generally very small effects of an intervention for most or all individuals.

As such, the between-group change is our sole available estimate of the specific effectiveness of the interventions in the included trials. Since the publication of our protocol for this review, Smart 2013, the OMERACT 12 group reported recommendations for minimally important difference for pain outcomes (Busse 2015). The group recommends a threshold of $10 \mathrm{~mm}$ on a 0 to 100 VAS as the threshold for minimal importance for average between-group change, though stress that this should be interpreted with caution as it remains possible that estimates which fall closely below this point may still reflect a treatment that benefits an appreciable number of participants. Using this largely more lenient threshold would not alter our conclusions regarding clinical importance. The OMERACT thresholds present similar problems to those associated with all generic thresholds and it seems likely that the discussion around what constitutes clinical importance will continue. Arguably, the thresholds used in this Cochrane review of a $15 \%$ or $30 \%$ improvement in baseline levels of pain that are specifically attributable to the interventions do not represent unreasonably high thresholds.

\section{Agreements and disagreements with other studies or reviews}

The results of this systematic review are largely consistent with the conclusions drawn in our recent overview of systematic reviews of all interventions for CRPS (O'Connell 2013). In O'Connell 2013 we drew our conclusions mainly based on two non-Cochrane reviews of physiotherapy interventions for CRPS (Daly 2009; Smith 2005) and we based the analysis of the evidence at the level of those included reviews. Our current review is more up-to-date, includes a number of additional studies and our conclusions are drawn from direct analysis of the original trials. Daly 2009 concluded that there was good to very good quality evidence to support the use of GMI for CRPS; and a review by Bowering 2013 (of which review author NEO was a co-author) concluded that there was limited evidence to suggest that GMI may be effective for CRPS. In O'Connell 2013 we concluded that there was low quality evidence for the effectiveness of GMI. In this Cochrane review we downgraded the GRADE rating for the evidence related to GMI to very low, largely due to the inconsistency introduced by the inclusion of Schreuders 2014. In Schreuders 2014 the trial authors adjusted the treatment schedule compared to the schedules delivered by Moseley 2004 and Moseley 2006, though it was based on the same theoretical model. Smith 2005 concluded that there was some evidence that exercise, acupuncture, TENS, relaxation techniques, mirror therapy, GMI and combined treatment programmes may be helpful and that it was not possible to determine the effectiveness of individual treatments for CRPS-I. Ten years on, that picture has not changed substantially. It is possible that future systematic reviews may provide further evaluations of the effectiveness of cortically-directed sensory-motor rehabilitation strategies (Plumbe 2013). 
Recent clinical guidelines from the USA (Harden 2013) and the UK (Goebel 2012) have placed rehabilitation therapies as first-line treatments for people with CRPS. Both guidelines describe and recommend an extensive range of possible physiotherapy modalities that might be employed. In making their recommendations, these guidelines (unlike this Cochrane review) draw on evidence from non-randomised studies, expert consensus and studies of neuropathic pain generally. This Cochrane review highlights the fragility of the evidence underpinning these recommendations. The optimal approach to physiotherapy for people with CRPS and the true extent of potential benefits and risks remain uncertain. Also, there may be substantial redundancy within the broad range of therapies described or recommended in the guidelines.

\section{Authors' conclusions}

\section{Implications for practice}

It is likely that, in line with contemporary clinical guidelines, physiotherapy and rehabilitation based interventions will continue to be first-line treatments for people with complex regional pain syndrome (CRPS). In this Cochrane review we have been unable to find compelling evidence of the effectiveness, or lack thereof, of physiotherapy interventions, or to inform an optimal approach to therapy, although very low quality evidence suggests a possible benefit of multimodal physiotherapy, graded motor imagery (GMI) and mirror therapy. The available evidence suggests that applying ultrasound to the stellate ganglion or manual lymphatic drainage (MLD) to the affected limb are unlikely to offer clinical benefit to people with CRPS type I.

\section{Implications for research}

Overall, given the existing limitations within the current body of evidence, there is a clear need for further research into physiotherapy interventions in people with CRPS but many challenges remain in addressing this problem. Given the relatively low incidence of CRPS, it is likely to be difficult to recruit adequate numbers of participants to clinical trials. It seems likely that the best chance of addressing this challenge is through multicentre, collaborative research projects aimed at recruiting participants from potentially larger pools of clinical populations. It seems unlikely that it will be possible to generate sufficient evidence to support the many individual modalities currently applied to people with CRPS. In this instance there is a case for taking a pragmatic approach to developing contemporary multi-modal, individually tailored "best practice" models of physiotherapy care and prioritising trials of these programmes against usual or minimal care. Such trials might provide pragmatic estimates of effectiveness which best reflect the value of guideline recommended practice. Larger replication trials of GMI and mirror therapy would also be useful in order to provide more accurate estimates of treatment effect for these interventions, which current evidence suggests may offer meaningful clinical benefit. Future trials should use established diagnostic criteria, clearly report the type of CRPS under investigation and their design should consider recent recommendations (Busse 2015; Dworkin 2008; Dworkin 2009; Dworkin 2010; Turk 2008a; Turk 2008b) for the design and reporting of trials in chronic pain. This will help to ensure that outcomes, thresholds for clinical importance and study design are optimal and we also highlight the need to measure patient-focused outcomes over clinically relevant periods of time. Furthermore, future trials should adhere to CONSORT guidance, including that related to the reporting of the development and evaluation of complex interventions (Möhler 2015).

\section{Acknowledgements}

We thank Joanne Abbott, the Trials Search Co-ordinator with the Cochrane Pain, Palliative and Supportive Care (PaPaS) Group, for her assistance with designing the search strategy. We also thank Prof Dr Nazan Bilgel (Uludağ University, Turkey) for checking the eligibility and subsequent translation of the two papers published in Turkish and Andrea Wand for checking the eligibility and subsequent translation of the two papers published in German. We are grateful to Dr Malgorzata M Bala (Jagiellonian University Medical College, Poland) and Dr Meldijana Omerbegovic (Anaesthesia, Pain Therapy \& ICU, University of Sarajevo, Bosnia and Herzegovina) for their assistance with eligibility checks of relevant studies that were not published in the 
English language.

Cochrane Review Group funding acknowledgement: the National Institute for Health Research (NIHR) is the largest single funder of the Cochrane PaPaS Group. Disclaimer: the views and opinions expressed therein are those of the review authors and do not necessarily reflect those of the NIHR, National Health Service (NHS) or the UK Department of Health.

\section{Contributions of authors}

KMS conceived and designed the protocol, implemented the search strategy, applied eligibility criteria, assessed studies, extracted and analysed data, and led the write-up of the review. BMW informed the protocol design, applied eligibility criteria, assessed studies, extracted and analysed data, and assisted with the write-up of the review. NEO informed the protocol design, acted as the third review author, oversaw data synthesis, and assisted with the write-up of the review. KMS will be responsible for updating this Cochrane review.

\section{Declarations of interest}

All review authors are qualified physiotherapists, although none currently practice in private health care or for a 'for profit' organisation.

KMS received honoraria from Pfizer (Ireland) to speak at public events, although we declare that Pfizer (Ireland) has no direct interest in this Cochrane review and did not provide any direct or indirect funding for this Cochrane review.

BMW and NEO have no known conflicts of interest.

\section{Differences between protocol and review}

With respect to Types of interventions, after the publication of Smart 2013 we decided to exclude studies that evaluated non-physiotherapy based interventions (e.g. pharmacological) in which all study arms received the same physiotherapy intervention (differing only in the application of the non-physiotherapy component) as they are unlikely to offer any insight into the value of physiotherapy management. In Smart 2013 we stated our intention to search the SciVerse SCOPUS electronic database. However we did not search this database as the primary review author (KMS) did not have institutional access. The Trials Search Co-ordinator of the Cochrane PaPaS group advised that its omission was unlikely to adversely influence our search results. We have described, in additional detail, our operational definitions upon which we based our 'Risk of bias' judgements (see the 'Assessment of risk of bias in included studies' section). In this Cochrane review we have specified the criteria upon which we based our GRADE judgements for rating the quality of evidence (see the 'Data synthesis' section).

\section{Published notes}

\section{Characteristics of studies}

\section{Characteristics of included studies}

\section{Askin 2014}




\begin{tabular}{|c|c|}
\hline Methods & $\begin{array}{l}\text { Design: parallel group, 3-arm, single-blind RCT (Turkey; dates not reported). } \\
\text { Setting: outpatient hospital clinic. } \\
\text { Interventions: conventional care plus low dose high frequency ultrasound } \\
\text { therapy }\left(0.5 \text { watts } / \mathrm{cm}^{2}\right) \text { for stellate ganglion blockade or conventional care plus } \\
\text { low dose high frequency ultrasound therapy }\left(3.0 \text { watts } / \mathrm{cm}^{2}\right) \text { for stellate ganglion } \\
\text { blockade or conventional care plus placebo ultrasound therapy. } \\
\text { Sample size calculation: not reported. }\end{array}$ \\
\hline Participants & 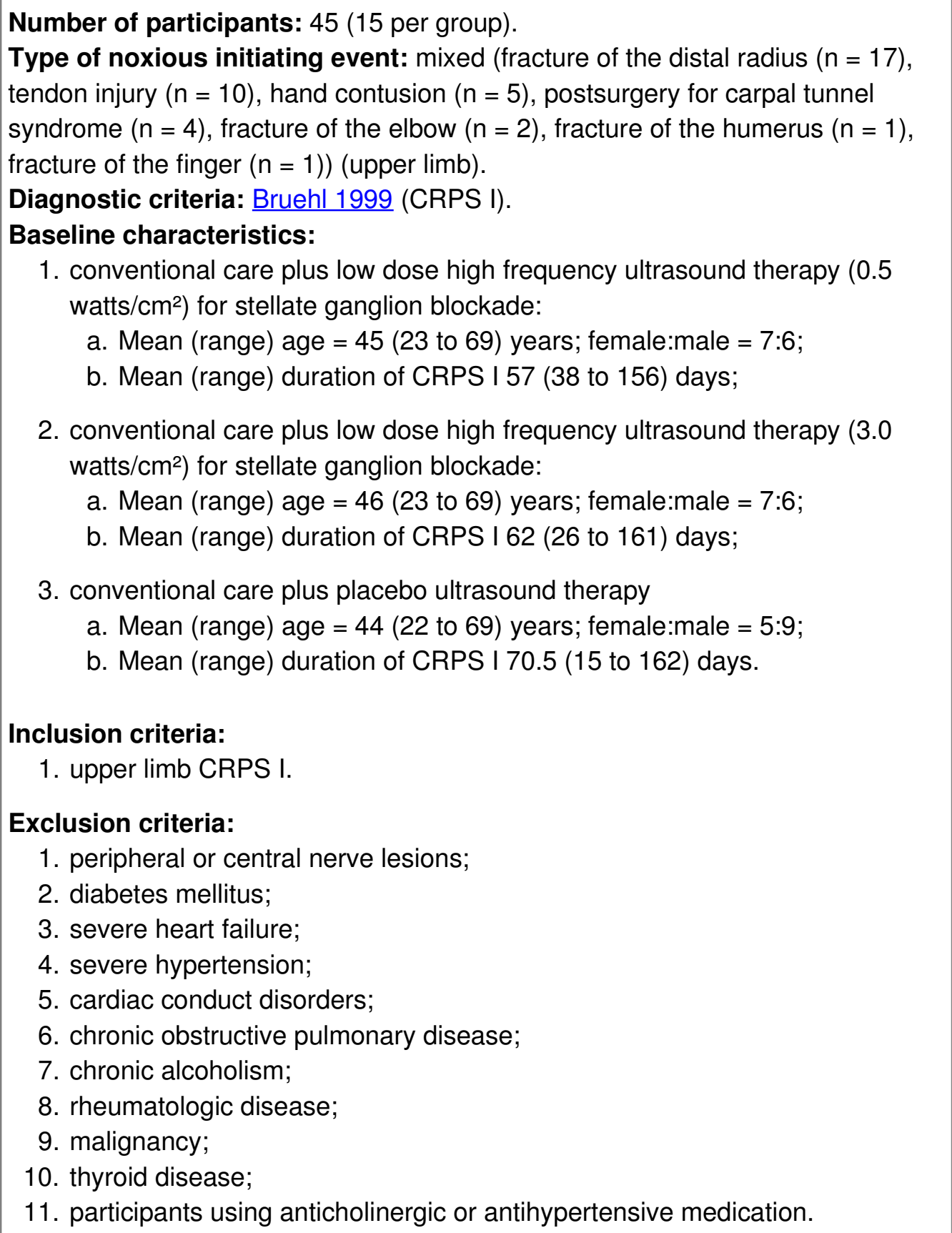 \\
\hline Interventions & $\begin{array}{l}\text { Participants in all } 3 \text { groups received conventional care including: } \\
\text { 1. pharmacotherapy (including } 500 \mathrm{mg} / \text { day vitamin C, Gabapentin (dose: } 1800 \\
\mathrm{mg} / \text { day) and Prednisolone (dose: } 30 \mathrm{mg} / \text { day- } 2 \text { weeks, stopped within next } 2 \\
\text { weeks)); } \\
\text { 2. } 20 \text { sessions of transcutaneous electrical nerve stimulation ((Enraf Nonius } \\
\text { brand Endomed } 582 \mathrm{ID}) 100 \text { hertz (Hz) frequency to the painful area of the } \\
\text { affected extremity once a day, } 20 \text { minutes); }\end{array}$ \\
\hline
\end{tabular}




\begin{tabular}{|c|c|}
\hline & 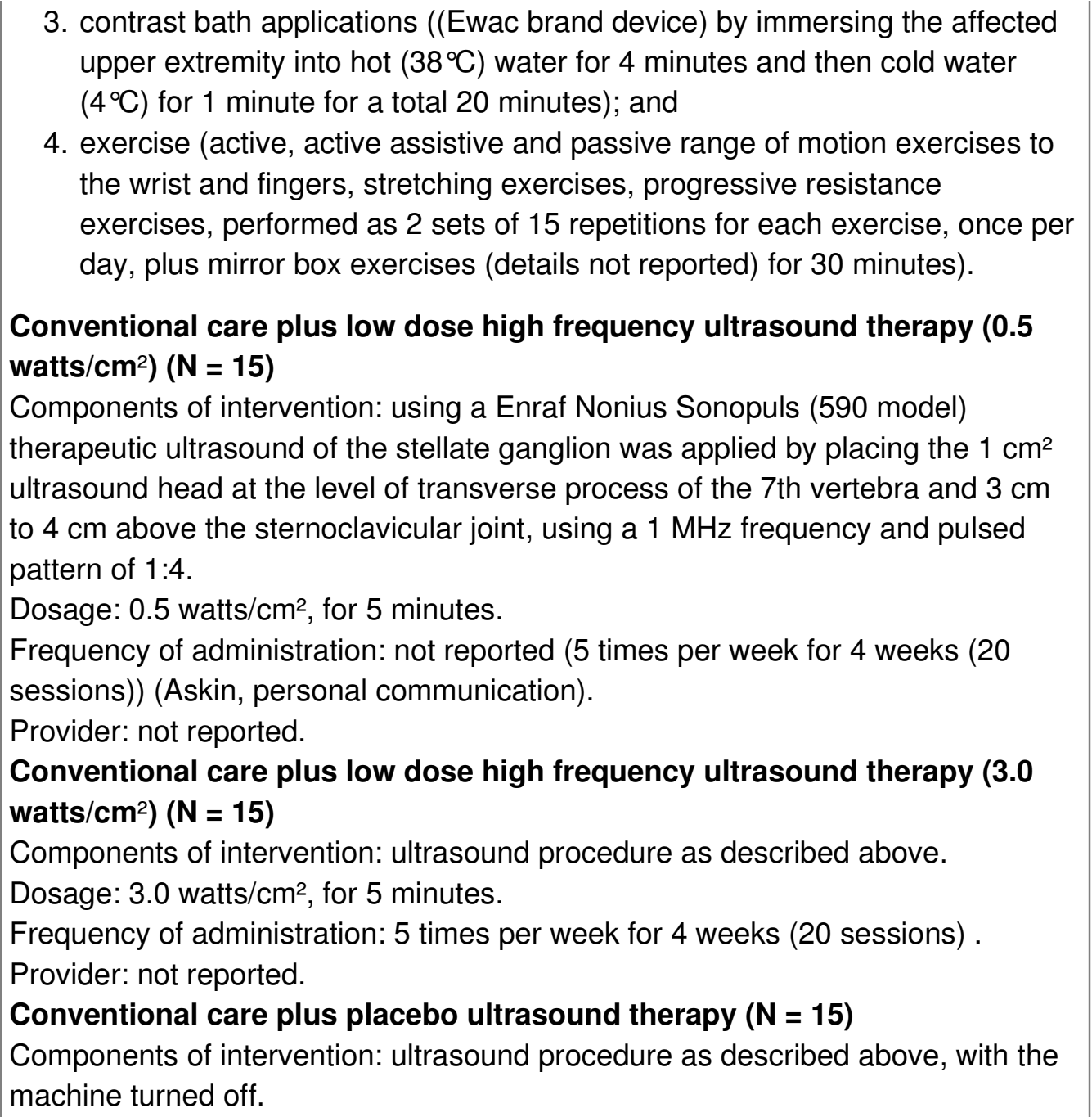 \\
\hline Outcomes & $\begin{array}{l}\text { Time points at which outcomes were measured were not explicitly specified in } \\
\text { the trial report. Outcomes were assessed at baseline and on completion of the } \\
\text { intervention period ( } 4 \text { weeks post recruitment) (Askin, personal communication). } \\
\text { The trial authors did not state any primary outcome. } \\
\text { 1. Self-rated pain intensity at rest using a } 10 \mathrm{~cm} \text { VAS ( } 0=\text { no pain, } 10= \\
\text { severe pain); } \\
\text { 2. limitation of total finger flexion was assessed by measuring finger pulp-distal } \\
\text { crease distance using a ruler; } \\
\text { 3. grip strength was assessed using a hand dynamometer (average of } 3 \\
\text { measurements in kg); } \\
\text { 4. self-reported upper extremity disability was assessed using the Disability of } \\
\text { the Arm, Shoulder and Hand (DASH) questionnaire (Turkish version), with } \\
\text { lower scores indicating better function (score range not reported). }\end{array}$ \\
\hline Notes & $\begin{array}{l}\text { Source of funding: not reported. } \\
\text { Statement regarding declarations of interest: none declared. }\end{array}$ \\
\hline
\end{tabular}

Risk of bias table 


\begin{tabular}{|c|c|c|}
\hline Bias & \begin{tabular}{|l|} 
Authors' \\
judgement
\end{tabular} & Support for judgement \\
\hline $\begin{array}{l}\text { Random sequence generation } \\
\text { (selection bias) }\end{array}$ & High risk & $\begin{array}{l}\text { Quote: "Patients were randomly divided into } 3 \text { groups by } \\
\text { picking cards in different colours. First, three groups of } \\
\text { cards (each group consisted of } 15 \text { cards) in } 3 \text { different } \\
\text { colours (blue for } 3 \text { watts } / \mathrm{cm} 2 \text {, pink for } 0.5 \text { watts } / \mathrm{cm} 2 \text {, yellow } \\
\text { for placebo) were prepared. Participants were asked to } \\
\text { choose a card before starting the treatment. The US dose } \\
\text { was determined according to the colour of the selected card } \\
\text { and it was recorded. The randomisation process was } \\
\text { performed by another physician". } \\
\text { Comment: the trial authors used a non-random sequence } \\
\text { generation process. }\end{array}$ \\
\hline $\begin{array}{l}\text { Allocation concealment (selection } \\
\text { bias) }\end{array}$ & Low risk & $\begin{array}{l}\text { Quote: "The randomisation process was performed by } \\
\text { another physician". } \\
\text { Comment: the trial authors probably used an acceptable } \\
\text { method to conceal the allocation sequence. }\end{array}$ \\
\hline $\begin{array}{l}\text { Blinding of participants and } \\
\text { personnel (performance bias) }\end{array}$ & Low risk & $\begin{array}{l}\text { Quote: "No information was given to patients and to the } \\
\text { physician who will make assessments and US application } \\
\text { about the randomisation process until the end of the study". } \\
\text { Comment: the participants were blinded to treatment } \\
\text { allocation. }\end{array}$ \\
\hline $\begin{array}{l}\text { Blinding of outcome assessment } \\
\text { (detection bias) } \\
\text { Self-reported outcomes }\end{array}$ & Low risk & $\begin{array}{l}\text { Quote: "No information was given to patients and to the } \\
\text { physician who will make assessments and US application } \\
\text { about the randomisation process until the end of the study". }\end{array}$ \\
\hline $\begin{array}{l}\text { Blinding of outcome assessment } \\
\text { (detection bias) } \\
\text { Investigator-administered } \\
\text { outcomes }\end{array}$ & Low risk & $\begin{array}{l}\text { Quote: "No information was given to patients and to the } \\
\text { physician who will make assessments and US application } \\
\text { about the randomisation process until the end of the study". }\end{array}$ \\
\hline $\begin{array}{l}\text { Incomplete outcome data (attrition } \\
\text { bias) } \\
\text { Drop-out rate described and } \\
\text { acceptable }\end{array}$ & Low risk & $\begin{array}{l}\text { Quote: "Thirteen patients from group I, } 13 \text { patients from } \\
\text { group II and } 14 \text { patients from group III, a total of } 40 \text { patients } \\
\text { completed the study". } \\
\text { Comment: an overall drop-out rate of } 11 \% \text { is unlikely to } \\
\text { have biased the results. }\end{array}$ \\
\hline $\begin{array}{l}\text { Incomplete outcome data (attrition } \\
\text { bias) } \\
\text { Participants analysed in the group } \\
\text { to which they were allocated }\end{array}$ & High risk & $\begin{array}{l}\text { Quote: "Two patients from group I, } 2 \text { patients from group II } \\
\text { and } 1 \text { patient from group III who did not come to therapy } \\
\text { sessions regularly were excluded". } \\
\text { Comment: the trial authors excluded } 5 \text { participants in } \\
\text { violation of the ITT principle. }\end{array}$ \\
\hline Selective reporting (reporting bias) & Low risk & $\begin{array}{l}\text { Comment: outcome data were fully reported for all } \\
\text { outcomes reported in the methods section of the publication. }\end{array}$ \\
\hline Sample size & High risk & $\begin{array}{l}\text { Quote: "Fourty-five patients with CRPS type I were } \\
\text { randomly allocated into three groups". } \\
\text { Comment: the small sample size may have introduced bias } \\
\text { in estimates of treatment effect }\end{array}$ \\
\hline
\end{tabular}




\begin{tabular}{||l||l|l||}
\hline Duration of follow-up & High risk & $\begin{array}{l}\text { Quote: "Before and after the treatment the severity of the } \\
\text { pain experienced at rest was assessed". } \\
\text { Comment: outcomes were re-measured on completion of } \\
\text { the intervention period only and were not measured over a } \\
\text { clinically relevant length of time. }\end{array}$ \\
\hline Other bias & Low risk & $\begin{array}{l}\text { Comment: we did not identify any other sources of bias } \\
\text { were identified. }\end{array}$ \\
\hline
\end{tabular}

\section{Aydemir 2006}

\begin{tabular}{|c|c|}
\hline Methods & $\begin{array}{l}\text { Design: parallel group, 3-arm double RCT (Turkey; dates not reported). } \\
\text { Setting: Department of Physical Medicine and Rehabilitation Clinic, Gulhane } \\
\text { Military Medical Academy. } \\
\text { Interventions: stellate ganglion block (SGB) with lidocaine and sham SGB with } \\
\text { ultrasound (US) or SGB with US and sham SGB with lidocaine or sham SGB } \\
\text { with lidocaine and sham SGB with US. } \\
\text { Sample size calculation: not reported. }\end{array}$ \\
\hline Participants & $\begin{array}{l}\text { Number of participants: } 25 \text { (SGB with lidocaine }(N=9) \text {; SGB with US }(N=9) \text {; } \\
\text { sham SGB with lidocaine and sham SGB with US }(N=7) \text { ). } \\
\text { Type of noxious initiating event: mixed (trauma } n=12 \text {, fracture } n=11 \text {, } \\
\text { idiopathic } n=2 \text { ) (upper limb). } \\
\text { Diagnostic criteria: Bruehl } 1999 \text { (CRPS I). } \\
\text { Baseline characteristics: } \\
\text { 1. SGB with lidocaine: } \\
\text { a. Mean ( } \pm \text { ) age = } 21.9 \text { (1.05) years; female:male = not reported } \\
\quad \text { (assumed to be all males as setting identical to (Hazneci 2005); } \\
\text { b. Mean (SD) duration of CRPS I = not reported; } \\
\text { 2. Group receiving SGB with US: } \\
\text { a. Mean ( } \pm \text { ) age = } 21.4 \text { (0.73) years; female:male = not reported } \\
\quad \text { (assumed to be all males); } \\
\text { b. Mean (SD) duration of CRPS I = not reported; } \\
\text { 3. Group receiving sham SGB with lidocaine and US: } \\
\text { a. Mean ( } \pm \text { ) age = } 21.1 \text { (0.38) years; female:male = not reported } \\
\quad \text { (assumed to be all males); } \\
\text { b. Mean (SD) duration of CRPS I = not reported. } \\
\text { Inclusion criteria: } \\
\text { 1. CRPS I. } \\
\text { Exclusion criteria: } \\
\text { 1. peripheral or central nervous system lesion affecting the upper limb; } \\
\text { 2. participants using anti-hypertensive or anti-cholinergic medications; } \\
\text { 3. lidocaine allergy; } \\
\text { 4. cardiac arrhthymias; } \\
\text { 5. history of stellate ganglion blockade within the last month. }\end{array}$ \\
\hline
\end{tabular}


Interventions

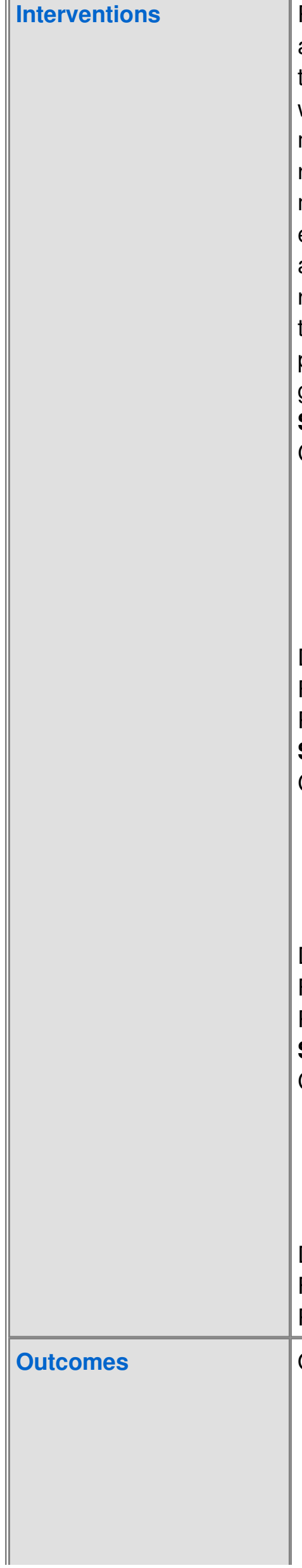

Participants in all 3 groups received 21 sessions of exercise (active, active assisted, passive exercises for the wrist and fingers, twice daily supervised by the same physiotherapist), contrast baths (extremities were put in $38^{\circ} \mathrm{C}$ hot water, $4{ }^{\circ} \mathrm{C}$ cold water for 4 minutes hot and 1 minute cold, 4 minutes cold and 1 minute hot and 4 minutes cold (total time 14 minutes)), transcutaneous electrical nerve stimulation (Enraf Nonius Endomed 582 instrument; for a period of 20 minutes with a frequency of $100 \mathrm{~Hz}$ ), external pneumatic compression (involved extremity was compressed by a pressure of $50 \mathrm{mmHg}$ for a period of 60 seconds and then pressure was released for 20 seconds and this compression and release procedure was repeated for 15 minutes, for participants who could not tolerate the $50 \mathrm{mmHg}$ pressure a lower level pressure was used) and paracetamol (500 $\mathrm{mg}$ orally every 4 hours, maximum dosage of $3 \mathrm{~g} /$ daily was given if it is needed).

\section{Stellate ganglion block with lidocaine $(\mathrm{N}=9)$}

Components of intervention:

1. $10 \mathrm{~mL}$ of $1 \%$ lidocaine was injected slowly into the stellate ganglion (on the line of 6 th vertebra, $1.5 \mathrm{~cm}$ lateral of the median line, $4 \mathrm{~cm}$ to $5 \mathrm{~cm}$ under the skin);

2. (sham SGB with US) using a Enraf Nonius Sonopuls 590 and with the machine turned off the instrument was put on the ganglion for 5 minutes.

Dosage: $10 \mathrm{~mL}$ of $1 \%$ lidocaine.

Frequency of administration: not reported.

Provider: anaesthetist (other providers not reported).

\section{Stellate ganglion block with ultrasound $(\mathbf{N}=9)$}

Components of intervention:

1. (sham SGB with lidocaine) $10 \mathrm{~mL}$ saline solution was used as placebo and injected slowly into the stellate ganglion;

2. SGB with US was applied by using Enraf Nonius Sonopuls 590 (further details regarding method of application not reported).

Dosage: 3 watt $/ \mathrm{cm}^{2}$ for 5 minutes.

Frequency of administration: not reported.

Provider: anaesthetist (other providers not reported).

Sham stellate ganglion block with lidocaine and ultrasound $(\mathbf{N}=7)$

Components of intervention:

1. (sham SGB with lidocaine) $10 \mathrm{~mL}$ saline solution was used as placebo and injected slowly into the stellate ganglion;

2. (sham SGB with US) using a Enraf Nonius Sonopuls 590 and with the machine turned off the instrument was put on the ganglion for 5 minutes.

Dosage: $n / a$.

Frequency of administration: not reported.

Provider: anaesthetist (other providers not reported).

Outcomes assessed at baseline, after treatment and 1 month post-treatment:

1. self-reported spontaneous pain measured using a $10 \mathrm{~cm}$ VAS (0 to 10) (anchor points not reported);

2. self-reported provocative pain measured using a Likert-type scale $(0=$ no pain, 1 = mild pain with deep palpation, 2 = serious pain with deep palpation, 3 = serious pain with superficial palpation, 4 = hyperaesthesia) (further details not reported); 


\begin{tabular}{||l||l||}
\hline 3. oedema measured using a standard forearm volumeter (measured in $\mathrm{mL}$, \\
further details not reported); \\
4. finger pulp-distal palmer crease distance (measured in cm, further details \\
not reported); \\
\begin{tabular}{l} 
5. grip strength measured using a Jamar dynamometer, in a sitting position \\
(measured in kg); \\
6. functional hand scale (score range 0 to 19 with lower scores indicating \\
better function); \\
$\begin{array}{l}\text { 7. Keitel index score (score range } 4 \text { to } 42 ; \text { interpretation of scores not } \\
\text { reported). }\end{array}$ \\
\hline Notes \\
Source of funding: not reported. \\
Statement regarding declarations of interest: not reported.
\end{tabular} \\
\hline \hline
\end{tabular}

Risk of bias table

\begin{tabular}{|c|c|c|}
\hline Bias & \begin{tabular}{|l|} 
Authors' \\
judgement
\end{tabular} & Support for judgement \\
\hline $\begin{array}{l}\text { Random sequence generation } \\
\text { (selection bias) }\end{array}$ & Low risk & $\begin{array}{l}\text { Quote: "Patients were randomised by envelope method and } \\
3 \text { groups were established". } \\
\text { Comment: "Treatment orders were made online..." } \\
\text { Comment: it is likely that the trial authors used an } \\
\text { acceptable method to generate the sequence allocation. }\end{array}$ \\
\hline $\begin{array}{l}\text { Allocation concealment (selection } \\
\text { bias) }\end{array}$ & Low risk & $\begin{array}{l}\text { Quote: "Patients were randomised by envelope method and } \\
3 \text { groups were established". } \\
\text { Comment: the trial authors probably used an acceptable } \\
\text { method to conceal the allocation sequence. }\end{array}$ \\
\hline $\begin{array}{l}\text { Blinding of participants and } \\
\text { personnel (performance bias) }\end{array}$ & Low risk & $\begin{array}{l}\text { Quote: "The study was designed as a double blind study. } \\
\text { Treatment orders were made online and except the } \\
\text { personnel who were involved in the therapy nobody even } \\
\text { the doctor was aware of the selected method". } \\
\text { Comment: participants were likely to have been adequately } \\
\text { blinded. }\end{array}$ \\
\hline $\begin{array}{l}\text { Blinding of outcome assessment } \\
\text { (detection bias) } \\
\text { Self-reported outcomes }\end{array}$ & Low risk & $\begin{array}{l}\text { Quote: "The study was designed as a double blind study. } \\
\text { Treatment orders were made online and except the } \\
\text { personnel who were involved in the therapy nobody even } \\
\text { the doctor was aware of the selected method". } \\
\text { Comment: participants who completed self-reported } \\
\text { outcome measures were blinded to treatment allocation. }\end{array}$ \\
\hline $\begin{array}{l}\text { Blinding of outcome assessment } \\
\text { (detection bias) } \\
\text { Investigator-administered } \\
\text { outcomes }\end{array}$ & Low risk & $\begin{array}{l}\text { Quote: "Treatment orders were made online and except the } \\
\text { personnel who were involved in the therapy nobody even } \\
\text { the doctor was aware of the selected method". } \\
\text { Comment: the outcome assessor was blinded to the } \\
\text { treatment allocation. }\end{array}$ \\
\hline $\begin{array}{l}\text { Incomplete outcome data (attrition } \\
\text { bias) } \\
\text { Drop-out rate described and } \\
\text { acceptable }\end{array}$ & Unclear risk & Comment: the drop-out rate was not reported. \\
\hline
\end{tabular}


Physiotherapy for pain and disability in adults with complex regional pain syndrome.26-Feb-2016

\begin{tabular}{|c|c|c|}
\hline $\begin{array}{l}\text { Incomplete outcome data (attrition } \\
\text { bias) } \\
\text { Participants analysed in the group } \\
\text { to which they were allocated }\end{array}$ & Unclear risk & $\begin{array}{l}\text { Comment: the method of analysis (ITT versus per protocol) } \\
\text { was not reported. }\end{array}$ \\
\hline Selective reporting (reporting bias) & Low risk & $\begin{array}{l}\text { Comment: the trial authors fully reported outcome data for } \\
\text { all outcomes reported in the methods section of the } \\
\text { publication. }\end{array}$ \\
\hline Sample size & High risk & $\begin{array}{l}\text { Quote: "Twenty-five patients were divided into three groups". } \\
\text { Comment: the small sample size may have introduced bias } \\
\text { in estimates of treatment effect. }\end{array}$ \\
\hline Duration of follow-up & Unclear risk & $\begin{array}{l}\text { Quote: "These evaluations were performed before and after } \\
\text { treatment and one month later". } \\
\text { Comment: the clinical relevance of a } 1 \text { month follow-up of } \\
\text { outcomes is uncertain. }\end{array}$ \\
\hline Other bias & Low risk & Comment: we did not identify any other sources of bias. \\
\hline
\end{tabular}

\section{Cacchio 2009a}

\begin{tabular}{|c|c|}
\hline Methods & $\begin{array}{l}\text { Design: parallel group, 2-arm, single-blind RCT (Italy; October } 2000 \text { to } \\
\text { December 2006). } \\
\text { Setting: inpatient and outpatient rehabilitation centre. } \\
\text { Interventions: mirror therapy or placebo control (covered mirror). } \\
\text { Sample size calculation: } 24 \text { participants per group required to detect a } 2 \mathrm{~cm} \\
\text { reduction in pain on a } 10 \mathrm{~cm} \text { VAS (SD 1.5) with } 0 \mathrm{~cm} \text { labelled as "no pain" and } \\
10 \mathrm{~cm} \text { as "worst pain i have ever had" at } 1 \text { week after treatment at } 1 \% \text { level of } \\
\text { statistical significance with } 90 \% \text { power, including a } 30 \% \text { rate of loss at follow-up. }\end{array}$ \\
\hline Participants & $\begin{array}{l}\text { Number of participants: } 48 \text { ( } 24 \text { per group). } \\
\text { Type of noxious initiating event: stroke (upper limb). } \\
\text { Diagnostic criteria: Bruehl } 1999 \text { (CRPS I). } \\
\text { Baseline characteristics: } \\
\text { 1. conventional stroke rehabilitation plus mirror therapy: } \\
\text { a. mean (SD) age = } 57.9 \text { (9.9) years; female:male = } 13: 11 \text {; } \\
\text { b. mean (SD) duration of CRPS I } 2.8 \text { (1.3) months; } \\
\text { 2. conventional stroke rehabilitation plus placebo control: } \\
\text { a. mean (SD) age = } 58.8 \text { ( } 9.4 \text { ) years; female:male = 13:11; } \\
\text { b. mean (SD) duration of CRPS I } 2.6 \text { (1.5) months. } \\
\text { Inclusion criteria: } \\
\text { 1. first episode of unilateral stroke with hemiparesis during the previous } 6 \\
\text { months; } \\
\text { 2. VAS, } 0 \text { to } 10 \text { cm) pain score > } 4 \text { cm. } \\
\text { Exclusion criteria: } \\
\text { 1. ipsilateral intra-articular shoulder injection within the last } 6 \text { months or use of } \\
\text { systemic corticosteroids with the previous } 4 \text { months; } \\
\text { 2. presence of another obvious explanation for the pain; } \\
\text { 3. prior surgery to either shoulder or neck region; } \\
\text { 4. serious uncontrolled medical conditions; }\end{array}$ \\
\hline
\end{tabular}




\begin{tabular}{|c|c|}
\hline & $\begin{array}{l}\text { 5. global aphasia, cognitive or visual impairments interfering with testing or } \\
\text { treatment; } \\
\text { 6. visual impairment that might interfere with the trial aims; } \\
\text { 7. evidence of recent drug or alcohol abuse or severe depression. }\end{array}$ \\
\hline Interventions & $\begin{array}{l}\text { Participants in both groups received } 4 \text { weeks of conventional stroke rehabilitation } \\
\text { comprising neuro-rehabilitation techniques, occupational therapy (OT) and } \\
\text { speech therapy (if required), consisting of } 51 \text {-hour sessions per week. } \\
\text { Conventional stroke rehabilitation plus mirror therapy ( } N=24) \\
\text { Components of intervention: mirror therapy programme: Whilst seated with a } \\
\text { mirror board positioned between the upper limbs, perpendicular to the midline } \\
\text { and with the unaffected limb facing the reflective surface and with their affected } \\
\text { upper limb hidden from view, participants observed the reflection of their } \\
\text { unaffected upper limb while performing flexion and extension at the shoulder, } \\
\text { elbow and wrist and pronation and supination of the forearm. } \\
\text { Dosage: } 30 \text { minutes per session (for the first } 2 \text { weeks), } 1 \text { hour per session (for } \\
\text { the second } 2 \text { weeks) } \\
\text { Frequency of administration: } 5 \text { times per week for } 4 \text { weeks ( } 20 \text { sessions) } \\
\text { Provider: physiotherapist. } \\
\text { Conventional stroke rehabilitation plus placebo control ( } \mathbf{N}=\mathbf{2 4 )} \\
\text { Components of intervention: participants performed the same exercises, } \\
\text { according to the same dosage and frequency, with the reflective mirror surface } \\
\text { covered. }\end{array}$ \\
\hline Outcomes & $\begin{array}{l}\text { Outcomes assessed at baseline and at } 1 \text { week and } 6 \text { months post-treatment. } \\
\text { Primary outcomes: } \\
\text { 1. self-rated pain intensity at rest using a } 10 \mathrm{~cm} \text { horizontal VAS labelled "no } \\
\text { pain" to "worst pain I have ever had" (pain location not reported); } \\
\text { 2. self-rated pain intensity on shoulder movement (forward flexion) using a } 10 \\
\text { cm VAS labelled "no pain" to "worst pain I have ever had"; } \\
\text { 3. brush evoked tactile allodynia, assessed by means of } 3 \text { brush movements } \\
\text { within the area of maximum pain, using a } 10 \mathrm{~cm} \text { VAS labelled "no pain" to } \\
\text { "worst pain I have ever had". } \\
\text { Secondary outcomes: } \\
\text { 1. functional ability value of the Wolf Motor Function Test (WMFT), to assess } \\
\text { upper limb functional limitation (score range } 0 \text { to } 5 \text {, higher scores indicate } \\
\text { poorer performance); } \\
\text { 2. performance time value of the WMFT, to assesses upper limb functional } \\
\text { performance speed (measured in seconds, longer times indicate poorer } \\
\text { performance); } \\
\text { 3. Quality of Movement (QOM) item in the Motor Activity Log (MAL), to assess } \\
\text { how well participants can use their affected upper limb in } 30 \text { activities of } \\
\text { daily living (score range } 0 \text { to } 5 \text {, lower scores indicate poorer performance). }\end{array}$ \\
\hline Notes & $\begin{array}{l}\text { Source of funding: not reported } \\
\text { Statement regarding declarations of interest: not reported }\end{array}$ \\
\hline
\end{tabular}

Risk of bias table 


\begin{tabular}{|c|c|c|}
\hline Bias & \begin{tabular}{|l|} 
Authors' \\
judgement
\end{tabular} & Support for judgement \\
\hline $\begin{array}{l}\text { Random sequence generation } \\
\text { (selection bias) }\end{array}$ & Unclear risk & $\begin{array}{l}\text { Quote: "...we undertook a randomized placebo-controlled } \\
\text { study in which stroke patients with CRPSt I were randomly } \\
\text { allocated..." } \\
\text { Comment: the trial authors did not report the method of } \\
\text { sequence generation. }\end{array}$ \\
\hline $\begin{array}{l}\text { Allocation concealment (selection } \\
\text { bias) }\end{array}$ & Unclear risk & $\begin{array}{l}\text { Comment: the trial authors did not report the method of } \\
\text { concealment allocation. }\end{array}$ \\
\hline $\begin{array}{l}\text { Blinding of participants and } \\
\text { personnel (performance bias) }\end{array}$ & Unclear risk & $\begin{array}{l}\text { Comment: given the nature of the intervention, participants } \\
\text { were not blinded to treatment allocation but the extent to } \\
\text { which the lack of blinding may have introduced bias is } \\
\text { uncertain. }\end{array}$ \\
\hline $\begin{array}{l}\text { Blinding of outcome assessment } \\
\text { (detection bias) } \\
\text { Self-reported outcomes }\end{array}$ & Unclear risk & $\begin{array}{l}\text { Comment: unblinded participants self-reported some } \\
\text { outcomes (e.g. pain intensity) but the extent to which the } \\
\text { lack of blinding may have introduced bias is uncertain. }\end{array}$ \\
\hline $\begin{array}{l}\text { Blinding of outcome assessment } \\
\text { (detection bias) } \\
\text { Investigator-administered } \\
\text { outcomes }\end{array}$ & Low risk & $\begin{array}{l}\text { Quote: "All the patients were examined } 3 \text { times by an } \\
\text { investigator who was blinded to the nature of treatment } \\
\text { performed". } \\
\text { Comment: the outcome assessor was blinded to treatment } \\
\text { allocation. }\end{array}$ \\
\hline $\begin{array}{l}\text { Incomplete outcome data (attrition } \\
\text { bias) } \\
\text { Drop-out rate described and } \\
\text { acceptable }\end{array}$ & Unclear risk & $\begin{array}{l}\text { Quote: "Two patients ( } 8 \% \text { ) in the mirror group and } 7 \text { patients } \\
\text { (29\%) in the control group dropped out of the study". } \\
\text { Quote: "One of the } 2 \text { patients in the mirror group dropped } \\
\text { out because he moved to another city, while the other } \\
\text { decided to perform corticosteroid injection therapy in } \\
\text { another center. Three of the } 7 \text { patients in the control group } \\
\text { refused to complete the study, while } 4 \text { decided to perform } \\
\text { corticosteroid injection therapy in another center". } \\
\text { Comment: the extent to which an overall drop-out rate of } \\
19 \% \text { and an unequal drop-out rate between groups may } \\
\text { have introduced biased estimates of treatment effect is } \\
\text { uncertain. }\end{array}$ \\
\hline $\begin{array}{l}\text { Incomplete outcome data (attrition } \\
\text { bias) } \\
\text { Participants analysed in the group } \\
\text { to which they were allocated }\end{array}$ & Low risk & $\begin{array}{l}\text { Quote: "Both the primary and secondary outcome analyses } \\
\text { were performed according to the intention-to-treat (ITT) } \\
\text { principle. In this study, subjects that provided baseline and } \\
\text { at least } 1 \text { post-treatment measurement constituted the ITT } \\
\text { population, whereas those who completed all tests from } \\
\text { baseline to the } 6 \text {-month follow-up constituted the per } \\
\text { protocol population. } \\
\text { Comment: the trial authors reported analyses according to } \\
\text { the ITT principle. }\end{array}$ \\
\hline Selective reporting (reporting bias) & Low risk & $\begin{array}{l}\text { Comment: the trial authors fully reported outcome data for } \\
\text { all outcomes reported in the methods section of the } \\
\text { publication. }\end{array}$ \\
\hline
\end{tabular}




\begin{tabular}{|l||l|l||}
\hline Sample size & High risk & $\begin{array}{l}\text { Quote: "48 patients with CRPSt1 of the affected upper limb } \\
\text { were enrolled". } \\
\text { Comment: the small sample size may have introduced bias } \\
\text { in estimates of treatment effect. }\end{array}$ \\
\hline Duration of follow-up & Low risk & $\begin{array}{l}\text { Quote: "The decision to set the follow-up at } 6 \text { months is } \\
\text { based on the hypothesis that pain improves spontaneously } \\
\text { over a long period of time". } \\
\text { Comment: the trial authors measured outcomes over a } \\
\text { clinically relevant length of time. }\end{array}$ \\
\hline Other bias & High risk & $\begin{array}{l}\text { Quote: "For the ITT population, outcome measurements } \\
\text { were analyzed using the last observation carried forward } \\
\text { method". } \\
\text { Comment: the use of 'last observation carried forward' when } \\
\text { accounting for missing data may have introduced bias in } \\
\text { estimates of treatment effect. }\end{array}$ \\
\hline \hline
\end{tabular}

\section{Cacchio 2009b}

\begin{tabular}{|c|c|}
\hline Methods & $\begin{array}{l}\text { Design: parallel group, single-blind, 3-arm, sham-controlled RCT (Italy, dates } \\
\text { not reported). (Whilst the trial authors reported that a number of participants from } \\
\text { the } 2 \text { comparator groups crossed over into the experimental group, this was not } \\
\text { undertaken in a randomised way and therefore we deemed that this trial did not } \\
\text { employ a true crossover design. We analysed it as a 3-arm parallel group trial up } \\
\text { to the endpoint just prior to crossover). } \\
\text { Setting: not reported. } \\
\text { Interventions: mirror therapy or placebo control (covered mirror) or mental } \\
\text { imagery. } \\
\text { Sample size calculation: not reported. }\end{array}$ \\
\hline Participants & $\begin{array}{l}\text { Number of participants: } 24 \text { (8 per group). } \\
\text { Type of noxious initiating event: stroke (upper limb). } \\
\text { Diagnostic criteria: Bruehl } 1999 \text { (CRPS I). } \\
\text { Baseline characteristics: not adequately reported. } \\
\text { Inclusion criteria: not explicitly reported. } \\
\text { Exclusion criteria: not reported. }\end{array}$ \\
\hline Interventions & $\begin{array}{l}\text { Mirror therapy }(\mathbf{N}=\mathbf{8}) \\
\text { Components of intervention: whilst viewing a reflected image of the unaffected } \\
\text { arm in a mirror, participants performed all of the cardinal (proximal to distal) } \\
\text { movements of the affected arm (reported as the 'affected' arm but assumed to be } \\
\text { the 'unaffected' arm). } \\
\text { Dosage: } 30 \text { minutes per session. } \\
\text { Frequency of administration: daily for } 4 \text { weeks ( } 28 \text { sessions). } \\
\text { Provider: not reported. } \\
\text { Placebo control }(\mathbf{N}=\mathbf{8}) \\
\text { Components of intervention: participants performed the same movements, } \\
\text { according to the same dosage and frequency, with the reflective mirror surface } \\
\text { covered. } \\
\text { Provider: not reported. } \\
\text { Mental imagery }(\mathbf{N}=\mathbf{8}) \\
\text { Components of intervention: not reported. }\end{array}$ \\
\hline
\end{tabular}




\begin{tabular}{|c|c|}
\hline & $\begin{array}{l}\text { Dosage: not reported. } \\
\text { Frequency of administration: not reported. } \\
\text { Provider: not reported. }\end{array}$ \\
\hline Outcomes & $\begin{array}{l}\text { The trial authors assessed outcomes at baseline and on completion of the } \\
\text { intervention period ( } 4 \text { weeks post recruitment). } \\
\text { Primary outcomes: } \\
\text { 1. self-rated pain intensity on movement using a } 100 \text { mm VAS (anchor point } \\
\text { labels not reported) but with higher scores indicating more severe pain. } \\
\text { Secondary outcomes: } \\
\text { 1. motor function as assessed by the Wolf Motor Function Test (WMFT) } \\
\text { (scoring properties not reported); } \\
\text { 2. brush-induced allodynia (method of assessment not reported); } \\
\text { 3. oedema (method of assessment not reported). }\end{array}$ \\
\hline Notes & $\begin{array}{l}\text { Source of funding: not reported. } \\
\text { Statement regarding declarations of interest: not reported. }\end{array}$ \\
\hline
\end{tabular}

Risk of bias table

\begin{tabular}{|c|c|c|}
\hline Bias & \begin{tabular}{|l|} 
Authors' \\
judgement
\end{tabular} & Support for judgement \\
\hline $\begin{array}{l}\text { Random sequence generation } \\
\text { (selection bias) }\end{array}$ & Unclear risk & $\begin{array}{l}\text { Quote: "We conducted a randomised, sham-controlled study } \\
\text { involving } 24 \text { patients with stroke". } \\
\text { Comment: the trial authors did not report the method of } \\
\text { sequence. }\end{array}$ \\
\hline $\begin{array}{l}\text { Allocation concealment (selection } \\
\text { bias) }\end{array}$ & Unclear risk & $\begin{array}{l}\text { Quote: "We randomly assigned the } 24 \text { patients to one of } \\
\text { three groups". } \\
\text { Comment: the trial authors did not report the method of } \\
\text { concealment allocation. }\end{array}$ \\
\hline $\begin{array}{l}\text { Blinding of participants and } \\
\text { personnel (performance bias) }\end{array}$ & Unclear risk & $\begin{array}{l}\text { Comment: given the nature of the intervention, participants } \\
\text { were not blinded to treatment allocation but the extent to } \\
\text { which the lack of blinding may have introduced bias is } \\
\text { uncertain. }\end{array}$ \\
\hline $\begin{array}{l}\text { Blinding of outcome assessment } \\
\text { (detection bias) } \\
\text { Self-reported outcomes }\end{array}$ & Unclear risk & $\begin{array}{l}\text { Comment: unblinded participants self-reported some } \\
\text { outcomes (e.g. pain intensity) but the extent to which the } \\
\text { lack of blinding may have introduced bias is uncertain. }\end{array}$ \\
\hline $\begin{array}{l}\text { Blinding of outcome assessment } \\
\text { (detection bias) } \\
\text { Investigator-administered } \\
\text { outcomes }\end{array}$ & Low risk & $\begin{array}{l}\text { Quote: "The investigators were unaware of the study-group } \\
\text { assignments". } \\
\text { Comment: outcome assessors were blinded to participants } \\
\text { group allocation. }\end{array}$ \\
\hline $\begin{array}{l}\text { Incomplete outcome data (attrition } \\
\text { bias) } \\
\text { Drop-out rate described and } \\
\text { acceptable }\end{array}$ & Low risk & $\begin{array}{l}\text { Quote: "In the active-mirror group, seven of eight patients } \\
(88 \%) \text { reported reduced pain". } \\
\text { Quote: "In the covered-mirror group, only one of eight } \\
\text { patients (12\%) reported reduced pain". } \\
\text { Quote: "In the mental-imagery group, two of eight patients } \\
(25 \%) \text { reported reduced pain". } \\
\text { Comment: there were no apparent drop-outs. }\end{array}$ \\
\hline
\end{tabular}


Physiotherapy for pain and disability in adults with complex regional pain syndrome.26-Feb-2016

\begin{tabular}{|c|c|c|}
\hline $\begin{array}{l}\text { Incomplete outcome data (attrition } \\
\text { bias) } \\
\text { Participants analysed in the group } \\
\text { to which they were allocated }\end{array}$ & Low risk & $\begin{array}{l}\text { Comment: the trial authors analysed participants in the } \\
\text { group to which they were allocated but did not report the } \\
\text { method of analysis (ITT versus per protocol). }\end{array}$ \\
\hline Selective reporting (reporting bias) & High risk & $\begin{array}{l}\text { Quote: "After } 4 \text { weeks of active mirror therapy, the pain } \\
\text { intensity decreased (Fig. 1), and motor function, } \\
\text { brush-induced allodynia, and edema improved (data not } \\
\text { shown)". } \\
\text { Comment: the trial authors presented mean values for the } \\
\text { primary outcome of pain severity in graphical format only; } \\
\text { they did not report raw data in numerical form with } \\
\text { measures of variation. } \\
\text { Comment: the trial authors did not report any outcome data } \\
\text { for the } 3 \text { secondary outcome measures (motor function, } \\
\text { brush-induced allodynia, oedema). }\end{array}$ \\
\hline Sample size & High risk & $\begin{array}{l}\text { Quote: "We conducted a randomised, sham-controlled study } \\
\text { involving } 24 \text { patients..." } \\
\text { Comment: the small sample size may have introduced bias } \\
\text { in estimates of treatment effect. }\end{array}$ \\
\hline Duration of follow-up & High risk & $\begin{array}{l}\text { Quote: "The primary end point was the score for the severity } \\
\text { of pain after } 4 \text { weeks of therapy". } \\
\text { Comment: the trial authors re-measured outcomes on } \\
\text { completion of the intervention period only and did not } \\
\text { measure them over a clinically relevant length of time. }\end{array}$ \\
\hline Other bias & Unclear risk & $\begin{array}{l}\text { Comment: the trial was reported and published as a 'Letter } \\
\text { to the Editor'. Full trial methodology and results have not } \\
\text { been published elsewhere (Cacchio, personal } \\
\text { communication). } \\
\text { Comment: the trial authors presented limited group-specific } \\
\text { baseline data. } \\
\text { Comment: the trial authors did not report any } \\
\text { inclusion/exclusion data. }\end{array}$ \\
\hline
\end{tabular}

\section{Dimitrijevic 2014}

\begin{tabular}{||}
\hline Methods \\
\\
\hline Participants \\
\end{tabular}

Design: parallel group, 2-arm, single-blind RCT (Serbia; December 2004 to January 2007).

Setting: outpatient clinic.

Interventions: low-level laser therapy and kinesitherapy or interferential current therapy and kinesitherapy.

Sample size calculation: not reported.

Number of participants: 50 (25 per group).

Type of noxious initiating event: trauma (no further details reported) (upper and lower limb).

Diagnostic criteria: Harden 2005 (CRPS I).

Baseline characteristics:

1. laser therapy and kinesitherapy:

a. Mean $( \pm)$ age $=53.9(13.36)$ years; female:male $=12: 8$; 


\begin{tabular}{|c|c|}
\hline & $\begin{array}{l}\text { b. Mean }( \pm \text { ) duration of CRPS I } 33.75 \text { (8.44) days. } \\
\text { 2. interferential current therapy and kinesitherapy: } \\
\text { a. Mean }( \pm) \text { age }=57.8(10.75) \text { years; female:male = } 17: 8 \text {; } \\
\text { b. Mean }( \pm \text { ) duration of CRPS I = } 31.64 \text { (7.79) days. } \\
\text { Inclusion criteria: } \\
\text { 1. CRPS I. } \\
\text { Exclusion criteria: } \\
\text { 1. acute and subacute thrombophlebitis; } \\
\text { 2. thrombosis; } \\
\text { 3. neoplastic disease; } \\
\text { 4. fever; } \\
\text { 5. pregnancy. }\end{array}$ \\
\hline Interventions & $\begin{array}{l}\text { Participants were instructed not to take any specific CRPS medication } \\
\text { (corticosteroids, bisphosphonates, calcitonin, nifedipine, antiepileptic drugs, etc.) } \\
\text { or analgesic medication. Participants in both groups received individual } \\
\text { kinesitherapy (active and active assisted exercises, strictly dosed up to pain } \\
\text { threshold) for } 30 \text { minutes, twice a day. } \\
\text { Low-level laser therapy and kinesitherapy ( } \mathbf{N}=\mathbf{2 0} \text { ) } \\
\text { Components of intervention: using a GaAs laser diode, } 8 \text { points along the joint } \\
\text { line and painful points in the affected area were treated using the following } \\
\text { parameters: a low power of } 70 \mathrm{~mW}, 810 \mathrm{~nm} \text { wavelength, and } 70 \mathrm{~Hz}, 640 \mathrm{~Hz} \text {, and } \\
5000 \mathrm{~Hz} \text { frequency, depending on the dominant findings. } \\
\text { Dosage: } 1.5 \mathrm{~J} / \mathrm{cm}^{2} \text {. } \\
\text { Frequency of administration: } 5 \text { days a week for } 2 \text { weeks (10 sessions), and then } \\
\text { every other day (10 sessions) ( } 20 \text { sessions). } \\
\text { Provider: not reported. } \\
\text { Interferential current therapy and kinesitherapy ( } \mathbf{N}=25 \text { ) } \\
\text { Components of intervention: bipolar IFC therapy was applied with electrodes } \\
\text { positioned locally on the painful and swollen part using the following parameters: } \\
90 \mathrm{~Hz} \text { frequency. } \\
\text { Dosage: } 15 \text { minutes. } \\
\text { Frequency of administration: } 5 \text { days a week for } 2 \text { weeks ( } 10 \text { sessions), and then } \\
\text { every other day ( } 10 \text { sessions) ( } 20 \text { sessions). } \\
\text { Provider: not reported. }\end{array}$ \\
\hline Outcomes & $\begin{array}{l}\text { The trial authors did not explicitly specify the time points at which outcomes were } \\
\text { measured in the trial report. Outcomes assessed at baseline and on completion } \\
\text { of the intervention period ( } 6 \text { weeks post recruitment) (Dimitrijevic, personal } \\
\text { communication). The trial authors did not state any primary outcome. } \\
\text { 1. Self-rated pain intensity at rest using a } 100 \text { mm horizontal VAS ( } 0=\text { no } \\
\text { pain, } 100=\text { worst pain possible) with responses based on the average pain } \\
\text { intensity over last few days; } \\
\text { 2. self-rated pain intensity during active movements of the wrist/ankle using a } \\
100 \mathrm{~mm} \text { horizontal VAS ( } 0=\text { no pain, } 100=\text { worst pain possible) with } \\
\text { responses based on the average pain intensity over last few days; } \\
\text { 3. oedema of the hand/foot using a figure-of- } 8 \text { measurement (measurement } \\
\text { tool and method not reported). Hand/foot oedema was expressed as the } \\
\text { difference between hand/foot circumference of the affected and unaffected }\end{array}$ \\
\hline
\end{tabular}



sides;

4. total active range of motion of the wrist/ankle joint in the sagittal plane using a standard full-circle goniometer and recorded in degrees with the final value derived from mean of 3 measurements.

Notes

Source of funding: the trial authors declared that this study received no financial support.

Statement regarding declarations of interest: none declared.

Risk of bias table

\begin{tabular}{|c|c|c|}
\hline Bias & $\begin{array}{l}\text { Authors' } \\
\text { judgement }\end{array}$ & Support for judgement \\
\hline $\begin{array}{l}\text { Random sequence generation } \\
\text { (selection bias) }\end{array}$ & Low risk & $\begin{array}{l}\text { Quote: "...patients were randomly selected and classified } \\
\text { into two groups using sequentially numbered, closed, } \\
\text { opaque envelopes that had been prepared earlier using a } \\
\text { computer-generated list of random numbers, and balanced } \\
\text { to ensure equal numbers in each group". } \\
\text { Comment: the trial authors used an acceptable method to } \\
\text { generate the sequence allocation. }\end{array}$ \\
\hline $\begin{array}{l}\text { Allocation concealment (selection } \\
\text { bias) }\end{array}$ & Low risk & $\begin{array}{l}\text { Quote: "...patients were randomly selected and classified } \\
\text { into two groups, using sequentially numbered, closed, } \\
\text { opaque envelopes that had been prepared earlier". } \\
\text { Comment: the trial authors used an acceptable method to } \\
\text { conceal the allocation sequence. }\end{array}$ \\
\hline $\begin{array}{l}\text { Blinding of participants and } \\
\text { personnel (performance bias) }\end{array}$ & Low risk & $\begin{array}{l}\text { Comment: the participants were not blinded to treatment } \\
\text { allocation but lack of blinding unlikely to have biased the } \\
\text { results given that participants received interventions judged } \\
\text { to have been of relatively equal credibility. }\end{array}$ \\
\hline $\begin{array}{l}\text { Blinding of outcome assessment } \\
\text { (detection bias) } \\
\text { Self-reported outcomes }\end{array}$ & Low risk & $\begin{array}{l}\text { Comment: the participants were not blinded to treatment } \\
\text { allocation and self-reported some outcomes but lack of } \\
\text { blinding unlikely to have biased the results given that } \\
\text { participants received interventions judged to have been of } \\
\text { relatively credibility. }\end{array}$ \\
\hline $\begin{array}{l}\text { Blinding of outcome assessment } \\
\text { (detection bias) } \\
\text { Investigator-administered } \\
\text { outcomes }\end{array}$ & Unclear risk & $\begin{array}{l}\text { Comment: the trial authors did not provide a statement of } \\
\text { procedures regarding blinding of the outcome assessor. }\end{array}$ \\
\hline $\begin{array}{l}\text { Incomplete outcome data (attrition } \\
\text { bias) } \\
\text { Drop-out rate described and } \\
\text { acceptable }\end{array}$ & Unclear risk & $\begin{array}{l}\text { Quote: "During the study, } 5 \text { out of } 50 \text { patients dropped out. } \\
\text { A total of } 45 \text { patients completed the study". } \\
\text { Comment: all } 5 \text { drop-outs came from the laser therapy } \\
\text { group (lost to follow-up, } n=2 \text {; discontinued intervention, } n= \\
\text { 3). Whilst the overall drop-out rate was } 10 \% \text {, the extent to } \\
\text { which an unequal drop-out rate between groups may have } \\
\text { biased the results is uncertain. }\end{array}$ \\
\hline
\end{tabular}


Physiotherapy for pain and disability in adults with complex regional pain syndrome.26-Feb-2016

\begin{tabular}{|l|l|l||}
\begin{tabular}{|l} 
Incomplete outcome data (attrition \\
bias) \\
Participants analysed in the group \\
to which they were allocated
\end{tabular} & High risk & $\begin{array}{l}\text { Comment: the trial authors excluded } 3 \text { participants from the } \\
\text { laser therapy group from the analysis because they } \\
\text { discontinued the intervention, in violation of the ITT principle. }\end{array}$ \\
\hline Selective reporting (reporting bias) & Low risk & $\begin{array}{l}\text { Comment: the trial authors fully reported outcome data for } \\
\text { all outcomes reported in the methods section of the } \\
\text { publication. }\end{array}$ \\
\hline Sample size & High risk & $\begin{array}{l}\text { Quote: "The prospective randomized study included } 50 \\
\text { patients with unilateral post-traumatic CRPS I". } \\
\text { Comment: the small sample size may have introduced bias } \\
\text { in estimates of treatment effect. }\end{array}$ \\
\hline Duration of follow-up & High risk & $\begin{array}{l}\text { Quote: "All patients underwent evaluation of each separate } \\
\text { parameter before treatment and after applying } 20 \\
\text { therapeutic procedures". } \\
\text { Comment: outcomes were re-measured on completion of } \\
\text { the intervention period only and were not measured over a } \\
\text { clinically relevant length of time. }\end{array}$ \\
\hline Other bias & Low risk & \begin{tabular}{l} 
Comment: we did not identify any other sources of bias. \\
\hline
\end{tabular} \\
\hline
\end{tabular}

\section{Duman 2009}

\begin{tabular}{||l|l||}
\hline Methods & Design: parallel group, 2-arm RCT (Turkey; dates not reported). \\
Setting: not reported. \\
Interventions: conventional care plus manual lymphatic drainage (MLD) or \\
conventional care. \\
Sample size calculation: not reported.
\end{tabular}




\begin{tabular}{|c|c|}
\hline & $\begin{array}{l}\text { affected limb (10 repetitions, twice per day; type of exercises performed not } \\
\text { reported) followed by a 2-month programme of home maintenance therapeutic } \\
\text { exercises. } \\
\text { MLD ( } \mathbf{N}=\mathbf{1 8}) \\
\text { Components of intervention: MLD. Light massage for superficial abdominal, } \\
\text { axillary and upper limb lymphatic stimulation of the affected upper limb followed } \\
\text { by light upper limb massage in a distal to proximal direction up to the axillary } \\
\text { region. } \\
\text { Dosage: } 1 \text { session per day for approximately } 45 \text { minutes administered by a } \\
\text { therapist plus } 1 \text { session per day of participant self-administered MLD (duration } \\
\text { not reported). } \\
\text { Frequency of administration: } 5 \text { times per week for } 3 \text { weeks (15 sessions), } \\
\text { followed by a home maintenance. programme of self-administered MLD for } 2 \\
\text { months } \\
\text { Provider: not reported. } \\
\text { Conventional care }(\mathbf{N}=\mathbf{1 6}) \text {. }\end{array}$ \\
\hline Outcomes & $\begin{array}{l}\text { Outcomes assessed at baseline, at the end of the } 3 \text {-week treatment period and } 2 \\
\text { months post-treatment. The trial authors did not state any primary outcome. } \\
\text { 1. Self-rated pain intensity during gentle passive finger flexion using a 10-cm } \\
\text { VAS labelled "no pain" to "worst possible pain"; } \\
\text { 2. upper limb oedema using volumetric measurements of water displacement; } \\
\text { 3. functional range of motion measuring the third finger pulp-distal palmer } \\
\text { crease distance. }\end{array}$ \\
\hline Notes & $\begin{array}{l}\text { Source of funding: not reported } \\
\text { Statement regarding declarations of interest: not reported. }\end{array}$ \\
\hline
\end{tabular}

Risk of bias table

\begin{tabular}{||l|l||l||}
\hline Bias & $\begin{array}{l}\text { Authors' } \\
\text { judgement }\end{array}$ & Support for judgement \\
\hline $\begin{array}{l}\text { Random sequence generation } \\
\text { (selection bias) }\end{array}$ & Unclear risk & $\begin{array}{l}\text { Quote: "The patients were allocated randomly into two } \\
\text { groups". } \\
\text { Comment: the trial authors did not report the method of } \\
\text { sequence generation. }\end{array}$ \\
\hline $\begin{array}{l}\text { Allocation concealment (selection } \\
\text { bias) }\end{array}$ & Unclear risk & $\begin{array}{l}\text { Comment: the trial authors did not report the method of } \\
\text { concealment allocation. }\end{array}$ \\
\hline $\begin{array}{l}\text { Blinding of participants and } \\
\text { personnel (performance bias) }\end{array}$ & High risk & $\begin{array}{l}\text { Comment: given the nature of the intervention, participants } \\
\text { were not blinded to treatment and may have had different } \\
\text { expectations about the benefits of each intervention. }\end{array}$ \\
\hline $\begin{array}{l}\text { Blinding of outcome assessment } \\
\text { (detection bias) } \\
\text { Self-reported outcomes }\end{array}$ & High risk & $\begin{array}{l}\text { Comment: unblinded participants, who may have had } \\
\text { different expectations about the benefits of the intervention } \\
\text { they received, self-reported some outcomes (e.g. pain } \\
\text { intensity). }\end{array}$ \\
\hline $\begin{array}{l}\text { Blinding of outcome assessment } \\
\text { (detection bias) } \\
\text { Investigator-administered } \\
\text { outcomes }\end{array}$ & Unclear risk & $\begin{array}{l}\text { Quote: "All of the parameters were obtained before the } \\
\text { treatment (baseline), after treatment and } 2 \text { months after } \\
\text { treatment (follow-up) by a different physician". } \\
\text { Comment: the trial authors did not report a statement of }\end{array}$ \\
\hline
\end{tabular}


Physiotherapy for pain and disability in adults with complex regional pain syndrome.26-Feb-2016

\begin{tabular}{|c|c|c|}
\hline & & procedures regarding blinding of the outcome assessor. \\
\hline $\begin{array}{l}\text { Incomplete outcome data (attrition } \\
\text { bias) } \\
\text { Drop-out rate described and } \\
\text { acceptable }\end{array}$ & Low risk & $\begin{array}{l}\text { Quote: "After } 2 \text { months, all of the patients were } \\
\text { re-evaluated". } \\
\text { Comment: there were no apparent drop-outs. }\end{array}$ \\
\hline $\begin{array}{l}\text { Incomplete outcome data (attrition } \\
\text { bias) } \\
\text { Participants analysed in the group } \\
\text { to which they were allocated }\end{array}$ & Low risk & $\begin{array}{l}\text { Quote: "After } 2 \text { months, all of the patients were } \\
\text { re-evaluated". } \\
\text { Comment: trial authors analysed participants analysed in } \\
\text { the group to which they were allocated but did not report the } \\
\text { method of analysis (ITT versus per protocol). }\end{array}$ \\
\hline Selective reporting (reporting bias) & Low risk & $\begin{array}{l}\text { Comment: the trial authors fully reported outcome data for } \\
\text { all outcomes reported in the methods section of the } \\
\text { publication. }\end{array}$ \\
\hline Sample size & High risk & $\begin{array}{l}\text { Quote: "A total of } 34 \text { patients who fulfilled the modified } \\
\text { International Association for the Study of Pain (IASP) } \\
\text { criteria and diagnosed as RSD were enrolled". } \\
\text { Comment: the small sample size may have introduced bias } \\
\text { in estimates of treatment effect. }\end{array}$ \\
\hline Duration of follow-up & Low risk & $\begin{array}{l}\text { Quote: "After } 2 \text { months, all of the patients were } \\
\text { re-evaluated". } \\
\text { Comment: the trial authors measured outcomes over a } \\
\text { clinically relevant length of time. }\end{array}$ \\
\hline Other bias & Low risk & $\begin{array}{l}\text { Comment: we did not identify any other other sources of } \\
\text { bias. }\end{array}$ \\
\hline
\end{tabular}

\section{Durmus 2004}

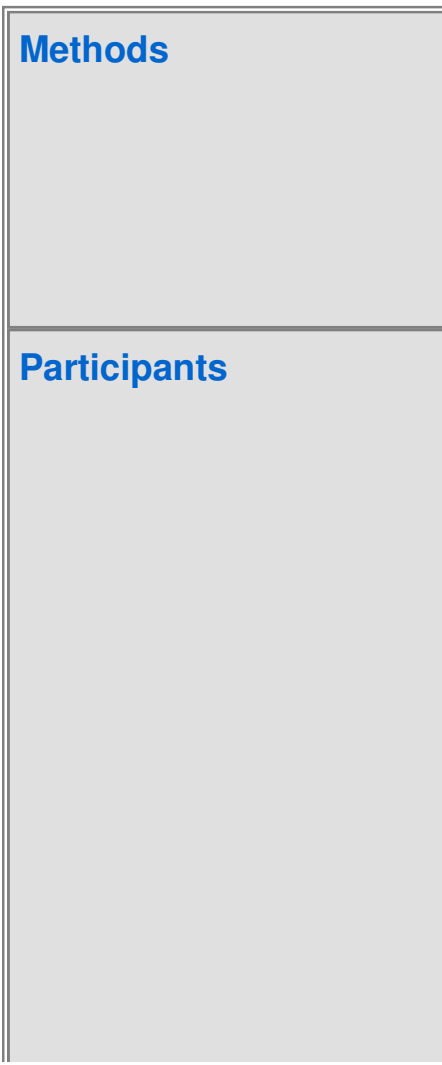

Design: parallel group, 2-arm, double-blind placebo-controlled RCT (Turkey; 1999 to 2001).

Setting: out-patient rehabilitation clinic.

Interventions: usual care plus pulsed electromagnetic field treatment or usual care plus placebo pulsed electromagnetic field treatment.

Sample size calculation: not reported.

Number of participants: 40 (number of participants per group not reported).

Type of noxious initiating event: Colles fracture (upper limb).

Diagnostic criteria: Merskey 1994 (CRPS I).

Baseline characteristics:

1. pulsed electromagnetic field treatment:

a. mean $(S D)$ age $=37.65(12.33)$ years; female:male $=50 \%: 50 \%$;

b. mean (SD) duration of CRPS I: 48.80 (28.63) days;

2. placebo:

a. mean (SD) age $=40.60(11.05)$ years; female:male $=45 \%: 55 \%$;

b. mean (SD) duration of CRPS I: 54.55 (36.24) days.

\section{Inclusion criteria:}

1. aged 18 to 55 years;

2. development of pathology after trauma; 


\begin{tabular}{|c|c|}
\hline & $\begin{array}{l}\text { 3. presence of phase I CRPS I based on } 3 \text { phase bone scintigraphy; } \\
\text { 4. absence of any known hypersensitivities to calcitonin. } \\
\text { Exclusion criteria: } \\
\text { 1. previous treatment for CRPS I; } \\
\text { 2. pacemaker; } \\
\text { 3. presence of an infectious or malignant disease; } \\
\text { 4. being either pregnant or in a menopausal state. }\end{array}$ \\
\hline Interventions & $\begin{array}{l}\text { Participants in both groups received } 100 \text { units of calcitonin via intramuscular } \\
\text { injection for } 6 \text { weeks; once per day for the first } 3 \text { weeks then once every other } \\
\text { day for the second } 3 \text { weeks, and performed active and active assisted range of } \\
\text { motion exercises and a stretching programme for } 30 \text { minutes, } 3 \text { times per day. } \\
\text { Electromagnetic field treatment ( } \mathbf{N}=\text { not reported) } \\
\text { Components of intervention: pulsed electric magnetic field treatment. Treatment } \\
\text { was administered using a Magnetic-Therapy Mg Port Cosgammaß device. The } \\
\text { trial authors did not report participant and equipment positioning. } \\
\text { Dosage: } 100 \text { Gauss intensity and } 50 \mathrm{~Hz} \text { frequency for } 60 \text { minutes per session. } \\
\text { Frequency of administration: } 5 \text { times per week for } 6 \text { weeks ( } 30 \text { sessions). } \\
\text { Provider: not reported. } \\
\text { Placebo ( } \mathbf{N}=\text { not reported) } \\
\text { Components of intervention: participants were placed in the same device without } \\
\text { it being switched on. }\end{array}$ \\
\hline Outcomes & $\begin{array}{l}\text { The trial authors assessed outcomes at baseline and on completion of the } \\
\text { intervention period ( } 6 \text { weeks post recruitment). The trial authors did not state any } \\
\text { primary outcome. } \\
\text { 1. Self-rated pain at rest using a } 10 \mathrm{~cm} \text { VAS graded between } 0 \text { and } 10 \text { (anchor } \\
\text { point descriptors not reported); } \\
\text { 2. self-rated pain with activity (details not reported) using a } 10 \mathrm{~cm} \text { VAS graded } \\
\text { between } 0 \text { and } 10 \text { (anchor point descriptors not reported); } \\
\text { 3. } 4 \text {-point verbal pain scale (measurement properties not described); } \\
\text { 4. pain on palpation using 5-point grading scale }(0=\text { no pain, } 4 \text { = } \\
\text { hyperesthesia) (further measurement properties not reported); } \\
\text { 5. ratings of stiffness and change of colour (measurement properties not } \\
\text { reported); } \\
\text { 6. change in oedema using volumetric displacement; } \\
\text { 7. range of motion using a goniometer (joints not specified); } \\
\text { 8. 3-phase bone scintigraphy (bone to soft-tissue ratios) (measurement } \\
\text { properties not reported); } \\
\text { 9. biochemical markers of bone formation (bone alkaline phosphatase, } \\
\text { osteocalcin, procollagen } 1 \text { ) and bone resorption (pyridinoline, } \\
\text { deoxypyridinoline, hydroxyproline) (measurement properties not reported). }\end{array}$ \\
\hline Notes & $\begin{array}{l}\text { Source of funding: not reported. } \\
\text { Statement regarding declarations of interest: not reported. }\end{array}$ \\
\hline
\end{tabular}

Risk of bias table 


\begin{tabular}{|c|c|c|}
\hline Bias & $\begin{array}{l}\text { Authors' } \\
\text { judgement }\end{array}$ & Support for judgement \\
\hline $\begin{array}{l}\text { Random sequence generation } \\
\text { (selection bias) }\end{array}$ & Low risk & $\begin{array}{l}\text { Quote: "The patients were divided into two groups with the } \\
\text { random numbers table". } \\
\text { Comment: the trial authors used an acceptable method was } \\
\text { used to generate the sequence allocation. }\end{array}$ \\
\hline $\begin{array}{l}\text { Allocation concealment (selection } \\
\text { bias) }\end{array}$ & Unclear risk & $\begin{array}{l}\text { Comment: the trial authors did not report the method of } \\
\text { concealment allocation. }\end{array}$ \\
\hline $\begin{array}{l}\text { Blinding of participants and } \\
\text { personnel (performance bias) }\end{array}$ & Low risk & $\begin{array}{l}\text { Quote: "In this randomized double-blind, placebo-controlled } \\
\text { study". } \\
\text { Quote: "the second group of patients received placebo } \\
\text { treatment by being placed in the same device without it } \\
\text { being switched on". } \\
\text { Comment: participants were likely to have been adequately } \\
\text { blinded but the trial authors did not explicitly report the } \\
\text { extent to which the placebo intervention controls for the } \\
\text { auditory and sensory characteristics of the intervention. } \\
\text { Comment: the trial authors did not report the procedure for } \\
\text { blinding of care providers. }\end{array}$ \\
\hline $\begin{array}{l}\text { Blinding of outcome assessment } \\
\text { (detection bias) } \\
\text { Self-reported outcomes }\end{array}$ & Low risk & $\begin{array}{l}\text { Quote: "the second group of patients received placebo } \\
\text { treatment by being placed in the same device without it } \\
\text { being switched on". } \\
\text { Comment: the participants who completed self-reported } \\
\text { outcome measures were blinded to treatment allocation. }\end{array}$ \\
\hline $\begin{array}{l}\text { Blinding of outcome assessment } \\
\text { (detection bias) } \\
\text { Investigator-administered } \\
\text { outcomes }\end{array}$ & Low risk & $\begin{array}{l}\text { Quote: "The patients were assessed at the beginning of a } 6 \\
\text { week course of treatment and on the final week of treatment } \\
\text { by a physician who did not know which group received the } \\
\text { applied magnetic field treatment". } \\
\text { Comment: the outcome assessor was blinded to treatment } \\
\text { allocation. }\end{array}$ \\
\hline $\begin{array}{l}\text { Incomplete outcome data (attrition } \\
\text { bias) } \\
\text { Drop-out rate described and } \\
\text { acceptable }\end{array}$ & Low risk & $\begin{array}{l}\text { Quote: "There were no refusals or drop-outs from the study" } \\
\text { Comment: all randomly assigned participants completed the } \\
\text { study. }\end{array}$ \\
\hline $\begin{array}{l}\text { Incomplete outcome data (attrition } \\
\text { bias) } \\
\text { Participants analysed in the group } \\
\text { to which they were allocated }\end{array}$ & Low risk & $\begin{array}{l}\text { Quote: "There were no refusals or drop-outs from the study". } \\
\text { Comment: the trial authors did not report the method of } \\
\text { analysis (ITT versus per protocol). }\end{array}$ \\
\hline Selective reporting (reporting bias) & Low risk & $\begin{array}{l}\text { Comment: the trial authors fully reported outcome data for } \\
\text { the } 2 \text { main pain outcomes but did not report any outcome } \\
\text { data for the 4-point verbal pain scale or any other outcomes } \\
\text { (pain on palpation, ratings of stiffness and change of colour, } \\
\text { range of motion and 3-phase bone scintigraphy), as } \\
\text { reported in the methods section of the publication. }\end{array}$ \\
\hline
\end{tabular}




\begin{tabular}{|l||l|l||}
\hline Sample size & High risk & $\begin{array}{l}\text { Quote: "Forty patients diagnosed as having Type I CRPS } \\
\text { subsequent to trauma (Colles Fracture), who consulted the } \\
\text { Physical Medicine and Rehabilitation Department of Istanbul } \\
\text { University, Istanbul Medical Faculty between } 1999 \text { and } 2001 \\
\text { were included in the study". } \\
\text { Comment: the small sample size may have introduced bias } \\
\text { in estimates of treatment effect. }\end{array}$ \\
\hline Duration of follow-up & High risk & $\begin{array}{l}\text { Quote: "Patients were assessed at the beginning of a } 6 \\
\text { week course of treatment and on the final week of } \\
\text { treatment". } \\
\text { Comment: the trial authors re-evaluated participants at the } \\
\text { end of the treatment period only. }\end{array}$ \\
\hline Other bias & Low risk & \begin{tabular}{l} 
Comment: we did not identify any other sources of bias. \\
\hline
\end{tabular} \\
\hline
\end{tabular}

\section{Hazneci 2005}

\begin{tabular}{|c|c|}
\hline Methods & $\begin{array}{l}\text { Design: parallel group, 2-arm RCT (Turkey; } 2001 \text { to } 2002 \text { ). } \\
\text { Setting: Department of Physical Medicine and Rehabilitation Clinic, Gulhane } \\
\text { Military Medical Academy. } \\
\text { Interventions: transcutaneous electrical nerve stimulation (TENS) or pulsed } \\
\text { ultrasound of the stellate ganglion. } \\
\text { Sample size calculation: not reported }\end{array}$ \\
\hline Participants & $\begin{array}{l}\text { Number of participants: } 30 \text { (TENS } N=16 \text {; pulsed ultrasound } N=14 \text { ). } \\
\text { Type of noxious initiating event: mixed (trauma } n=20 \text {, sports injury } n=5 \text {, } \\
\text { post finger amputation } n=1 \text {, post injection } n=1 \text {, idiopathic } n=3 \text { ) (upper limb). } \\
\text { Diagnostic criteria: Kozin } 1992 \text { (stage I and II) (Reflex sympathetic dystrophy } \\
\text { syndrome). } \\
\text { Baseline characteristics } \\
\text { 1. TENS: } \\
\quad \text { a. mean (SD) age }=20.75(0.58) \text { years; female:male }=0: 16 \text {; } \\
\text { b. mean (SD) duration of CRPS I } 45.31 \text { (26.68) days; } \\
\text { 2. pulsed ultrasound of the stellate ganglion: } \\
\text { a. mean (SD) age }=20.6 \text { ( } 0.76 \text { ) years; female:male }=0: 14 \text {; } \\
\text { b. mean (SD) duration of CRPS I } 43.21 \text { (17.72) days. } \\
\text { Inclusion criteria: CRPS I. } \\
\text { Exclusion criteria: not reported. }\end{array}$ \\
\hline Interventions & $\begin{array}{l}\text { Participants in both groups received contrast bathing (the upper extremity was } \\
\text { put in hot water for } 4 \text { minutes and then in cold water for } 1 \text { minute and this } \\
\text { procedure was repeated for } 20 \text { minutes) and an exercise programme } \\
\text { (undertaken with the assistance of a physiotherapist and comprising active, } \\
\text { assisted active and passive exercise within the pain limits; including extension, } \\
\text { flexion, ulnar and radial deviation for the wrist, abduction and flexion for the } \\
\text { thumb, flexion and extension for the metacarpophalangeal, proximal and distal } \\
\text { interphalangeal joints). } \\
\text { TENS ( } \mathbf{N}=\mathbf{1 6} \text { ) } \\
\text { Components of intervention: TENS was applied, using a Myomed } 932 \text { Enraf } \\
\text { model, to the painful area of the involved upper extremity. }\end{array}$ \\
\hline
\end{tabular}




\begin{tabular}{|c|c|}
\hline & $\begin{array}{l}\text { Dosage: frequency } 100 \mathrm{~Hz} \text {, mono-rec wave module. } \\
\text { Frequency of administration: once per day, for } 20 \text { minutes, for } 3 \text { weeks (total } \\
\text { number of sessions not reported). } \\
\text { Provider: not reported. } \\
\text { Pulsed ultrasound of the stellate ganglion ( } \mathbf{N}=\mathbf{1 4} \text { ) } \\
\text { Components of intervention: using a BTL } 07 p \text { model ultrasound device pulsed } \\
\text { ultrasound was applied with a } 1 \mathrm{~cm}^{2} \text { probe to the stellate ganglion on the } \\
\text { involved side of the upper extremity. } \\
\text { Dosage: } 3 \text { watt/cm² (pulsed). } \\
\text { Frequency of administration: once per day, for } 5 \text { minutes, for } 3 \text { weeks (total } \\
\text { number of sessions not reported). } \\
\text { Provider: not reported. }\end{array}$ \\
\hline Outcomes & $\begin{array}{l}\text { The trial authors assessed outcomes at baseline and on completion of the } \\
\text { intervention period ( } 3 \text { weeks post recruitment): } \\
\text { 1. self-reported spontaneous pain measured using a VAS ( } 0=\text { no pain to } 10= \\
\text { worst pain); } \\
\text { 2. self-reported provocative pain (pain on palpation) measured using a } \\
\text { Likert-type scale ( } 0 \text { = no pain, } 1=\text { mild pain with deep palpation, } 2=\text { severe } \\
\text { pain with deep palpation, } 3=\text { severe pain with superficial palpation, } 4= \\
\text { hyperaesthesia); } \\
\text { 3. grip strength measured using a hand dynamometer device with the score } \\
\text { (in kg) determined by the mean of } 3 \text { attempts; } \\
\text { 4. joint mobility (extension, flexion, ulnar and radial deviation of the wrist; } \\
\text { flexion and extension for the fingers). Active joint movement distance was } \\
\text { measured by standard goniometer. Mobility loss was calculated by the } \\
\text { formula: } 100 \text { - (measured value/normal joint movement distance) } x 100 \text {. } \\
\text { The mean value for the joint movement distance for all directions was } \\
\text { calculated and compared with the values of the normal extremity. The scale } \\
\text { was as follows: } 0=\text { total mobility; } 1=1 \% \text { to } 25 \% \text { mobility loss; } 2=26 \% \text { to } \\
50 \% \text { mobility loss; } 4=\text { mobility loss of more than } 76 \% \text {; } \\
\text { 5. oedema measured using standard volumetric measurements. Firstly the } \\
\text { participant's uninvolved upper extremity was placed in a container filled with } \\
\text { water. The volume (in mL) of displaced water was measured and compared } \\
\text { to the volume displaced when he involved upper extremity was placed in } \\
\text { the same container with the value taken as the difference between the } \\
\text { volumes displaced by the affected and normal extremities. }\end{array}$ \\
\hline Notes & $\begin{array}{l}\text { Source of funding: not reported. } \\
\text { Statement regarding declarations of interest: not reported. }\end{array}$ \\
\hline
\end{tabular}

Risk of bias table

\begin{tabular}{||l|l||l||}
\hline \hline Bias & $\begin{array}{l}\text { Authors' } \\
\text { judgement }\end{array}$ & Support for judgement \\
\hline $\begin{array}{l}\text { Random sequence generation } \\
\text { (selection bias) }\end{array}$ & Unclear risk & $\begin{array}{l}\text { Quote: "Patients were divided into two groups randomly". } \\
\text { Comment: the trial authors did not report the method of } \\
\text { sequence generation. }\end{array}$ \\
\hline $\begin{array}{l}\text { Allocation concealment (selection } \\
\text { bias) }\end{array}$ & Unclear risk & $\begin{array}{l}\text { Comment: the trial authors did not report the method of } \\
\text { concealment allocation. }\end{array}$ \\
\hline
\end{tabular}


Physiotherapy for pain and disability in adults with complex regional pain syndrome.26-Feb-2016

\begin{tabular}{|c|c|c|}
\hline $\begin{array}{l}\text { Blinding of participants and } \\
\text { personnel (performance bias) }\end{array}$ & Low risk & $\begin{array}{l}\text { Comment: the participants appear not to have been blinded } \\
\text { to treatment allocation but lack of blinding is unlikely to have } \\
\text { biased the results given that participants received } \\
\text { interventions judged to have been of relatively equal } \\
\text { credibility. }\end{array}$ \\
\hline $\begin{array}{l}\text { Blinding of outcome assessment } \\
\text { (detection bias) } \\
\text { Self-reported outcomes }\end{array}$ & Low risk & $\begin{array}{l}\text { Comment: participants appear not to have been blinded to } \\
\text { treatment allocation and self-reported some outcomes, but } \\
\text { lack of blinding is unlikely to have biased the results given } \\
\text { that participants received interventions judged to have been } \\
\text { of relatively equal credibility. }\end{array}$ \\
\hline $\begin{array}{l}\text { Blinding of outcome assessment } \\
\text { (detection bias) } \\
\text { Investigator-administered } \\
\text { outcomes }\end{array}$ & Unclear risk & $\begin{array}{l}\text { Comment: the trial authors did not give a statement of } \\
\text { procedures regarding blinding of the outcome assessor. }\end{array}$ \\
\hline $\begin{array}{l}\text { Incomplete outcome data (attrition } \\
\text { bias) } \\
\text { Drop-out rate described and } \\
\text { acceptable }\end{array}$ & Unclear risk & Comment: the trial authors did not report the drop-out rate. \\
\hline $\begin{array}{l}\text { Incomplete outcome data (attrition } \\
\text { bias) } \\
\text { Participants analysed in the group } \\
\text { to which they were allocated }\end{array}$ & Unclear risk & $\begin{array}{l}\text { Comment: the trial authors did not report the method of } \\
\text { analysis (ITT versus per protocol). }\end{array}$ \\
\hline Selective reporting (reporting bias) & Low risk & $\begin{array}{l}\text { Comment: the trial authors fully reported outcome data for } \\
\text { all outcomes reported in the methods section of the } \\
\text { publication. }\end{array}$ \\
\hline Sample size & High risk & $\begin{array}{l}\text { Quote: "30 patients diagnosed with Reflex Sympathetic } \\
\text { Dystrophy Syndrome at the upper extremities were included } \\
\text { into the study". } \\
\text { Comment: the small sample size may have introduced bias } \\
\text { in estimates of treatment effect. }\end{array}$ \\
\hline Duration of follow-up & High risk & $\begin{array}{l}\text { Quote: "All patients evaluated before treatment and 3rd } \\
\text { week following the treatment" } \\
\text { Comment: the trial authors re-measured outcomes on } \\
\text { completion of the intervention period only and were not } \\
\text { measured over a clinically relevant length of time. }\end{array}$ \\
\hline Other bias & Low risk & Comment: we did not identify any other sources of bias. \\
\hline
\end{tabular}

\section{Jeon 2014}

Methods

Design: parallel group, 2-arm, placebo-controlled pilot RCT (South Korea; dates not reported).

Setting: tertiary university pain centre.

Interventions: virtual body swapping with mental rehearsal or virtual body swapping alone.

Sample size calculation: pilot RCT with bootstrapping method to increase the robustness of small-sample analyses. 


\begin{tabular}{|c|c|}
\hline Participants & $\begin{array}{l}\text { Number of participants: } 10 \text { (number per group not reported). } \\
\text { Type of noxious initiating event: not reported (upper limb only } n=1 \text {, lower } \\
\text { limb only } n=1 \text {, multiple limbs } n=4 \text {, and whole body } n=4 \text { ). } \\
\text { Diagnostic criteria: } \text { Harden } 2007 \text { (CRPS I). } \\
\text { Baseline characteristics: } \\
\text { Total sample (separate intervention and control group data not reported but no } \\
\text { statistically significant between-group differences). } \\
\text { Mean (SD) age: } 39.30 \text { (10.99) years; female:male }=0: 10 . \\
\text { Median (range) duration of CRPS I: } 52(33 \text { to } 120) \text { months. } \\
\text { Inclusion criteria: CRPS I } \\
\text { Exclusion criteria: not reported }\end{array}$ \\
\hline Interventions & $\begin{array}{l}\text { The trial authors did not report any co-interventions. } \\
\text { Virtual body swapping with mental rehearsal ( } \mathbf{N}=\text { not reported) } \\
\text { Components of intervention: } \\
\text { 1. whilst lying down and wearing a head mounted display (VR2000; Virtual } \\
\text { Realities, Ltd.) participants watched a virtual body swapping training video } \\
\text { in order to evoke a virtual body swapping illusion. The } 3 \text { minute } 20 \text { second } \\
\text { long video clip was filmed from the first person perspective and consisted of } \\
\quad 4 \text { physical movements (making fists and opening up the fingers, bending } \\
\text { and unbending the elbows, bending the ankles forward and backward, and } \\
\text { bending and unbending the legs). The first person perspective would help } \\
\text { participants to feel as if they observed their body when they watch the video; } \\
\text { 2. participants were additionally asked to assume a posture similar to that of } \\
\text { the body on the screen and rehearse the movements mentally, as if the } \\
\quad \text { body presented on the display was their own body. } \\
\text { Dosage: } 1 \text { training session. } \\
\text { Frequency of administration: the experimental video clip was played twice with a } \\
\text { 1-minute break given between viewing's. } \\
\text { Provider: } 1 \text { specialist in pain and } 2 \text { assistants (trained graduate students); } \\
\text { professional discipline not reported. } \\
\text { Virtual body swapping alone ( } \mathbf{N}=\text { not reported) } \\
\text { Components of intervention: participants watched the same video but did not } \\
\text { perform mental rehearsal of the } 4 \text { physical movements. } \\
\text { Dosage: } 1 \text { training session. } \\
\text { Frequency of administration: the experimental video clip was played twice with a } \\
\text { 1-minute break given between viewings. } \\
\text { Provider: } 1 \text { specialist in pain and } 2 \text { assistants (trained graduate students); } \\
\text { professional discipline not reported. }\end{array}$ \\
\hline Outcomes & $\begin{array}{l}\text { The trial authors did not explicitly specify the time points at which they measured } \\
\text { outcomes in the trial report. The outcomes were assessed immediately } \\
\text { pre-intervention and postintervention. The trial authors did not state any primary } \\
\text { outcome. } \\
\text { 1. Self-rated pain intensity measured on an 11-point Likert scale ranging from } \\
0 \text { (no pain) to } 10 \text { (severe pain); } \\
\text { 2. the modified Body Perception Disturbance Questionnaire (BPDQ) } \\
\text { consisting of } 9 \text { items with each item rated on an } 11 \text {-point scale ranging from } \\
0 \text { (not at all) to } 10 \text { (very likely). Scores range from } 0 \text { to } 90 \text { with higher scores } \\
\text { indicating greater body perception disturbance. }\end{array}$ \\
\hline
\end{tabular}


Statement regarding declarations of interest: none declared.

Risk of bias table

\begin{tabular}{|c|c|c|}
\hline Bias & $\begin{array}{l}\text { Authors' } \\
\text { judgement }\end{array}$ & Support for judgement \\
\hline $\begin{array}{l}\text { Random sequence generation } \\
\text { (selection bias) }\end{array}$ & Unclear risk & $\begin{array}{l}\text { "Ten patients who met the diagnostic criterion for CRPS } \\
\text { type } 1 \text { were randomly assigned to either the treatment or } \\
\text { control group". } \\
\text { Comment: the trial authors did not report the method of } \\
\text { sequence generation. }\end{array}$ \\
\hline $\begin{array}{l}\text { Allocation concealment (selection } \\
\text { bias) }\end{array}$ & Unclear risk & $\begin{array}{l}\text { Comment: the trial authors did not report the method of } \\
\text { concealment allocation. }\end{array}$ \\
\hline $\begin{array}{l}\text { Blinding of participants and } \\
\text { personnel (performance bias) }\end{array}$ & Unclear risk & $\begin{array}{l}\text { Comment: given the nature of the intervention, participants } \\
\text { were not blinded to treatment allocation but the extent to } \\
\text { which the lack of blinding may have introduced bias is } \\
\text { uncertain. }\end{array}$ \\
\hline $\begin{array}{l}\text { Blinding of outcome assessment } \\
\text { (detection bias) } \\
\text { Self-reported outcomes }\end{array}$ & Unclear risk & $\begin{array}{l}\text { Comment: given the nature of the intervention, participants } \\
\text { were not blinded to treatment allocation but the extent to } \\
\text { which the lack of blinding may have introduced bias is } \\
\text { uncertain. }\end{array}$ \\
\hline $\begin{array}{l}\text { Blinding of outcome assessment } \\
\text { (detection bias) } \\
\text { Investigator-administered } \\
\text { outcomes }\end{array}$ & Low risk & Not applicable. \\
\hline $\begin{array}{l}\text { Incomplete outcome data (attrition } \\
\text { bias) } \\
\text { Drop-out rate described and } \\
\text { acceptable }\end{array}$ & Low risk & $\begin{array}{l}\text { Comment: the trial authors did not report the drop-out rate } \\
\text { but, given the methodology, it is likely there were no } \\
\text { drop-outs. }\end{array}$ \\
\hline $\begin{array}{l}\text { Incomplete outcome data (attrition } \\
\text { bias) } \\
\text { Participants analysed in the group } \\
\text { to which they were allocated }\end{array}$ & Low risk & $\begin{array}{l}\text { Comment: the trial authors did not report the method of } \\
\text { analysis but, given the methodology, it is likely that they } \\
\text { analysed all participants in the group to which they were } \\
\text { allocated. }\end{array}$ \\
\hline Selective reporting (reporting bias) & High risk & $\begin{array}{l}\text { Quote: "There was no significant difference between the } \\
\text { groups in pain intensity, } F(1,7)=0.05, p=0.81 \text { ". } \\
\text { Comment: the trial authors did not report any } \\
\text { pre-intervention or postintervention outcome data for } \\
\text { self-reported pain intensity. }\end{array}$ \\
\hline Sample size & High risk & $\begin{array}{l}\text { "Ten patients with CRPS type } 1 \text { were recruited from a } \\
\text { tertiary university pain center in Seoul, Korea". } \\
\text { Comment: the small sample size may have introduced bias } \\
\text { in estimates of treatment effect. }\end{array}$ \\
\hline
\end{tabular}




\begin{tabular}{||l||l|l||}
\hline Duration of follow-up & High risk & $\begin{array}{l}\text { Quote: "The experimental video clip was played twice with a } \\
\text { 1-minute break given between viewing's. The participants } \\
\text { were then asked to respond to the pain intensity } \\
\text { question...and to complete the BPDQ". } \\
\text { Comment: the trial authors re-measured outcomes on } \\
\text { immediate completion of the intervention period only and did } \\
\text { not measure them over a clinically relevant length of time. }\end{array}$ \\
\hline Other bias & Unclear risk & Comment: the trial authors did not report baseline pain data. \\
\hline \hline
\end{tabular}

\section{Li 2012}

\begin{tabular}{|c|c|}
\hline Methods & $\begin{array}{l}\text { Design: parallel group, 2-arm RCT (China; July } 2008 \text { to July 2010). } \\
\text { Setting: hospital. } \\
\text { Interventions: acupuncture and massage or rehabilitation therapy. } \\
\text { Sample size calculation: not reported. }\end{array}$ \\
\hline Participants & 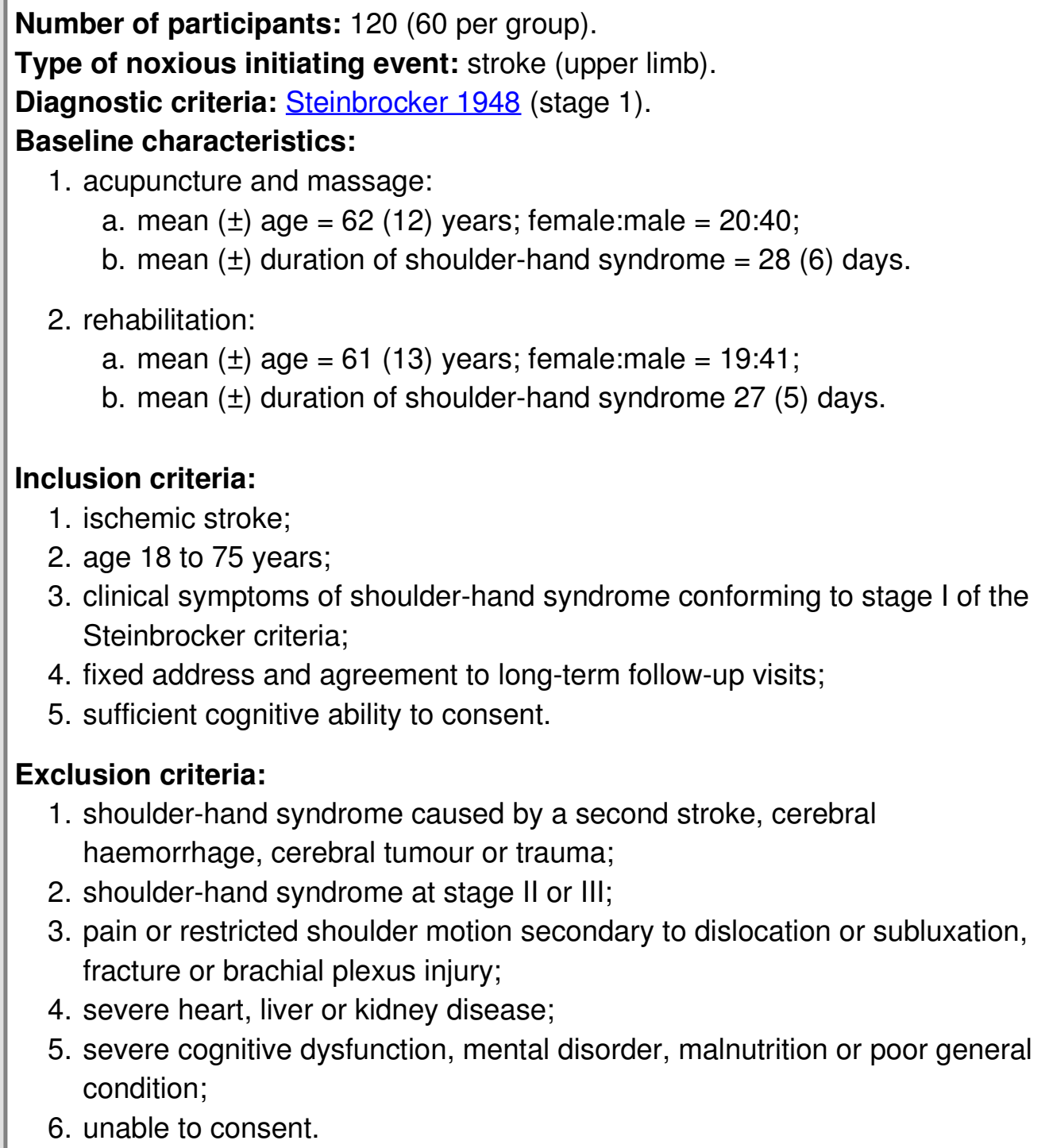 \\
\hline Interventions & $\begin{array}{l}\text { Acupuncture and massage ( } \mathbf{N}=\mathbf{6 0}) \\
\text { Components of intervention: } \\
\text { 1. acupuncture: electric and non-electric acupuncture involving the following } \\
\text { points: Sanjian (LI 3), Houxi (SI 3), Zhongzhu (SJ 3), Jianzhongshu (SI 15), } \\
\text { Jianliao (SJ 14), Shousanli (LI 10), Waiguan (SJ 5) and Tianzong (SI 11); }\end{array}$ \\
\hline
\end{tabular}




\begin{tabular}{|c|c|}
\hline & $\begin{array}{l}\text { 2. massage: massage of the affected upper limb, passive shoulder } \\
\text { movements without pain. } \\
\text { Dosage: acupuncture = } 25 \text { minutes, massage = } 25 \text { minutes. } \\
\text { Frequency of administration: once per day for } 6 \text { therapeutic courses; each course } \\
\text { comprised } 5 \text { sessions, with a 2-day interval between courses ( } 30 \text { sessions). } \\
\text { Provider: doctors. } \\
\text { Rehabilitation therapy ( } \mathbf{n}=60) \\
\text { Components of intervention: active-assisted scapular movements; Bobath } \\
\text { exercises to clench the fist, functional transfers (e.g. changing position from } \\
\text { prone to sitting, sitting to standing); proprioceptive neuromuscular facilitation } \\
\text { (PNF). } \\
\text { Dosage: active-assisted scapular movements = } 15 \text { minutes, Bobath exercises } \\
\text { and functional transfers = } 15 \text { minutes, PNF = } 10 \text { minutes. } \\
\text { Frequency of administration: once per day for } 6 \text { therapeutic courses; each course } \\
\text { comprised } 5 \text { sessions, with a 2-day interval between courses ( } 30 \text { sessions). } \\
\text { Provider: doctors. }\end{array}$ \\
\hline Outcomes & $\begin{array}{l}\text { The trial authors assessed outcomes at baseline, at the end of the } 6 \text {-week } \\
\text { treatment period and at } 12 \text { weeks post-treatment. } \\
\text { Primary outcomes: } \\
\text { 1. self-rated pain on passive shoulder motion [direction of motion not } \\
\text { described] to } 90^{\circ} \text { with the participant in a seated position using a numeric } \\
\text { pain rating scale (scale characteristics not reported); } \\
\text { 2. number of participants with shoulder-hand syndrome at Steinbrocker stage } \\
\text { II or III after treatment. } \\
\text { Secondary outcomes } \\
\text { 1. Fugl-Meyer evaluation of functional movement of the upper limb ( } 33 \text { items, } \\
\text { maximum possible score = } 66 \text {; higher scores indicating more normal } \\
\text { movement); } \\
\text { 2. Fugl-Meyer evaluation of functional movement of the hand ( } 7 \text { items, } \\
\text { maximum possible score = } 14 \text {; higher scores indicating more normal } \\
\text { movement); } \\
\text { 3. Modified Rankin scale (scale properties and scoring method not reported); } \\
\text { 4. adverse events (incidence of shoulder dislocation, fainting during } \\
\text { acupuncture, haematoma, other). }\end{array}$ \\
\hline Notes & $\begin{array}{l}\text { Source of funding: not reported. } \\
\text { Statement regarding declarations of interest: not reported. }\end{array}$ \\
\hline
\end{tabular}

Risk of bias table

\begin{tabular}{||l|l|l||}
\hline \hline Bias & $\begin{array}{l}\text { Authors' } \\
\text { judgement }\end{array}$ & Support for judgement \\
\hline $\begin{array}{l}\text { Random sequence generation } \\
\text { (selection bias) }\end{array}$ & Low risk & $\begin{array}{l}\text { Quote: "A random encoding plan was designed using SPSS } \\
\text { software". } \\
\text { Comment: the trial authors used an acceptable method to } \\
\text { generate the sequence allocation. }\end{array}$ \\
\hline
\end{tabular}


Physiotherapy for pain and disability in adults with complex regional pain syndrome.26-Feb-2016

\begin{tabular}{|c|c|c|}
\hline $\begin{array}{l}\text { Allocation concealment (selection } \\
\text { bias) }\end{array}$ & Low risk & $\begin{array}{l}\text { Quote: "A random encoding plan was designed using SPSS } \\
\text { software and concealed in an envelope } \\
\text { Comment: the trial authors used an adequate method to } \\
\text { conceal the allocation sequence. }\end{array}$ \\
\hline $\begin{array}{l}\text { Blinding of participants and } \\
\text { personnel (performance bias) }\end{array}$ & High risk & $\begin{array}{l}\text { Comment: given the nature of the intervention, participants } \\
\text { were not blinded to treatment and may have had different } \\
\text { expectations about the benefits of each intervention. }\end{array}$ \\
\hline $\begin{array}{l}\text { Blinding of outcome assessment } \\
\text { (detection bias) } \\
\text { Self-reported outcomes }\end{array}$ & High risk & $\begin{array}{l}\text { Comment: unblinded participants who may have had } \\
\text { different expectations about the benefits of the intervention } \\
\text { they received self-reported some outcomes (e.g. pain } \\
\text { intensity). }\end{array}$ \\
\hline $\begin{array}{l}\text { Blinding of outcome assessment } \\
\text { (detection bias) } \\
\text { Investigator-administered } \\
\text { outcomes }\end{array}$ & Unclear risk & $\begin{array}{l}\text { Comment: the trial authors did not give a statement of } \\
\text { procedures regarding blinding of the outcome assessor. }\end{array}$ \\
\hline $\begin{array}{l}\text { Incomplete outcome data (attrition } \\
\text { bias) } \\
\text { Drop-out rate described and } \\
\text { acceptable }\end{array}$ & Low risk & $\begin{array}{l}\text { Quote: "All patients finished the treatment and had a } \\
\text { follow-up visit". } \\
\text { Comment: all randomly assigned participants completed the } \\
\text { study. }\end{array}$ \\
\hline $\begin{array}{l}\text { Incomplete outcome data (attrition } \\
\text { bias) } \\
\text { Participants analysed in the group } \\
\text { to which they were allocated }\end{array}$ & Low risk & $\begin{array}{l}\text { Quote: "All patients finished the treatment and had a } \\
\text { follow-up visit". } \\
\text { Comment: the trial authors did not report the method of } \\
\text { analysis (ITT versus per protocol). }\end{array}$ \\
\hline Selective reporting (reporting bias) & Low risk & $\begin{array}{l}\text { Comment: the trial authors fully reported outcome data for } \\
\text { all outcomes reported in the methods section of the } \\
\text { publication. }\end{array}$ \\
\hline Sample size & Unclear risk & $\begin{array}{l}\text { Quote: "The } 120 \text { subjects in this series...were selected from } \\
202 \text { stroke patients...They were randomly divided into an } \\
\text { acupuncture-massage group and a rehabilitation group, with } \\
60 \text { cases in each". } \\
\text { Comment: the extent to which the small to moderate sample } \\
\text { size may have introduced bias into estimates of treatment } \\
\text { effect is uncertain. }\end{array}$ \\
\hline Duration of follow-up & Low risk & $\begin{array}{l}\text { Quote: "Each of the above indices was recorded before } \\
\text { treatment, at the end of the } 6 \text {-week treatment period and at } \\
\text { the } 12 \text { th-week follow-up visit". } \\
\text { Comment: the trial authors measured outcomes over a } \\
\text { clinically relevant length of time. }\end{array}$ \\
\hline Other bias & Low risk & Comment: we did not identify any other sources of bias. \\
\hline
\end{tabular}

\section{Moseley 2004}




\begin{tabular}{|c|c|}
\hline Methods & $\begin{array}{l}\text { Design: single-blind, 2-arm RCT (Australia; dates not reported). (The trial author } \\
\text { reported that participants in the control group crossed over into the experimental } \\
\text { group. However, we deemed that this trial had not employed a true crossover } \\
\text { design and we analysed it as a 2-arm parallel group trial up to the endpoint just } \\
\text { prior to crossover). } \\
\text { Setting: hospital physiotherapy department. } \\
\text { Interventions: graded motor imagery (GMI) or ongoing medical management. } \\
\text { Sample size calculation: not reported. }\end{array}$ \\
\hline Participants & $\begin{array}{l}\text { Number of participants: } 13 \text { (experimental group } n=7 \text {; control group } n=6 \text { ). } \\
\text { Type of noxious initiating event: wrist fracture (upper limb). } \\
\text { Diagnostic criteria: Bruehl } 1999 \text { (CRPS I). } \\
\text { Baseline characteristics: } \\
\text { 1. GMI: } \\
\text { a. Mean (SD) age = } 35 \text { (15) years; female:male = 5:2; } \\
\text { b. Mean (SD) duration of CRPS I: } 51 \text { (18) weeks; } \\
\text { 2. ongoing medical management: } \\
\text { a. Mean (SD) age = } 38 \text { (14) years; female:male = 4:2; } \\
\text { b. Mean (SD) duration of CRPS I : } 65 \text { (19) weeks. } \\
\text { Inclusion criteria: > } 6 \text { months post non-complicated wrist fracture. } \\
\text { Exclusion criteria: } \\
\text { 1. previously benefited from an intravenous regional sympathetic blockade; } \\
\text { 2. any other upper limb pathology or pain; } \\
\text { 3. any neurological or motor disorder including dyslexia or difficulty performing } \\
\text { a rapid naming task; } \\
\text { 4. visually impaired; } \\
\text { 5. a diagnosed psychopathology; } \\
\text { 6. any invasive analgesic strategy (e.g. spinal cord stimulator); } \\
\text { 7. lived beyond the immediate metropolitan area of the host department. }\end{array}$ \\
\hline Interventions & $\begin{array}{l}\text { GMI (N = 7) } \\
\text { Components of intervention: } \\
\text { 1. recognition of hand laterality stage ( } 2 \text { weeks): whilst seated at a computer } \\
\text { monitor, participants viewed a random sequence of } 56 \text { photographic images } \\
\text { of either a right or left hand in a variety of postures. Participants were } \\
\text { instructed to identify whether the displayed image was of a right or left hand } \\
\text { by pressing an appropriate button on the computer keyboard. participants } \\
\text { borrowed a notebook computer to repeat the task at home; } \\
\text { 2. imagined hand movements stage ( } 2 \text { weeks): whilst viewing a random } \\
\text { sequence of } 28 \text { images of the affected hand participants were advised to } \\
\text { deliberately imagine moving their hand to adopt the posture shown in the } \\
\text { picture, } 3 \text { times } \\
\text { 3. Mirror therapy stage ( } 2 \text { weeks): using a mirror box which concealed the } \\
\text { affected limb from view but allowed participants to view a mirror image of } \\
\text { their unaffected limb, participants viewed a sequence of } 20 \text { pictures of the } \\
\text { unaffected hand and were instructed to slowly and smoothly adopt the } \\
\text { posture shown in each picture with both hands. Emphasis was placed on } \\
\text { watching the reflection of their unaffected hand in the mirror. } \\
\text { Dosage: hand laterality and imagined movements tasks - } 3 \text { times; mirror therapy }\end{array}$ \\
\hline
\end{tabular}




\begin{tabular}{|c|c|}
\hline & $\begin{array}{l}\text { task - } 10 \text { times. } \\
\text { Frequency of administration: each waking hour, daily for } 2 \text { weeks ( } 6 \text { weeks in } \\
\text { total). } \\
\text { Provider: not reported. } \\
\text { Ongoing medical management }(\mathbf{N}=6) \\
\text { Components of intervention: } \\
\text { 1. no limitations placed on treatment; } \\
\text { 2. participants were requested not to change medication type or dosage and } \\
\text { to record any new treatments received; } \\
\text { 3. predominantly physical therapy ( } 2 \text { to } 3 \text { sessions per week) comprising } \\
\text { active and passive limb mobilisation, systemic desensitisation and } \\
\text { hydrotherapy; } \\
\text { 4. chiropractic manipulation and acupuncture ( } 1 \text { participant); psychological } \\
\text { counselling (1 participant). }\end{array}$ \\
\hline Outcomes & $\begin{array}{l}\text { Trial authors assessed outcomes at baseline, at } 2 \text { and } 4 \text { weeks after } \\
\text { commencement of treatment, at the end of the } 6 \text {-week treatment period (week 6) } \\
\text { and } 6 \text { weeks post-treatment (week 12). The trial authors did not state a primary } \\
\text { outcome. } \\
\text { 1. Neuropathic pain scale (NPS), with responses regarding the } 2 \text { previous } \\
\text { days (scoring properties not reported); } \\
\text { 2. swelling, using the average of measure of the circumference of the base of } \\
\text { the } 2 \text { nd and 3rd digits, as measured with a hand measuring tape. }\end{array}$ \\
\hline Notes & $\begin{array}{l}\text { Source of funding: Clinical Research Fellowship from the National Health and } \\
\text { Medical Research Council of Australia ID } 210348 . \\
\text { Statement regarding declarations of interest: not reported. }\end{array}$ \\
\hline
\end{tabular}

Risk of bias table

\begin{tabular}{|l|l|l||}
\hline Bias & $\begin{array}{l}\text { Authors' } \\
\text { judgement }\end{array}$ & Support for judgement \\
\hline $\begin{array}{l}\text { Random sequence generation } \\
\text { (selection bias) }\end{array}$ & Low risk & $\begin{array}{l}\text { Quote: "Patients were randomised by an independent } \\
\text { investigator to the 6-week MIP treatment group or to } \\
\text { ongoing medical management (control) using a random } \\
\text { number table". } \\
\text { Comment: the trial authors used an acceptable method to } \\
\text { generate the sequence allocation. }\end{array}$ \\
\hline $\begin{array}{l}\text { Allocation concealment (selection } \\
\text { bias) }\end{array}$ & Low risk & $\begin{array}{l}\text { Quote: "Patients were randomised by an independent } \\
\text { investigator..." } \\
\text { Comment: the trial authors used an acceptable method to } \\
\text { conceal the allocation sequence. }\end{array}$ \\
\hline $\begin{array}{l}\text { Blinding of participants and } \\
\text { personnel (performance bias) }\end{array}$ & High risk & $\begin{array}{l}\text { Comment: given the nature of the intervention, participants } \\
\text { were not blinded to treatment and may have had different } \\
\text { expectations about the benefits of each intervention. }\end{array}$ \\
\hline $\begin{array}{l}\text { Blinding of outcome assessment } \\
\text { (detection bias) } \\
\text { Self-reported outcomes }\end{array}$ & High risk & $\begin{array}{l}\text { Comment: unblinded participants, who may have had } \\
\text { different expectations about the benefits of the intervention } \\
\text { they received, self-reported some outcomes (e.g. NPS). }\end{array}$ \\
\hline \hline
\end{tabular}


Physiotherapy for pain and disability in adults with complex regional pain syndrome.26-Feb-2016

\begin{tabular}{|c|c|c|}
\hline $\begin{array}{l}\text { Blinding of outcome assessment } \\
\text { (detection bias) } \\
\text { Investigator-administered } \\
\text { outcomes }\end{array}$ & Low risk & $\begin{array}{l}\text { Quote: "All assessments were made by a separate } \\
\text { investigator who was blind to experimental group and } \\
\text { measurement occasion". } \\
\text { Comment: the outcome assessor of objective outcomes was } \\
\text { blinded to treatment allocation. }\end{array}$ \\
\hline $\begin{array}{l}\text { Incomplete outcome data (attrition } \\
\text { bias) } \\
\text { Drop-out rate described and } \\
\text { acceptable }\end{array}$ & Low risk & $\begin{array}{l}\text { Comment: all randomly assigned participants completed the } \\
\text { study (as displayed in the published report's 'Experimental } \\
\text { plan'). }\end{array}$ \\
\hline $\begin{array}{l}\text { Incomplete outcome data (attrition } \\
\text { bias) } \\
\text { Participants analysed in the group } \\
\text { to which they were allocated }\end{array}$ & Low risk & $\begin{array}{l}\text { Comment: the trial authors analysed participants in the } \\
\text { group to which they were allocated. }\end{array}$ \\
\hline Selective reporting (reporting bias) & High risk & $\begin{array}{l}\text { Comment: the trial authors fully reported outcome data } \\
\text { graphically for all outcomes; but did not report raw data in } \\
\text { numerical form with measures of variation. }\end{array}$ \\
\hline Sample size & High risk & $\begin{array}{l}\text { Quote: "Written informed consent was obtained from the } \\
\text { remaining } 13 \text { subjects". } \\
\text { Comment: the small sample size may have introduced bias } \\
\text { in estimates of treatment effect. }\end{array}$ \\
\hline Duration of follow-up & Unclear risk & $\begin{array}{l}\text { Quote: "Post hoc analyses showed...a significant reduction } \\
\text { in all three variables during the MIP with the effect } \\
\text { maintained for at least } 6 \text { weeks after the completion of } \\
\text { treatment". } \\
\text { Comment: the clinical relevance of a } 6 \text {-week follow-up of } \\
\text { outcomes is uncertain. }\end{array}$ \\
\hline Other bias & Unclear risk & Comment: we did not identify any other sources of bias. \\
\hline
\end{tabular}

\section{Moseley 2005}

\begin{tabular}{||l|}
\hline Methods \\
\hline Participants \\
\end{tabular}

Design: parallel group, 3-arm, single-blind RCT (Australia; dates not reported). Setting: not reported.

Interventions: hand laterality recognition followed by imagined movements followed by mirror movements (ReclmMir, MIP) or imagined movements followed by laterality recognition followed by imagined movements $(\mathrm{ImRec} / \mathrm{m})$ or laterality recognition followed by mirror movements followed by recognition (RecMirRec). Sample size calculation: not reported.

Number of participants: 20 (ReclmMir, MIP group (1) $N=7 ;$ ImReclm group (2) $\mathrm{N}=6$; RecMirRec group (3) $\mathrm{N}=7$ ).

Type of noxious initiating event: wrist fracture (upper limb). Diagnostic criteria: Bruehl 1999 (CRPS I) Baseline characteristics:

1. ReclmMir, MIP:
a. mean (SD) age $=36$
(8) years; female:male $=5: 2$;
b. mean (SD) duration of CRPS I: 12 (6) months;

2. ImReclm:

a. mean $(\mathrm{SD})$ age $=27(7)$ years; female $:$ male $=4: 2$; 


\begin{tabular}{|c|c|}
\hline & $\begin{array}{l}\text { b. mean (SD) duration of CRPS I : } 16 \text { (5) months; } \\
\text { 3. RecMirRec: } \\
\text { a. mean (SD) age = } 39 \text { (8) years; female:male = 5:2; } \\
\text { b. mean (SD) duration of CRPS I : } 14 \text { (5) months. } \\
\text { Inclusion criteria: onset of CRPS I post non-complicated wrist fracture > } 6 \\
\text { months prior to enrolment. } \\
\text { Exclusion criteria: } \\
\text { 1. previously obtained relief from an intravenous regional sympathetic } \\
\text { blockade; } \\
\text { 2. any invasive analgesic strategy (e.g. spinal cord stimulator, } \\
\text { sympathectomy); } \\
\text { 3. any other neurological, psychopathology or motor disorder or dyslexia; } \\
\text { 4. difficulty performing a rapid naming task; } \\
\text { 5. visually impaired; } \\
\text { 6. any other upper limb pathology or pain; } \\
\text { 7. lived outside the immediate metropolitan area of the host department. }\end{array}$ \\
\hline Interventions & $\begin{array}{l}\text { Participants were advised to avoid changing medication or seeking alternative } \\
\text { treatment during the course of the trial up to and including the } 12 \text {-week follow-up. } \\
\text { Participants were permitted to attend physiotherapy during the 12-week } \\
\text { follow-up, but no criteria about physiotherapy were set. } \\
\text { ReclmMir, group } 1 \text { ( } \mathbf{N}=7 \text { ) } \\
\text { Components of intervention: } \\
\text { 1. hand laterality recognition ( } 2 \text { weeks): whilst seated at a computer monitor, } \\
\text { participants viewed a random sequence of } 56 \text { photographic images of either } \\
\text { a right or left hand in a variety of postures. Participants were instructed to } \\
\text { identify whether the displayed image was of a right or left hand by pressing } \\
\text { an appropriate button on the computer keyboard. Participants borrowed a } \\
\text { notebook computer to repeat the task at home; } \\
\text { 2. imagined hand movements ( } 2 \text { weeks): whilst viewing a random sequence of } \\
28 \text { images of the affected hand participants were advised to imagine } \\
\text { moving their own hand to adopt the posture shown in the picture then } \\
\text { returning it to its resting position, and to repeat the process twice for each } \\
\text { picture; } \\
\text { 3. mirror therapy ( } 2 \text { weeks): using a mirror box which concealed the affected } \\
\text { limb from view but allowed participants to view a mirror image of their } \\
\text { unaffected limb, participants viewed a sequence of } 20 \text { pictures of the } \\
\text { unaffected hand and were instructed to slowly and smoothly adopt the } \\
\text { posture shown in each picture with both hands. Emphasis was placed on } \\
\text { watching the reflection of their unaffected hand in the mirror. } \\
\text { Dosage: hand laterality task - } 3 \text { times, imagined movements task - twice; mirror } \\
\text { therapy task - } 5 \text { times. } \\
\text { Frequency of administration: each waking hour, daily for } 2 \text { weeks ( } 6 \text { weeks in } \\
\text { total). } \\
\text { Provider: not reported. } \\
\text { ImReclm, group } 2 \text { ( } \mathbf{N}=6 \text { ) } \\
\text { Components of intervention: } 2 \text { weeks imagined movements, } 2 \text { weeks hand } \\
\text { laterality recognition, } 2 \text { weeks imagined movements (components described }\end{array}$ \\
\hline
\end{tabular}




\begin{tabular}{|c|c|}
\hline & $\begin{array}{l}\text { above). } \\
\text { Dosage and frequency of administration: as described above. } \\
\text { RecMirRec, group } \mathbf{3}(\mathbf{N}=7 \text { ) } \\
\text { Components of intervention: } 2 \text { weeks hand laterality recognition, } 2 \text { weeks mirror } \\
\text { therapy, } 2 \text { weeks hand laterality recognition (components described above). } \\
\text { Dosage and frequency of administration: as described above. }\end{array}$ \\
\hline Outcomes & $\begin{array}{l}\text { The trial authors assessed outcomes at baseline, at } 2 \text { and } 4 \text { weeks after } \\
\text { commencement of treatment, at the end of the } 6 \text {-week treatment period (week } 6 \text { ) } \\
\text { and } 12 \text { weeks post-treatment (week 18). The trial authors did not state a primary } \\
\text { outcome. } \\
\text { 1. NPS, with responses regarding the } 2 \text { previous days (possible range } 0 \text { to } \\
\text { 100); } \\
\text { 2. self-rated function with respect to } 5 \text { self-selected activities or tasks using an } \\
\text { 11-point numerical rating scale (NRS) anchored with "0, completely unable } \\
\text { to perform" and "10, able to perform normally" (final score average of } 5 \\
\text { tasks, possible range } 0 \text { to } 10 \text { higher number indicates less severe limitation). }\end{array}$ \\
\hline Notes & $\begin{array}{l}\text { Source of funding: Australian Clinical Research Fellowship from the National } \\
\text { Health and Medical Research Council of Australia ID } 210348 . \\
\text { Statement regarding declarations of interest: not reported. }\end{array}$ \\
\hline
\end{tabular}

Risk of bias table

\begin{tabular}{|c|c|c|}
\hline Bias & $\begin{array}{l}\text { Authors' } \\
\text { judgement }\end{array}$ & Support for judgement \\
\hline $\begin{array}{l}\text { Random sequence generation } \\
\text { (selection bias) }\end{array}$ & Low risk & $\begin{array}{l}\text { Quote: "Using a random numbers table, an independent } \\
\text { investigator allocated consenting patients into one of three } \\
\text { treatment groups". } \\
\text { Comment: the trial authors used an acceptable method to } \\
\text { generate the sequence allocation. }\end{array}$ \\
\hline $\begin{array}{l}\text { Allocation concealment (selection } \\
\text { bias) }\end{array}$ & Low risk & $\begin{array}{l}\text { Quote: "Using a random numbers table, an independent } \\
\text { investigator allocated consenting patients..." } \\
\text { Comment: the trial authors used an acceptable method to } \\
\text { conceal the allocation sequence. }\end{array}$ \\
\hline $\begin{array}{l}\text { Blinding of participants and } \\
\text { personnel (performance bias) }\end{array}$ & Low risk & $\begin{array}{l}\text { Comment: participants were not blinded to treatment } \\
\text { allocation but a lack of blinding is unlikely to have biased the } \\
\text { results given that participants received interventions judged } \\
\text { to have been of relatively equal credibility. }\end{array}$ \\
\hline $\begin{array}{l}\text { Blinding of outcome assessment } \\
\text { (detection bias) } \\
\text { Self-reported outcomes }\end{array}$ & Low risk & $\begin{array}{l}\text { Comment: participants were not blinded to treatment } \\
\text { allocation and self-reported their outcomes but lack of } \\
\text { blinding unlikely to have biased the results given that } \\
\text { participants received interventions judged to have been of } \\
\text { relatively equal credibility. }\end{array}$ \\
\hline $\begin{array}{l}\text { Blinding of outcome assessment } \\
\text { (detection bias) } \\
\text { Investigator-administered } \\
\text { outcomes }\end{array}$ & Unclear risk & Not applicable. \\
\hline
\end{tabular}


Physiotherapy for pain and disability in adults with complex regional pain syndrome.26-Feb-2016

\begin{tabular}{|l|l|l||}
\begin{tabular}{|l} 
Incomplete outcome data (attrition \\
bias) \\
Drop-out rate described and \\
acceptable
\end{tabular} & Low risk & $\begin{array}{l}\text { Comment: all but 1 randomly assigned participant } \\
\text { completed the study, and the 1 participant appeared to have } \\
\text { dropped out from group 3 (as displayed in the published } \\
\text { report's 'Treatment plan'). }\end{array}$ \\
\hline $\begin{array}{l}\text { Incomplete outcome data (attrition } \\
\text { bias) } \\
\text { Participants analysed in the group } \\
\text { to which they were allocated }\end{array}$ & High risk & $\begin{array}{l}\text { Comment: the trial author did not report the method of } \\
\text { analysis (ITT versus per protocol). The trial authors appear } \\
\text { to have excluded 1 participant from group 3 from the } \\
\text { analysis in an apparent violation of the principle of ITT. }\end{array}$ \\
\hline Selective reporting (reporting bias) & High risk & $\begin{array}{l}\text { Comment: the trial authors fully reported outcome data } \\
\text { graphically for all outcomes; but did not report raw data in } \\
\text { numerical form with measures of variation. }\end{array}$ \\
\hline Sample size & High risk & $\begin{array}{l}\text { Quote: "Twenty subjects with chronic CRPS1 initiated by } \\
\text { wrist fracture and who satisfied stringent inclusion criteria, } \\
\text { were randomly allocated to one of three groups". } \\
\text { Comment: the small sample size may have introduced bias } \\
\text { in estimates of treatment effect. }\end{array}$ \\
\hline Duration of follow-up & Low risk & $\begin{array}{l}\text { Quote: "Single blind randomised trial with 12-week } \\
\text { follow-up". } \\
\text { Comment: the trial authors measured outcomes over a } \\
\text { clinically relevant length of time. }\end{array}$ \\
\hline Other bias & Unclear risk & \begin{tabular}{l} 
Comment: we did not identify any other sources of bias. \\
\hline
\end{tabular} \\
\hline
\end{tabular}

\section{Moseley 2006}

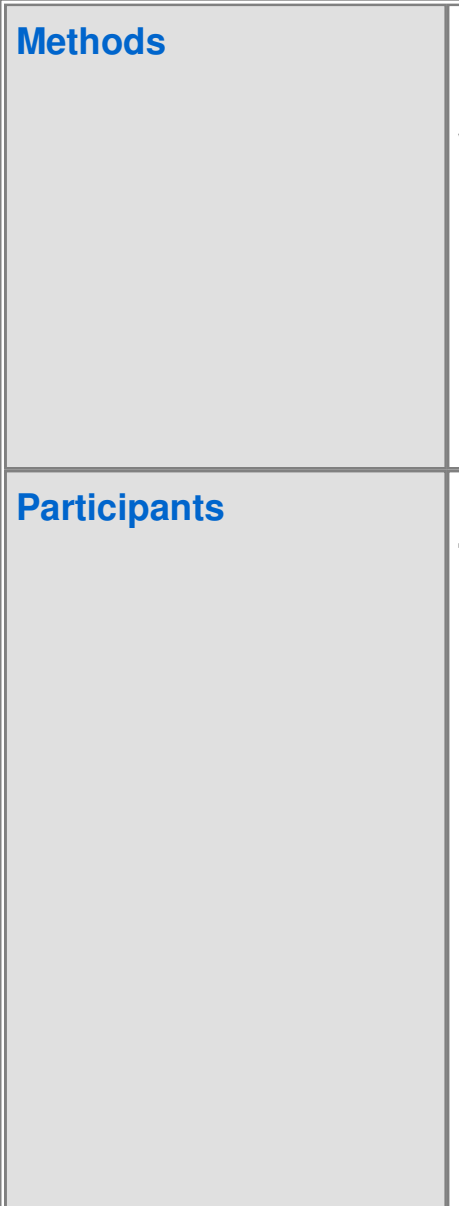

Design: parallel group, 2-arm, single-blind RCT (Australia; dates not reported). NB: this trial recruited participants with CRPS I and phantom limb pain. However we only included information and data from participants with CRPS for the purpose of this systematic review.

Setting: not reported.

Interventions: GMI or physiotherapy and ongoing medical care.

Sample size calculation: a total sample size of 51 participants would detect an effect size of 0.80 (equivalent to a reduction in pain of $29 \mathrm{~mm}$ on a $100 \mathrm{~mm}$ VAS), with a probability of $80 \%$, assuming an alpha level of 0.05 .

Number of participants: 37 (experimental group $N=17$; control group $N=20$ ). Type of noxious initiating event: mixed (fractures $n=14$, soft-tissue injury $n=$ 15 , post carpal tunnel release $n=2$, venepuncture site $n=2$, post finger/toe amputation $n=2$, carpal tunnel syndrome $n=1$, nail infection $n=1$ ) (upper and lower limb).

Diagnostic criteria: Bruehl 1999 (CRPS I).

\section{Baseline characteristics:}

1. GMI:

a. mean (SD) age $=45$ (14) years; female:male $=11: 6$;

b. mean (SD) duration of CRPS I: 14 (10) months;

2. physical therapy and ongoing medical care:

a. mean $(S D)$ age $=41$ (14) years; female: male $=15: 5$;

b. mean (SD) duration of CRPS I: 12 (8) months. 


\begin{tabular}{|c|c|}
\hline & $\begin{array}{l}\text { Inclusion criteria: CRPS I of an upper or lower limb. } \\
\text { Exclusion criteria: } \\
\text { 1. any other neurologic, psychopathology or motor disorder; } \\
\text { 2. dyslexia; } \\
\text { 3. difficulty performing a rapid naming task; } \\
\text { 4. visually impaired; } \\
\text { 5. any other limb pathology or pain; } \\
\text { 6. lived outside the immediate metropolitan area of the host department. }\end{array}$ \\
\hline Interventions & $\begin{array}{l}\text { GMI (N = 17) } \\
\text { Components of intervention } \\
\text { 1. limb laterality recognition phase ( } 2 \text { weeks): whilst seated at a computer, } \\
\text { participants viewed a random sequence of photographic images (matched } \\
\text { to gender) of either a right or left hand (participants with an affected upper } \\
\text { limb) or foot (participants with an affected lower limb) in a variety of } \\
\text { positions and alignments. Participants indicated whether the displayed } \\
\text { image was of a right or left limb by pressing an appropriate key on the } \\
\text { computer keyboard; } \\
\text { 2. imagined movements phase ( } 2 \text { weeks): whilst viewing a random sequence } \\
\text { of images of both limbs participants were required to imagine twice adopting } \\
\text { the posture shown with a smooth and pain-free movement; } \\
\text { 3. mirror movements phase (2 weeks): using a mirror box which concealed the } \\
\text { affected limb from view but allowed participants to view a mirror image of } \\
\text { their unaffected limb, participants viewed a sequence of images and were } \\
\text { instructed to twice adopt the posture shown with both limbs, using smooth } \\
\text { and pain-free movements. } \\
\text { Dosage: participants were prescribed a training protocol of gradually increased } \\
\text { training load according to task difficulty during each of the } 3 \text { GMl phases, as } \\
\text { detailed by the trial authors. } \\
\text { Frequency of administration: hourly training (further details not reported). } \\
\text { Provider: physiotherapist. } \\
\text { Physiotherapy and ongoing medical care ( } \mathbf{N}=\mathbf{2 0} \text { ) } \\
\text { Components of intervention: not reported. } \\
\text { Dosage: not reported. } \\
\text { Frequency of administration: minimum of once per week together with a hourly } \\
\text { home programme. } \\
\text { Provider: physiotherapists. }\end{array}$ \\
\hline Outcomes & $\begin{array}{l}\text { Outcomes assessed at baseline, at the end of the } 6 \text {-week treatment period and } 6 \\
\text { months post-treatment. } \\
\text { Primary outcomes: } \\
\text { 1. self-rated function with respect to } 5 \text { self-selected activities or tasks using an } \\
\text { 11-point NRS anchored with "0, completely unable to perform" and "10, able } \\
\text { to perform normally"; } \\
\text { 2. self-rated pain severity using a } 0 \text { to } 100 \mathrm{~mm} \text { VAS (anchor points not } \\
\text { described) to rate average level of pain over the last } 2 \text { days; } \\
\text { 3. McGill Pain Questionnaire (MPQ). }\end{array}$ \\
\hline
\end{tabular}



limb pain $(\mathrm{N}=51)$. Details reported above refer to only those participants with CRPS I ( $\mathrm{N}=37)$.

Source of funding: not reported

Statement regarding declarations of interest: the authors declared no conflicts of interest.

\section{Risk of bias table}

\begin{tabular}{|c|c|c|}
\hline Bias & \begin{tabular}{|l|} 
Authors' \\
judgement
\end{tabular} & Support for judgement \\
\hline $\begin{array}{l}\text { Random sequence generation } \\
\text { (selection bias) }\end{array}$ & Low risk & $\begin{array}{l}\text { Quote: "Patients were randomized via random number } \\
\text { generation by an independent investigator...using a random } \\
\text { numbers table". } \\
\text { Comment: the trial authors used an acceptable method to } \\
\text { generate the sequence allocation. }\end{array}$ \\
\hline $\begin{array}{l}\text { Allocation concealment (selection } \\
\text { bias) }\end{array}$ & Low risk & $\begin{array}{l}\text { Quote: "Patients were randomized via random number } \\
\text { generation by an independent investigator..." } \\
\text { Comment: the trial authors used an acceptable method to } \\
\text { conceal the allocation sequence. }\end{array}$ \\
\hline $\begin{array}{l}\text { Blinding of participants and } \\
\text { personnel (performance bias) }\end{array}$ & High risk & $\begin{array}{l}\text { Comment: given the nature of the intervention, participants } \\
\text { were not blinded to treatment and may have had different } \\
\text { expectations about the benefits of each intervention. }\end{array}$ \\
\hline $\begin{array}{l}\text { Blinding of outcome assessment } \\
\text { (detection bias) } \\
\text { Self-reported outcomes }\end{array}$ & High risk & $\begin{array}{l}\text { Comment: unblinded participants, who may have had } \\
\text { different expectations about the benefits of the intervention } \\
\text { they received, self-reported some outcomes (e.g. pain } \\
\text { intensity). }\end{array}$ \\
\hline $\begin{array}{l}\text { Blinding of outcome assessment } \\
\text { (detection bias) } \\
\text { Investigator-administered } \\
\text { outcomes }\end{array}$ & Low risk & Not applicable. \\
\hline $\begin{array}{l}\text { Incomplete outcome data (attrition } \\
\text { bias) } \\
\text { Drop-out rate described and } \\
\text { acceptable }\end{array}$ & Low risk & $\begin{array}{l}\text { Quote: "One female subject in the control group withdrew } \\
\text { from the study because she sustained an unrelated injury. } \\
\text { There were no other dropouts or withdrawals". } \\
\text { Comment: the minimal drop-out rate ( } 5 \% \text { from } 1 \text { trial arm) is } \\
\text { unlikely to have biased the results. }\end{array}$ \\
\hline $\begin{array}{l}\text { Incomplete outcome data (attrition } \\
\text { bias) } \\
\text { Participants analysed in the group } \\
\text { to which they were allocated }\end{array}$ & Low risk & $\begin{array}{l}\text { Comment: the trial authors performed an available case } \\
\text { analysis. }\end{array}$ \\
\hline Selective reporting (reporting bias) & Low risk & $\begin{array}{l}\text { Comment: the trial authors fully reported outcome data for } \\
\text { self-reported function and pain severity outcomes for } \\
\text { participants with CRPS and phantom limb pain combined as } \\
\text { conceived in the original trial design. They presented } \\
\text { outcome data for participants with CRPS graphically only. }\end{array}$ \\
\hline
\end{tabular}




\begin{tabular}{|l|l|l||}
\hline Sample size & High risk & $\begin{array}{l}\text { Quote: "Fifty-one patients [37 with CRPS] with phantom limb } \\
\text { pain or CRPS1 were randomly allocated". } \\
\text { Comment: the small sample size may have introduced bias } \\
\text { in estimates of treatment effect. (We acknowledge that our } \\
\text { judgement regarding the risk of bias linked to sample size } \\
\text { for this study is based on the purposeful exclusion of a } \\
\text { number of participants with phantom limb pain }(\mathrm{N}=14) \text { that } \\
\text { the original design did not intend). }\end{array}$ \\
\hline Duration of follow-up & Low risk & $\begin{array}{l}\text { Quote: "All assessments were undertaken at } \\
\text { prerandomization and at } 6 \text { weeks (completion of the } \\
\text { treatment period). Pain VAS and function NRS were also } \\
\text { undertaken at } 6 \text { months follow-up". } \\
\text { Comment: the trial authors measured outcomes over a } \\
\text { clinically relevant length of time. }\end{array}$ \\
\hline Other bias & Unclear risk & \begin{tabular}{l} 
Comment: we did not identify any other sources of bias. \\
\hline
\end{tabular}
\end{tabular}

Moseley 2009

\begin{tabular}{|c|c|}
\hline Methods & $\begin{array}{l}\text { Design: within-subject randomised crossover design (Australia; dates not } \\
\text { reported). } \\
\text { Setting: not reported. } \\
\text { Interventions: tactile discrimination training (TDT) under } 4 \text { separate conditions. } \\
\text { Sample size calculation: not reported. }\end{array}$ \\
\hline Participants & $\begin{array}{l}\text { Number of participants: } 10 \text {. } \\
\text { Type of noxious initiating event: mixed (fractures of the hand or wrist } n=4 \text {, } \\
\text { sprains } n=2 \text {, carpal tunnel syndrome } n=2 \text {, post hand cannulation } n=1 \text {, thumb } \\
\text { dislocation } n=1 \text { ) (upper limb). } \\
\text { Diagnostic criteria: Bruehl } 1999 \text { (CRPS I). } \\
\text { Baseline characteristics: } \\
\text { 1. mean (SD) age = } 43(11) \text { years; female:male }=6: 4 \text {; } \\
\text { 2. mean (SD) duration of CRPS I: } 20 \text { (5) months. } \\
\text { Inclusion criteria: CRPS of } 1 \text { wrist of hand. } \\
\text { Exclusion criteria: not reported. }\end{array}$ \\
\hline Interventions & $\begin{array}{l}\text { TDT }(\mathbf{N}=\mathbf{1 0}) \\
\text { Components of intervention: } \\
\text { 1. two probes ( } 2 \mathrm{~mm} \text { and } 12 \mathrm{~mm} \text { in diameter) were applied to } 1 \text { of } 5 \\
\text { stimulation sites on the affected limb in a random order, with an } \\
\text { interstimulus interval of } 15 \text { seconds; } \\
\text { 2. TDT was performed under } 4 \text { different conditions: } \\
\text { a. facing + skin: involved participants watching the reflected image of their } \\
\text { unaffected, non-stimulated arm in a mirror placed between the upper } \\
\text { limbs while facing the stimulated arm; } \\
\text { b. skin only: involved participants watching their unaffected, } \\
\text { non-stimulated arm directly } \\
\text { c. facing only: involved participants looking in the direction of their } \\
\text { affected, stimulated arm but with no mirror and the unaffected limb } \\
\text { hidden; } \\
\text { d. control condition: involved participants looking away from their }\end{array}$ \\
\hline
\end{tabular}




\begin{tabular}{||l||l||}
\multicolumn{1}{||}{} & \multicolumn{1}{|c||}{ stimulated limb with the unaffected limb hidden. } \\
& $\begin{array}{l}\text { Dosage: three 6-minute blocks of } 24 \text { stimuli were undertaken with a 3-minute rest } \\
\text { period between blocks. Each treatment session involved } 72 \text { stimuli and lasted for } \\
24 \text { minutes. } \\
\text { Frequency of administration: each participant received } 4 \text { sessions of each } \\
\text { experimental condition in varying order (total of } 16 \text { sessions), with } 3 \text { to } 4 \text { days } \\
\text { between sessions. } \\
\text { Provider: not reported. }\end{array}$ \\
\hline Outcomes & $\begin{array}{l}\text { The trial authors assessed outcomes at baseline, immediately and } 2 \text { days } \\
\text { post-treatment. } \\
\text { Primary outcomes: 2-point discrimination threshold, measured in mm, using a } \\
\text { mechanical calliper. } \\
\text { Secondary outcomes: self-rated current pain (at rest) severity using a } 100 \text { mm } \\
\text { VAS anchored with "no pain" and "worst possible pain". }\end{array}$ \\
\hline Notes & $\begin{array}{l}\text { Source of funding: Nuffield Oxford Medical Fellowship, NHMRC Senior } \\
\text { Research Fellowship, Templeton Foundation. } \\
\text { Statement regarding declarations of interest: the authors declared no } \\
\text { conflicts of interest. }\end{array}$ \\
\hline
\end{tabular}

Risk of bias table

\begin{tabular}{||l|l|l||}
\hline Bias & $\begin{array}{l}\text { Authors' } \\
\text { judgement }\end{array}$ & Support for judgement \\
\hline $\begin{array}{l}\text { Random sequence generation } \\
\text { (selection bias) }\end{array}$ & Unclear risk & $\begin{array}{l}\text { Quote: "The conditions were randomised and } \\
\text { counterbalanced so that each participant had four sessions } \\
\text { of each condition, but in varying order". } \\
\text { Comment: the trial authors did not report the method of } \\
\text { sequence generation. }\end{array}$ \\
\hline $\begin{array}{l}\text { Allocation concealment (selection } \\
\text { bias) }\end{array}$ & Low risk & $\begin{array}{l}\text { Comment: this was not applicable (when crossover design } \\
\text { employed). }\end{array}$ \\
\hline $\begin{array}{l}\text { Blinding of participants and } \\
\text { personnel (performance bias) }\end{array}$ & Unclear risk & $\begin{array}{l}\text { Comment: given the nature of the intervention, participants } \\
\text { were not blinded to treatment allocation but the extent to } \\
\text { which the lack of blinding may have introduced bias is } \\
\text { uncertain. }\end{array}$ \\
\hline $\begin{array}{l}\text { Blinding of outcome assessment } \\
\text { (detection bias) } \\
\text { Self-reported outcomes }\end{array}$ & Unclear risk & $\begin{array}{l}\text { Comment: unblinded participants self-reported some } \\
\text { outcomes (e.g. pain intensity) but the extent to which the } \\
\text { lack of blinding may have introduced bias is uncertain. }\end{array}$ \\
\hline $\begin{array}{l}\text { Blinding of outcome assessment } \\
\text { (detection bias) } \\
\text { Investigator-administered } \\
\text { outcomes }\end{array}$ & Unclear risk & $\begin{array}{l}\text { Comment: we do not known whether or not the outcome } \\
\text { assessors were blinded to the treatment condition. }\end{array}$ \\
\hline $\begin{array}{l}\text { Incomplete outcome data (attrition } \\
\text { bias) } \\
\text { Drop-out rate described and } \\
\text { acceptable }\end{array}$ & Low risk & $\begin{array}{l}\text { Comment: the trial authors did not report any drop-outs; } \\
\text { they presented results based on the total number of } \\
\text { included participants. }\end{array}$ \\
\hline
\end{tabular}


Physiotherapy for pain and disability in adults with complex regional pain syndrome.26-Feb-2016

\begin{tabular}{||l|l|l||}
\begin{tabular}{|l} 
Incomplete outcome data (attrition \\
bias) \\
Participants analysed in the group \\
to which they were allocated
\end{tabular} & Low risk & $\begin{array}{l}\text { Comment: not applicable (when crossover design } \\
\text { employed). }\end{array}$ \\
\hline Selective reporting (reporting bias) & High risk & $\begin{array}{l}\text { Comment: the trial authors fully reported outcome data } \\
\text { graphically for all outcomes; they did not report raw data in } \\
\text { numerical form with measures of variation. }\end{array}$ \\
\hline Sample size & High risk & $\begin{array}{l}\text { Quote: "Ten patients with chronic CRPS of one hand or } \\
\text { wrist (diagnosed according to Bruehl et al.) were recruited". } \\
\text { Comment: the small sample size may have introduced bias } \\
\text { in estimates of treatment effect. }\end{array}$ \\
\hline Duration of follow-up & High risk & $\begin{array}{l}\text { Quote: "The TPD for the three sites was averaged to } \\
\text { provide a measure at pre-training, post-training and } 2 \text { days } \\
\text { later". } \\
\text { Comment: the trial authors did not measure outcomes over } \\
\text { a clinically relevant length of time. }\end{array}$ \\
\hline Other bias & Unclear risk & $\begin{array}{l}\text { Quote: "...there were 1-2 days between the follow-up } \\
\text { assessment and the next training session. Participants were } \\
\text { advised not to undertake tactile training in between } \\
\text { sessions". } \\
\text { Comment: the extent to which an interval of 1 to 2 days } \\
\text { between outcome assessment and training sessions } \\
\text { represented an adequate wash-out period, and therefore } \\
\text { the extent to which a carry-over effect may have introduced } \\
\text { bias in estimates of treatment effect, is not known. }\end{array}$ \\
\hline
\end{tabular}

\section{Mucha 1992}

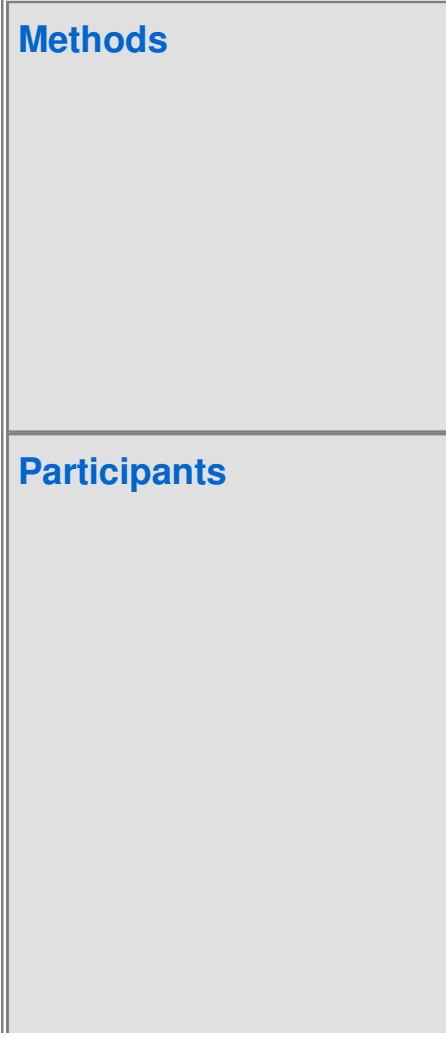

Design: parallel group, 2-arm RCT (Germany; dates not reported). (The trial authors reported that participants in the control group crossed over into the experimental group. However, we deemed that this trial did not employ a true crossover design and we analysed it as a 2-arm parallel group trial up to the endpoint just prior to crossover).

Setting: not reported.

Interventions: $\mathrm{CO}_{2}$ baths plus exercise therapy or exercise therapy alone.

Sample size calculation: not reported.

Number of participants: 40 (20 per group).

Type of noxious initiating event: post-trauma (no further details reported) (upper limb).

Diagnostic criteria: acute algodystrophy of the hand (diagnostic criteria not reported).

Baseline characteristics:

Total sample (separate intervention and control group data not reported).

Age range 47 to 56 years (group data not reported).

Duration of CRPS (range) 2 to 6 weeks (group data not reported).

1. $\mathrm{CO}_{2}$ baths plus exercise therapy

a. Female:male $=13: 7$ 


\begin{tabular}{|c|c|}
\hline & $\begin{array}{l}\text { 2. exercise alone } \\
\text { a. Female:male }=11: 9 \\
\text { Inclusion criteria: } \\
\text { 1. CRPS I of the hand; } \\
\text { 2. post-traumatic onset; } \\
\text { 3. 'high active stage of condition'; } \\
\text { 4. minimum of } 2 \text { weeks duration of symptoms. } \\
\text { Exclusion criteria: more than } 6 \text { weeks duration of symptoms. }\end{array}$ \\
\hline Interventions & $\begin{array}{l}\text { Those participants on medication prior to the trial were instructed to cease their } \\
\text { medication at the start of the trial. } \\
\mathrm{CO}_{2} \text { baths plus exercise }(\mathbf{N}=20) \\
\text { Components of intervention } \\
\text { 1. } \mathrm{CO}_{2} \text { bath; } \\
\text { 2. after the bath, } 30 \text { to } 45 \text { minutes rest in an anti-swelling functional position; } \\
\text { 3. exercise therapy (as below). } \\
\text { Dosage: } 12 \text { minute } \mathrm{CO}_{2} \text { bath with water temperature of } 32 \text { to } 33^{\circ} \mathrm{C} \text { and a } \mathrm{CO}_{2} \\
\text { concentration of } 800 \text { to } 1000 \mathrm{mg} / \mathrm{L} \text {. } \\
\text { Frequency of administration: } 5 \text { times a week for } 4 \text { weeks ( } 20 \text { sessions). } \\
\text { Provider: not reported. } \\
\text { Exercise ( } \mathbf{N}=20 \text { ) } \\
\text { Components of intervention: progressive exercise therapy. The intensity was } \\
\text { dependent on pain level and symptom behaviour. } \\
\text { Dosage: not reported. } \\
\text { Frequency of administration: } 5 \text { times a week for } 4 \text { weeks ( } 20 \text { sessions). } \\
\text { Provider: not reported. }\end{array}$ \\
\hline Outcomes & $\begin{array}{l}\text { The trial authors assessed outcomes at baseline and twice weekly until } \\
\text { completion of the intervention period ( } 4 \text { weeks post recruitment). The trial authors } \\
\text { did not state any primary outcomes. } \\
\text { 1. self-rated pain intensity at rest; measured using a graphic analogue scale } \\
\text { (no scale reported); } \\
\text { 2. self-rated pain intensity at night; measured using a graphic analogue scale } \\
\text { (no scale reported); } \\
\text { 3. self-rated pain intensity with movement; measured using a graphic } \\
\text { analogue scale (no scale points reported); } \\
\text { 4. hand circumference: measured over the wrist, MCPs and DIPs, recorded in } \\
\text { cm. Probably difference between sides. Only MCP data provided; } \\
\text { 5. range of motion: neutral } 0 \text { method of forearm, hand and fingers, recorded in } \\
\text { degrees, only wrist data reported; } \\
\text { 6. grip strength: hand held dynamometer, relative to other side; } \\
\text { 7. temperature: difference between sides; more than } 0.8 \text { degrees difference } \\
\text { was recorded as positive. }\end{array}$ \\
\hline Notes & $\begin{array}{l}\text { Source of funding: not reported } \\
\text { Statement regarding declarations of interest: not reported }\end{array}$ \\
\hline
\end{tabular}


Physiotherapy for pain and disability in adults with complex regional pain syndrome.26-Feb-2016

Risk of bias table

\begin{tabular}{|c|c|c|}
\hline Bias & $\begin{array}{l}\text { Authors' } \\
\text { judgement }\end{array}$ & Support for judgement \\
\hline $\begin{array}{l}\text { Random sequence generation } \\
\text { (selection bias) }\end{array}$ & Unclear risk & $\begin{array}{l}\text { Quote: " Patients were randomised into two groups". } \\
\text { Comment: the trial authors did not report the method of } \\
\text { sequence generation. }\end{array}$ \\
\hline $\begin{array}{l}\text { Allocation concealment (selection } \\
\text { bias) }\end{array}$ & Unclear risk & $\begin{array}{l}\text { Comment: the trial authors did not report the method of } \\
\text { concealment allocation. }\end{array}$ \\
\hline $\begin{array}{l}\text { Blinding of participants and } \\
\text { personnel (performance bias) }\end{array}$ & High risk & $\begin{array}{l}\text { Comment: given the nature of the intervention, participants } \\
\text { were not blinded to treatment and may have had different } \\
\text { expectations about the benefits of each intervention. }\end{array}$ \\
\hline $\begin{array}{l}\text { Blinding of outcome assessment } \\
\text { (detection bias) } \\
\text { Self-reported outcomes }\end{array}$ & High risk & $\begin{array}{l}\text { Comment: unblinded participants, who may have had } \\
\text { different expectations about the benefits of the intervention } \\
\text { they received, self-reported some outcomes (e.g. pain } \\
\text { intensity). }\end{array}$ \\
\hline $\begin{array}{l}\text { Blinding of outcome assessment } \\
\text { (detection bias) } \\
\text { Investigator-administered } \\
\text { outcomes }\end{array}$ & Unclear risk & $\begin{array}{l}\text { Comment: the trial authors did not report the statement of } \\
\text { procedures regarding blinding of the outcome assessor. }\end{array}$ \\
\hline $\begin{array}{l}\text { Incomplete outcome data (attrition } \\
\text { bias) } \\
\text { Drop-out rate described and } \\
\text { acceptable }\end{array}$ & Low risk & Comment: there were no apparent drop-outs. \\
\hline $\begin{array}{l}\text { Incomplete outcome data (attrition } \\
\text { bias) } \\
\text { Participants analysed in the group } \\
\text { to which they were allocated }\end{array}$ & Low risk & $\begin{array}{l}\text { Comment: the trial authors analysed participants in the } \\
\text { group to which they were allocated but did not report the } \\
\text { method of analysis (ITT versus per protocol). }\end{array}$ \\
\hline Selective reporting (reporting bias) & High risk & $\begin{array}{l}\text { Comment: the trial authors fully reported outcome data } \\
\text { graphically for all outcomes; but did not report raw data in } \\
\text { numerical form with measures of variation. }\end{array}$ \\
\hline Sample size & High risk & $\begin{array}{l}\text { Quote: "20 participants per group". } \\
\text { Comment: the small sample size may have introduced bias } \\
\text { in estimates of treatment effect. }\end{array}$ \\
\hline Duration of follow-up & High risk & $\begin{array}{l}\text { Comment: comparison was only possible immediately at the } \\
\text { end of the 4-week therapy session as the control group } \\
\text { crossed over to the treatment arm at this point. }\end{array}$ \\
\hline Other bias & Low risk & $\begin{array}{l}\text { Quote: "Statistical testing showed homogeneity across both } \\
\text { groups". } \\
\text { Comment: there were no apparent baseline differences } \\
\text { between groups. } \\
\text { Comment: we did not identify any other sources of bias. }\end{array}$ \\
\hline
\end{tabular}




\section{Oerlemans 1999}

\begin{tabular}{|c|c|}
\hline Methods & $\begin{array}{l}\text { Design: parallel group, } 3 \text {-arm, single-blind RCT (The Netherlands; June } 1994 \text { to } \\
\text { February 1998). } \\
\text { Setting: outpatient clinics of } 2 \text { university hospitals. } \\
\text { Interventions: physical therapy (PT) plus medical treatment or occupational } \\
\text { therapy (OT) plus medical treatment or social work (SW) plus medical treatment } \\
\text { (control). } \\
\text { Sample size calculation: the study planned to recruit } 150 \text { participants ( } 50 \text { per } \\
\text { group) in order to be able to detect between-group differences of } 6 \text { to } 7 \text { points in } \\
\text { the impairment level sumscore (ISS) with } 80 \% \text { power. }\end{array}$ \\
\hline Participants & $\begin{array}{l}\text { Number of participants: } 135 \text { (physical therapy group } N=44 \text {; OT group } N=44 \text {; } \\
\text { SW (control) group } N=47) \text {. } \\
\text { Type of noxious initiating event: mixed (fracture ( } 53 \%) \text {, spontaneous onset } \\
\text { (13\%), contusion (11\%), mallet finger, carpal tunnel syndrome, postoperative } \\
\text { interventions, sprains (proportions not reported) (upper limb). } \\
\text { Diagnostic criteria: Veldman } 1993 \text { (CRPS I). } \\
\text { Baseline characteristics: } \\
\text { 1. PT: } \\
\text { a. mean (SD) age = } 50.4 \text { (15.6) years; female:male = } 29: 15 \text {; } \\
\text { b. mean (SD) duration of CRPS I: } 3.1 \text { (3.4) months; } \\
\text { 2. OT: } \\
\text { a. mean (SD) age }=56.3 \text { (17) years; female:male = } 31: 13 \text {; } \\
\text { b. mean (SD) duration of CRPS I: } 2.9 \text { (2.5) months; } \\
\text { 3. SW: } \\
\text { a. mean (SD) age }=51.5 \text { (16.9) years; female:male = } 35: 12 ; \\
\text { b. mean (SD) duration of CRPS I: } 2.9 \text { (3.1) months. } \\
\text { Inclusion criteria: } \\
\text { 1. CRPS I of } 1 \text { upper limb of less than } 1 \text { year duration; } \\
\text { 2. participants could complete treatment at } 1 \text { of } 2 \text { study sites; } \\
\text { 3. aged } 18 \text { years or older. } \\
\text { Exclusion criteria: } \\
\text { 1. impairment of contralateral extremity; } \\
\text { 2. relapse of CRPS I; } \\
\text { 3. pregnancy or lactation; } \\
\text { 4. prior sympathectomy of the affected extremity. }\end{array}$ \\
\hline Interventions & $\begin{array}{l}\text { All participants received medical treatment according to a fixed pre-established } \\
\text { protocol, consisting of free-radical scavengers (dimethylsulfoxide (DMSO) } 50 \% \\
\text { applied locally } 5 \text { times a day at the affected location or if DMSO-intolerant, } \\
\mathrm{N} \text {-acetylcysteine ( } 600 \mathrm{mg} 3 \text { times a day), peripheral vasodilators in the case of } \\
\text { primarily cold CRPS I (calcium entry blocker verapamil, sustained-release } 240 \\
\text { mg once per day or ketanserine } 20 \mathrm{mg} \text { twice per day eventually increased to } 40 \\
\text { mg or pentoxifylline } 400 \mathrm{mg} \text { twice per day) and treatment of trigger points. } \\
\text { Participants also received general information regarding CRPS I; including } \\
\text { advice to rest the extremity and not provoke pain. } \\
\text { PT }(\mathbf{N}=\mathbf{4 4 )}\end{array}$ \\
\hline
\end{tabular}




\begin{tabular}{|c|c|}
\hline & $\begin{array}{l}\text { Components of intervention: } \\
\text { 1. intensity and form of treatment adjusted to the needs of each individual } \\
\text { participant; } \\
\text { 2. pain management advice/counselling directed towards helping participants } \\
\text { gain control of the pain and optimise coping by offering insight, practical } \\
\text { advice, and support and/or by relaxation exercises; } \\
\text { 3. connective tissue massage, transcutaneous electric nerve stimulation } \\
\text { (TENS), exercises for reducing the pain (details not reported); } \\
\text { 4. instruction, training and practicing of skills by addressing compensatory } \\
\text { activities and body positioning (details not reported). } \\
\text { Dosage: } 30 \text { minutes per session (details for individual components not reported). } \\
\text { Frequency of administration: adjusted to the needs of each individual participant } \\
\text { (details not reported). } \\
\text { Provider: physical therapists. } \\
\text { OT ( } \mathbf{N}=\mathbf{4 4 )} \\
\text { Components of intervention: } \\
\text { 1. intensity and form of treatment adjusted to the needs of each individual } \\
\text { participant; } \\
\text { 2. splinting; } \\
\text { 3. desensitisation (tactile and proprioceptive) programme (details not reported); } \\
\text { 4. improving functional abilities of the arm/hand by executing various activities, } \\
\text { while moving as normally as possible; } \\
\text { 5. training to improve performance of activities of daily living (e.g. learning how } \\
\text { to perform activities differently, advice regarding assistive devices). } \\
\text { Dosage: } 30 \text { minutes per session (details for individual components not reported). } \\
\text { Frequency of administration: adjusted to the needs of each individual participant } \\
\text { (details not reported). } \\
\text { Provider: occupational therapists. } \\
\text { SW ( } \mathbf{N}=47 \text { ) } \\
\text { Components of intervention: } \\
\text { 1. participants were given attention in the form of listening and insight into the } \\
\text { Pocial problems accompanying CRPS I; } \\
\text { Provider: social workers. } \\
\text { (details not reported). }\end{array}$ \\
\hline Outcomes & $\begin{array}{l}\text { Outcomes, as reported across trial reports, variously assessed at baseline and at } \\
6 \text { weeks, } 3 \text { months, } 6 \text { months and } 12 \text { months post recruitment. The primary } \\
\text { endpoint was the difference in impairment level sum score between baseline and } \\
12 \text { months post recruitment. } \\
\text { 1. Self-rated pain intensity (present) using a VAS ( } 0 \text { to } 100 \text { scale, anchor } \\
\text { points not reported); } \\
\text { 2. self-rated pain intensity (resulting from effort with the affected extremity) } \\
\text { using a VAS ( } 0 \text { to } 100 \text { scale, anchor points not reported); } \\
\text { 3. self-rated pain intensity (least pain experienced in the preceding week) } \\
\text { using a VAS ( } 0 \text { to } 100 \text { scale, anchor points not reported); } \\
\text { 4. self-rated pain intensity (worst pain experienced in the preceding week) }\end{array}$ \\
\hline
\end{tabular}




\begin{tabular}{|c|c|}
\hline & 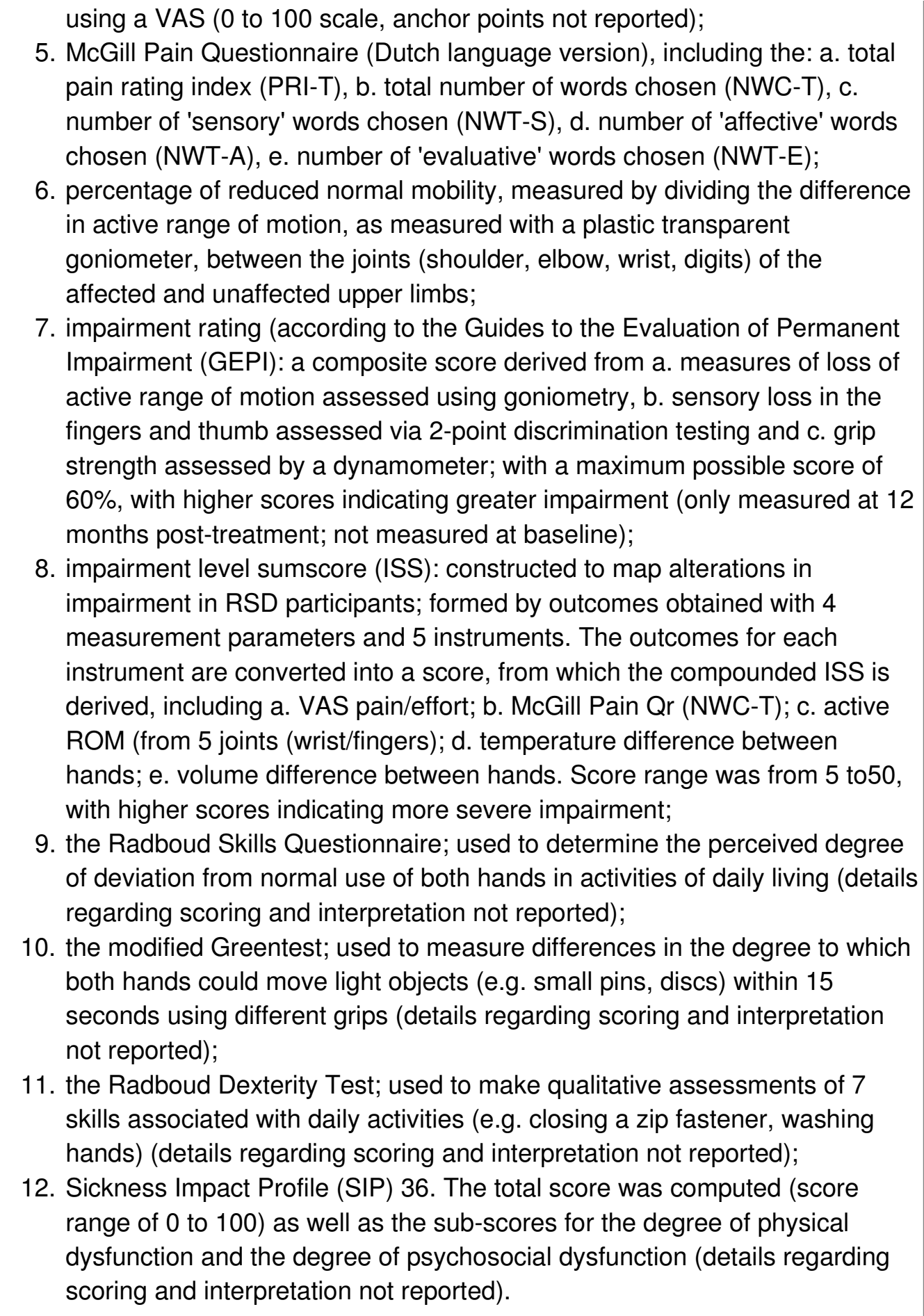 \\
\hline Notes & $\begin{array}{l}\text { Source of funding: research grant from the National Health Insurance Board } \\
\text { (Ziekenfondsraad), The Netherlands. } \\
\text { Statement regarding declarations of interest: not reported. }\end{array}$ \\
\hline
\end{tabular}

Risk of bias table

\begin{tabular}{||l|l|l||}
\hline \hline Bias & $\begin{array}{l}\text { Authors' } \\
\text { judgement }\end{array}$ & Support for judgement \\
\hline $\begin{array}{l}\text { Random sequence generation } \\
\text { (selection bias) }\end{array}$ & Low risk & $\begin{array}{l}\text { Quote: "Patients were randomly assigned to one of three } \\
\text { groups". } \\
\text { Quote: "Randomisation was restricted to blocks of six". }\end{array}$ \\
\hline
\end{tabular}




\begin{tabular}{|c|c|c|}
\hline & & $\begin{array}{l}\text { Quote: "Assigmnent to groups was performed according to } \\
\text { allocation lists established by the Department of Medical } \\
\text { Statistics of the University of Nijmegen". } \\
\text { Comment: the trial authors used an acceptable method to } \\
\text { generate the sequence allocation. }\end{array}$ \\
\hline $\begin{array}{l}\text { Allocation concealment (selection } \\
\text { bias) }\end{array}$ & Unclear risk & $\begin{array}{l}\text { Quote: "Assigmnent to groups was performed according to } \\
\text { allocation lists established by the Department of Medical } \\
\text { Statistics of the University of Nijmegen". } \\
\text { Comment: the trial authors did not adequately report the } \\
\text { method of concealment allocation. }\end{array}$ \\
\hline $\begin{array}{l}\text { Blinding of participants and } \\
\text { personnel (performance bias) }\end{array}$ & High risk & $\begin{array}{l}\text { Comment: given the nature of the intervention, participants } \\
\text { were not blinded to treatment and may have had different } \\
\text { expectations about the benefits of each intervention. }\end{array}$ \\
\hline $\begin{array}{l}\text { Blinding of outcome assessment } \\
\text { (detection bias) } \\
\text { Self-reported outcomes }\end{array}$ & High risk & $\begin{array}{l}\text { Comment: unblinded participants, who may have had } \\
\text { different expectations about the benefits of the intervention } \\
\text { they received, self-reported some outcomes (e.g. pain } \\
\text { intensity). }\end{array}$ \\
\hline $\begin{array}{l}\text { Blinding of outcome assessment } \\
\text { (detection bias) } \\
\text { Investigator-administered } \\
\text { outcomes }\end{array}$ & Unclear risk & $\begin{array}{l}\text { Comment: we do not know if outcome assessors were } \\
\text { blinded to treatment allocation when measuring percentage } \\
\text { loss of joint mobility, impairment ratings, impairment level } \\
\text { sumscore and disability-based measures. }\end{array}$ \\
\hline $\begin{array}{l}\text { Incomplete outcome data (attrition } \\
\text { bias) } \\
\text { Drop-out rate described and } \\
\text { acceptable }\end{array}$ & Unclear risk & $\begin{array}{l}\text { Quote: "After inclusion in the study, } 44 \text { patients were } \\
\text { assigned to PT, } 44 \text { patients to OT and } 47 \text { patients to CT. In } \\
\text { the course of the } 1 \text {-year study period, seven, four and four } \\
\text { patients abandoned the trial, respectively". } \\
\text { Comment: whilst the overall drop-out rate was acceptable } \\
\text { (11\%), there was an unequal drop-out rate between groups } \\
\text { (PT: } 16 \% \text {, OT: } 9 \% \text {, CT: } 9 \% \text { ) and the trial authors did not } \\
\text { report the reasons for dropping out. }\end{array}$ \\
\hline $\begin{array}{l}\text { Incomplete outcome data (attrition } \\
\text { bias) } \\
\text { Participants analysed in the group } \\
\text { to which they were allocated }\end{array}$ & Low risk & $\begin{array}{l}\text { Quote: "Two analyses were done: an intention-to-treat } \\
\text { analysis (ITT) and a per-protocol analysis (PP). In the ITT } \\
\text { analysis, outcomes of all the participants were used for the } \\
\text { group they were originally assigned to. In the PP analysis, } \\
\text { outcomes of protocol violators were ignored". } \\
\text { Quote: "Three patients from the PT group could not } \\
\text { complete the treatment protocol (so were protocol violators) } \\
\text { but had test continuity". } \\
\text { Comment: the trial authors presented limited data from both } \\
\text { ITT and per protocol analyses for selected outcomes. }\end{array}$ \\
\hline Selective reporting (reporting bias) & High risk & $\begin{array}{l}\text { Comment: the trial authors reported limited and incomplete } \\
\text { outcome data across } 4 \text { separate trial reports for } \\
\text { self-reported pain and disability outcomes and for } \\
\text { investigator-administered outcomes. } \\
\text { Comment: no numerical data presented for } 3 \text { out of the } 4 \\
\text { measures of self-rated pain intensity or percentage of } \\
\text { reduced normal mobility outcomes. } \\
\text { Comment: no numerical data reported for impairment rating. } \\
\text { Comment: limited numerical data presented for ISS. }\end{array}$ \\
\hline
\end{tabular}




\begin{tabular}{|l|l|l||}
\hline Sample size & $\begin{array}{l}\text { Comment: no numerical data presented for the Radboud } \\
\text { Skills Questionnaire, modified Greentest or Radboud } \\
\text { Dexterity Test. }\end{array}$ \\
\hline Duration of follow-up & Low risk & $\begin{array}{l}\text { Quote: "After inclusion in the study, 44 patients were } \\
\text { assigned to PT, 44 patients to OT and } 47 \text { patients to CT". } \\
\text { Comment: the small sample size may have introduced bias } \\
\text { in estimates of treatment effect. }\end{array}$ \\
\hline Other bias & $\begin{array}{l}\text { Quote: "Re-assessment was performed } 6 \text { weeks (t1), } 3 \\
\text { months (t2), } 6 \text { months (t3) and } 12 \text { months (t4) after inclusion } \\
\text { in the study". } \\
\text { Comment: the trial authors measured outcomes over a } \\
\text { clinically relevant length of time. }\end{array}$ \\
\hline High risk & $\begin{array}{l}\text { Quote: "If, during the period of the trial, the patient explicitly } \\
\text { indicated that he or she wanted to switch to another } \\
\text { adjuvant therapy, this was allowed. Using a coin, with heads } \\
\text { or tails it was decided which adjuvant therapy was next". } \\
\text { Quote: "Fourteen patients switched therapies: } 12 \text { from CT to } \\
\text { PT (nine patients) or OT (three patients) and two from OT to } \\
\text { PT". } \\
\text { Comment: violations of the random sequence generation } \\
\text { were permitted. } \\
\text { Quote: "Thus, with the inclusion of } 135 \text { patients, the power } \\
\text { to recognize significant differences was somewhat smaller: } \\
\text { the power to detect a significant treatment effect within each } \\
\text { group was 72\%, whereas differences between the 3 groups } \\
\text { could be established with a power of 79\%". } \\
\text { Comment: the trial was slightly underpowered, which may } \\
\text { have introduced bias in estimates of treatment effect and/or } \\
\text { contributed to a lack of precision regarding estimates of } \\
\text { treatment effect. }\end{array}$ \\
\hline \hline
\end{tabular}

\section{Schreuders 2014}

Methods

Participants
Design: parallel group, 2-arm, single-blind RCT (The Netherlands; dates not reported).

Setting: not reported.

Interventions: GMI programme plus conventional treatment or conventional treatment alone.

Sample size calculation: not reported.

Number of participants: 18 (experimental group $N=11$, control group $N=7$ ).

Type of noxious initiating event: not reported (upper limb).

Diagnostic criteria: Bruehl 1999 (CRPS I).

Baseline characteristics:

1. GMI programme (and included in the analysis $N=10$ ):

a. mean $(S D)$ age $=42.4$ (16.8) years; female: male $=8: 2$;

b. mean (SD) duration of CRPS I: 50.3 (53.7) months;

2. standard care (and included in the analysis $N=5$ ):

a. mean $(S D)$ age $=52.8$ (12.7) years; female: male $=4: 1$;

b. mean (SD) duration of CRPS I: 127.4 (87.5) months. 


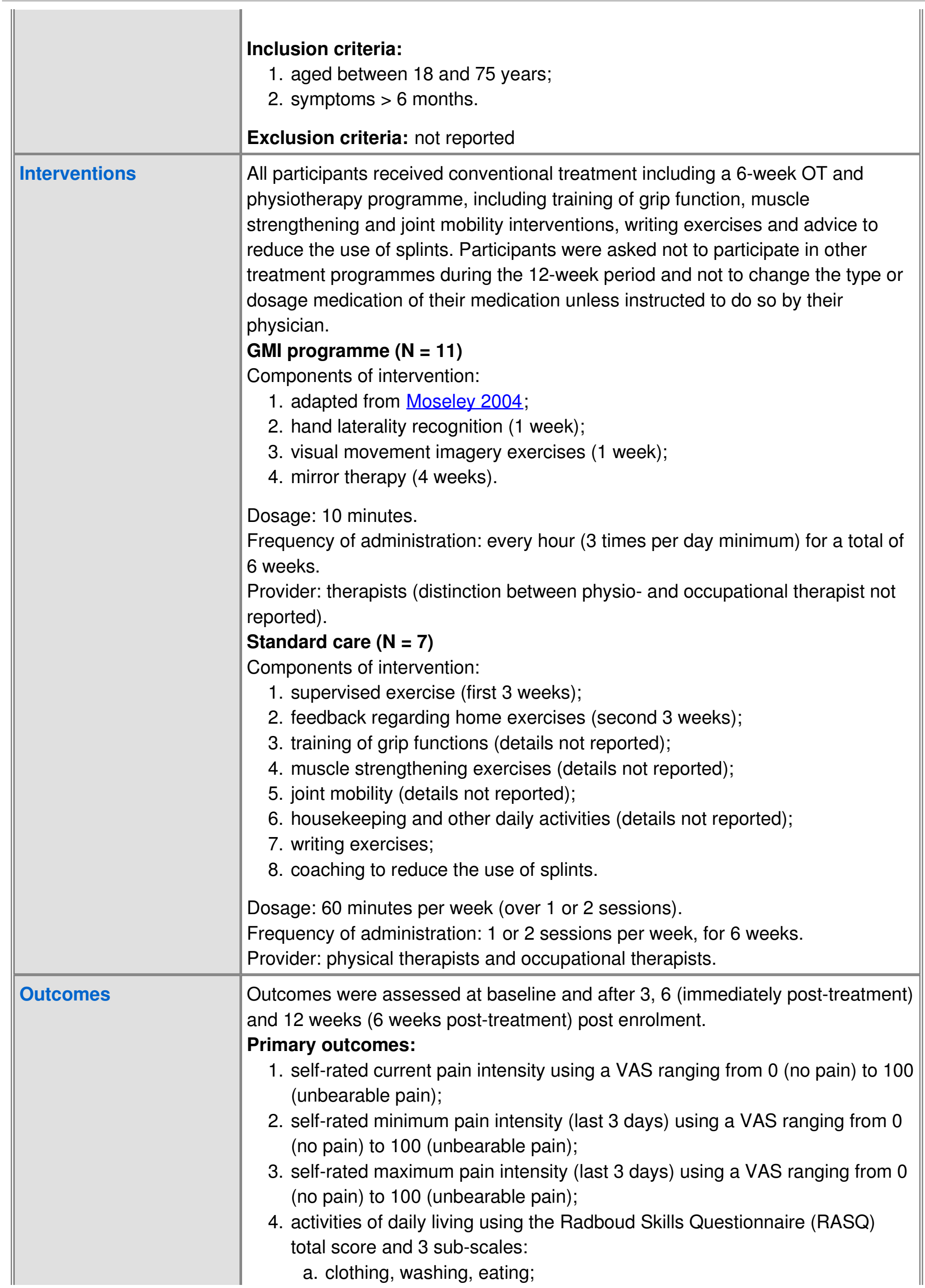




\begin{tabular}{||l||l||}
\multicolumn{1}{||}{} & \multicolumn{1}{c||}{$\begin{array}{c}\text { b. household activities; } \\
\text { c. recreation, social activities. } \\
\text { Secondary outcomes: fine hand coordination of both hands by using the Nine } \\
\text { Hole Peg Test (recorded in seconds). }\end{array}$} \\
\hline Notes & $\begin{array}{l}\text { Source of funding: ErasmusMC Mrace Project Zorg 2004-20, grant number } \\
\text { 2004-20. } \\
\text { Statement regarding declarations of interest: the trial authors declared no } \\
\text { conflicts of interest. }\end{array}$ \\
\hline
\end{tabular}

\section{Risk of bias table}

\begin{tabular}{|c|c|c|}
\hline Bias & $\begin{array}{l}\text { Authors' } \\
\text { judgement }\end{array}$ & Support for judgement \\
\hline $\begin{array}{l}\text { Random sequence generation } \\
\text { (selection bias) }\end{array}$ & Low risk & $\begin{array}{l}\text { Quote: "Based on a computerized random schedule..." } \\
\text { Comment: the trial authors used an acceptable method to } \\
\text { generate the sequence allocation. }\end{array}$ \\
\hline $\begin{array}{l}\text { Allocation concealment (selection } \\
\text { bias) }\end{array}$ & Low risk & $\begin{array}{l}\text { Quote: "Based on a computerized random schedule, a } \\
\text { researcher not involved in the execution of the trial, made a } \\
\text { sequence of numbered opaque envelopes. These } \\
\text { envelopes were prepared with equality being achieved after } \\
\text { every ten subjects (block size 10)". } \\
\text { Quote: "Envelopes were given in sequence of entry to the } \\
\text { patient and were opened by the patient". } \\
\text { Comment: the trial authors used an acceptable method to } \\
\text { conceal the allocation sequence. }\end{array}$ \\
\hline $\begin{array}{l}\text { Blinding of participants and } \\
\text { personnel (performance bias) }\end{array}$ & High risk & $\begin{array}{l}\text { Quote: "Patients were not blinded to the treatment as they } \\
\text { were aware of the treatment content". } \\
\text { Comment: given the nature of the intervention, participants } \\
\text { were not blinded to treatment and may have had different } \\
\text { expectations about the benefits of each intervention. }\end{array}$ \\
\hline $\begin{array}{l}\text { Blinding of outcome assessment } \\
\text { (detection bias) } \\
\text { Self-reported outcomes }\end{array}$ & High risk & $\begin{array}{l}\text { Comment: unblinded participants, who may have had } \\
\text { different expectations about the benefits of the intervention } \\
\text { they received, self-reported some outcomes (e.g. pain } \\
\text { intensity). }\end{array}$ \\
\hline $\begin{array}{l}\text { Blinding of outcome assessment } \\
\text { (detection bias) } \\
\text { Investigator-administered } \\
\text { outcomes }\end{array}$ & Low risk & $\begin{array}{l}\text { Quote: "The assessor was blinded for the allocation to the } \\
\text { experimental or control group". } \\
\text { Quote: "The measurements were performed by trained } \\
\text { blinded assessors". } \\
\text { Comment: the trial authors blinded outcome assessors to } \\
\text { participant group allocation }\end{array}$ \\
\hline $\begin{array}{l}\text { Incomplete outcome data (attrition } \\
\text { bias) } \\
\text { Drop-out rate described and } \\
\text { acceptable }\end{array}$ & High risk & $\begin{array}{l}\text { Comment: the trial authors did not adequately report } \\
\text { drop-out rate in the 'Results' section of the manuscript. } \\
\text { Comment: according to 'Figure } 2 \text { ' of the manuscript, } 1 \\
\text { participant was lost to follow-up and } 2 \text { discontinued the } \\
\text { intervention from the experimental group, } 1 \text { participant } \\
\text { withdrew after randomisation, } 1 \text { participant was lost to } \\
\text { follow-up and } 3 \text { discontinued the intervention from the }\end{array}$ \\
\hline
\end{tabular}




\begin{tabular}{|c|c|c|}
\hline & & $\begin{array}{l}\text { conventional treatment group, giving drop-out rates of } 27 \% \\
\text { and } 71 \% \text { respectively, and an overall drop-out rate of } 44 \% \text {. } \\
\text { Comment: the high drop-out rate may have introduced bias } \\
\text { in estimates of treatment effect. }\end{array}$ \\
\hline $\begin{array}{l}\text { Incomplete outcome data (attrition } \\
\text { bias) } \\
\text { Participants analysed in the group } \\
\text { to which they were allocated }\end{array}$ & High risk & $\begin{array}{l}\text { Comment: the trial authors reported analysis as ITT in } \\
\text { Figure } 2 \text { of the unpublished manuscript. } \\
\text { Quote: "Three patients (one in the experimental group, two } \\
\text { in the control group) could not be included in the analysis } \\
\text { due to insufficient compliance in filling out the VAS and } \\
\text { RASQ questionnaires or because of immediate withdrawal } \\
\text { from the control therapy because the participants only } \\
\text { wanted the graded MIP". } \\
\text { Comment: violation of the principle of ITT analysis may } \\
\text { have introduced bias in estimates of treatment effect. } \\
\text { Quote: "From seven of the remaining fifteen patients (five in } \\
\text { the experimental group and two in the control group) there } \\
\text { were missing end-tests" (i.e. at } 12 \text { weeks post enrolment/6 } \\
\text { weeks postintervention). } \\
\text { Quote: "Differences in changes in both groups over times } \\
\text { were tested using a generalized estimating equations (GEE) } \\
\text { approach. Under the assumption that missing data were } \\
\text { random and not due to group allocation or treatment effect, } \\
\text { this model estimates missing data values, thereby allowing } \\
\text { the use of data from all participants, irrespective of whether } \\
\text { they were measured at all time points". } \\
\text { Comment: use of GEE may have introduced bias in } \\
\text { estimates of treatment effect. }\end{array}$ \\
\hline Selective reporting (reporting bias) & High risk & $\begin{array}{l}\text { Comment: the trial authors reported outcome data } \\
\text { graphically for all self-reported pain outcomes; and did not } \\
\text { report raw data in numerical form with measures of } \\
\text { variation. The trial authors presented effect sizes with } \\
\text { measures of variation for the Radboud Skills Questionnaire } \\
\text { and Nine Hole Peg Test; and did not report numerical data } \\
\text { with measures of variation. }\end{array}$ \\
\hline Samp & High risk & $\begin{array}{l}\text { Quote: "For this trial eighteen patients were included". } \\
\text { Quote: "For this study only } 18 \text { patients were assessed for } \\
\text { eligibility and only } 15 \text { of them could be included in the } \\
\text { analysis. The number of patients in the study was therefore } \\
\text { too small to detect possible effects with the intended power } \\
\text { for which } 52 \text { patients were needed". } \\
\text { Comment: the small sample size may have introduced bias } \\
\text { in estimates of treatment effect. }\end{array}$ \\
\hline Duration of follow-up & Unclear risk & $\begin{array}{l}\text { Quote: "Outcome was assessed at baseline, after } 3,6 \text { and } \\
12 \text { [i.e. } 6 \text { weeks post-treatment] weeks". } \\
\text { Comment: the clinical relevance of a } 6 \text {-week follow-up of } \\
\text { outcomes is uncertain. }\end{array}$ \\
\hline
\end{tabular}




\begin{tabular}{|l|l|l||} 
Other bias & High risk & $\begin{array}{l}\text { Comment: baseline data for } 3 \text { participants excluded from } \\
\text { the analysis not reported. } \\
\text { Comment: likely highly significant baseline imbalance in } \\
\text { duration of symptoms between groups. }\end{array}$ \\
\hline
\end{tabular}

\section{Uher 2000}

\begin{tabular}{|c|c|}
\hline Methods & $\begin{array}{l}\text { Design: parallel group, 2-arm, RCT (Germany, dates not reported). } \\
\text { Setting: not reported. } \\
\text { Interventions: manual lymph drainage (MLD) plus exercise or exercise alone. } \\
\text { Sample size calculation: not reported. }\end{array}$ \\
\hline Participants & $\begin{array}{l}\text { Number of participants: } 40 \text { ( } 15 \text { in the manual lymph drainage group, } 25 \text { in the } \\
\text { exercise alone group). } \\
\text { Type of noxious initiating event: mixed (postfracture } n=27 \text {, post dislocation } n \\
=9 \text {, postsurgery } n=4 \text { ) (lower limb). } \\
\text { Diagnostic criteria: CRPS I (diagnostic criteria not reported). } \\
\text { Baseline characteristics: } \\
\text { Total sample: female:male } 31: 4 \text {. } \\
\text { 1. Group receiving manual lymph drainage plus exercise: } \\
\text { a. mean (SD) age = not reported; female:male = not reported; } \\
\quad \text { b. mean (SD) duration of CRPS I = not reported. } \\
\text { 2. Group receiving exercise: } \\
\quad \text { a. mean (SD) age = not reported; female:male = not reported; } \\
\text { b. mean (SD) duration of CRPS I = not reported. } \\
\text { Inclusion criteria: } \\
\text { 1. clinical, radiographic and scintigraphic signs of CRPS } 1 \text {; } \\
\text { 2. < } 6 \text { months post-trauma/surgery. } \\
\text { Exclusion criteria: } \\
\text { 1. venous insufficiency; } \\
\text { 2. recurrent thrombophlebitis; } \\
\text { 3. peripheral vascular disease; } \\
\text { 4. blood disorders; } \\
\text { 5. currently receiving physical treatment. }\end{array}$ \\
\hline Interventions & $\begin{array}{l}\text { Participants were given a brochure providing general advice (details not } \\
\text { reported), no analgesic or anti-inflammatory medication prescribed, participants } \\
\text { were asked to inform the clinician if they took analgesia or anti-inflammatory } \\
\text { medication for more than } 3 \text { days. } \\
\text { Manual lymph drainage plus exercise }(\mathbf{N}=\mathbf{1 5}) \\
\text { Components of intervention: } \\
\text { 1. manual lymph drainage (further details not reported); } \\
\text { 2. exercise (as below). } \\
\text { Dosage: } 30 \text { minutes } \\
\text { Frequency of administration: } 3 \text { times per week for } 6 \text { weeks (18 sessions) } \\
\text { Provider: physiotherapists } \\
\text { Exercise ( } \mathbf{N}=\mathbf{2 5} \text { ) } \\
\text { Components of intervention: } \\
\text { 1. goal to improve range of motion and reduce pain; }\end{array}$ \\
\hline
\end{tabular}




\begin{tabular}{|c|c|}
\hline & $\begin{array}{l}\text { 2. rhythmic stabilisation techniques of Klein Vogelbach and passive } \\
\text { movements as tolerated of the affected ankle. } \\
\text { Dosage: } 30 \text { minutes. } \\
\text { Frequency of administration: } 3 \text { times per week for } 6 \text { weeks (18 sessions). } \\
\text { Provider: physiotherapists. }\end{array}$ \\
\hline Outcomes & $\begin{array}{l}\text { Outcomes assessed at baseline and immediately on completion of the } \\
\text { intervention period ( } 6 \text { weeks post recruitment). The trial authors did not state any } \\
\text { primary outcome. } \\
\text { 1. Self-rated pain intensity measured using a } 6 \text {-point verbal rating scale ( } 0= \\
\text { no pain, } 5 \text { = maximum pain); } \\
\text { 2. range of motion (dorsiflexion and plantarflexion) at the talocrural joint } \\
\text { measured using a goniometer; } \\
\text { 3. temperature measured using a surface thermometer, between the malleoli, } \\
\text { with the value recorded as the difference between } 2 \text { sides; } \\
\text { 4. swelling measured as the difference in ankle circumference (in } \mathrm{cm}) \text {, at level } \\
\text { of malleoli, between } 2 \text { sides; } \\
\text { 5. radiological assessment (details not reported); } \\
\text { 6. scintigraphic assessment (details not reported). }\end{array}$ \\
\hline Notes & $\begin{array}{l}\text { Source of funding: not reported. } \\
\text { Statement regarding declarations of interest: not reported. }\end{array}$ \\
\hline
\end{tabular}

Risk of bias table

\begin{tabular}{||l|l|l||}
\hline \hline Bias & $\begin{array}{l}\text { Authors' } \\
\text { judgement }\end{array}$ & Support for judgement \\
\hline $\begin{array}{l}\text { Random sequence generation } \\
\text { (selection bias) }\end{array}$ & Unclear risk & $\begin{array}{l}\text { Comment: the trial authors did not report the method of } \\
\text { sequence generation. }\end{array}$ \\
\hline $\begin{array}{l}\text { Allocation concealment (selection } \\
\text { bias) }\end{array}$ & Low risk & $\begin{array}{l}\text { Quote: "Randomisation was done using the sealed } \\
\text { envelope method, by a doctor not involved in the study". } \\
\text { Comment: the trial authors used an acceptable method to } \\
\text { conceal the allocation sequence. }\end{array}$ \\
\hline $\begin{array}{l}\text { Blinding of participants and } \\
\text { personnel (performance bias) }\end{array}$ & High risk & $\begin{array}{l}\text { Comment: given the nature of the intervention, participants } \\
\text { were not blinded to treatment and may have had different } \\
\text { expectations about the benefits of each intervention. }\end{array}$ \\
\hline $\begin{array}{l}\text { Blinding of outcome assessment } \\
\text { (detection bias) } \\
\text { Self-reported outcomes }\end{array}$ & High risk & $\begin{array}{l}\text { Comment: unblinded participants, who may have had } \\
\text { different expectations about the benefits of the intervention } \\
\text { they received, self-reported some outcomes (e.g. pain } \\
\text { intensity). }\end{array}$ \\
\hline $\begin{array}{l}\text { Blinding of outcome assessment } \\
\text { (detection bias) } \\
\text { Investigator-administered } \\
\text { outcomes }\end{array}$ & Low risk & $\begin{array}{l}\text { Quote: "Tested by a doctor who did not know group } \\
\text { assignment". } \\
\text { Comment: the outcome assessor was blinded to treatment } \\
\text { allocation. }\end{array}$ \\
\hline $\begin{array}{l}\text { Incomplete outcome data (attrition } \\
\text { bias) } \\
\text { Drop-out rate described and } \\
\text { acceptable }\end{array}$ & Low risk & $\begin{array}{l}\text { Comment: an overall, and balanced, drop-out rate of 12\% is } \\
\text { unlikely to have biased the results. }\end{array}$ \\
\hline
\end{tabular}


Physiotherapy for pain and disability in adults with complex regional pain syndrome.26-Feb-2016

\begin{tabular}{|c|c|c|}
\hline $\begin{array}{l}\text { Incomplete outcome data (attrition } \\
\text { bias) } \\
\text { Participants analysed in the group } \\
\text { to which they were allocated }\end{array}$ & High risk & $\begin{array}{l}\text { Comment: the trial authors excluded } 3 \text { participants ( } 2 \text { from } \\
\text { the MLD group and } 1 \text { from the exercise group) were } \\
\text { excluded from the analysis because they did not regularly } \\
\text { attend for therapy, in violation of the ITT principle. Two } \\
\text { participants from the exercise group were excluded after } \\
\text { randomisation secondary to wrongful inclusion despite } \\
\text { fulfilment of exclusion criteria }\end{array}$ \\
\hline Selective reporting (reporting bias) & High risk & $\begin{array}{l}\text { Comment: the trial authors did not report outcome data for } \\
\text { pain intensity. }\end{array}$ \\
\hline Sample size & High risk & $\begin{array}{l}\text { Comment: the small sample size may have introduced bias } \\
\text { in estimates of treatment effect. }\end{array}$ \\
\hline Duration of follow-up & High risk & $\begin{array}{l}\text { Quote: "Assessment after six weeks of therapy". } \\
\text { Comment: outcomes were re-measured on immediate } \\
\text { completion of the intervention period only and were not } \\
\text { measured over a clinically relevant length of time. }\end{array}$ \\
\hline Other bias & Low risk & Comment: we did not identify any other sources of bias. \\
\hline
\end{tabular}

\section{Footnotes}

Abbreviations: CRPS I: complex regional pain syndrome type 1; CT: control therapy; GMI: graded motor imagery; IFC: interferential current; ITT: intention to treat; MIP: motor imagery programme; MLD: manual lymphatic drainage; NRS: numerical rating scale; OT: occupational therapy; PT: physiotherapy/physical therapy; RCT: randomised controlled trial; RSD: reflex sympathetic dystrophy; SD: standard deviation; SGB: stellate ganglion block; SPSS: Statistical Package for the Social Sciences; SW: social work; TDT: tactile discrimination training; TENS: transcutaneous electrical nerve stimulation; TPD: two-point discrimination; US: ultrasound; VAS: visual analogue scale.

\section{Characteristics of excluded studies}

\section{Bolel 2006}

Reason for exclusion This study only evaluated the outcome measure of 'sympathetic skin response' and fell outside the inclusion criteria of this review.

\section{Fialka 1992}

Reason for exclusion

Not a RCT.

\section{Fialka 1996}

\begin{tabular}{|l|l} 
Reason for exclusion & Autogenic training does not fall within the scope of practice of physiotherapy.
\end{tabular}

\section{Field 1993}

Reason for exclusion

Not a RCT.

\section{Gromo 1974}

Reason for exclusion

Not a RCT. 
Physiotherapy for pain and disability in adults with complex regional pain syndrome.26-Feb-2016 Jasmina 2012

\begin{tabular}{|l|l|}
\hline Reason for exclusion & Not a RCT.
\end{tabular}

Karabegović 2009

\begin{tabular}{|l|l|}
\hline Reason for exclusion & Not a RCT.
\end{tabular}

Kocić 2010

Reason for exclusion The study authors only evaluated 'infrared thermovision' as the only outcome measure and fell outside the inclusion criteria of this review.

Perrigot 1982

\begin{tabular}{|l|l|}
\hline Reason for exclusion & Not a RCT. \\
\hline
\end{tabular}

Toth 2014

\begin{tabular}{|l|l|}
\hline Reason for exclusion & $\begin{array}{l}\text { The trial included participants }(\mathrm{N}=54) \text { with mixed aetiologies but only } 2 \\
\text { participants with complex regional pain syndrome (CRPS) with } 1 \text { randomised to } \\
\text { each trial arm. We could not make any meaningful comparison. }\end{array}$ \\
\hline
\end{tabular}

Tulgar 1991

\begin{tabular}{|l|l|}
\hline Reason for exclusion & Not a RCT.
\end{tabular}

Wu 1999

\begin{tabular}{|l|l|l}
\hline Reason for exclusion & Qigong does not fall within the scope of practice of physiotherapy.
\end{tabular}

\section{Zyluk 1994}

\begin{tabular}{|l|l|}
\hline Reason for exclusion & Not a RCT.
\end{tabular}

\section{Footnotes}

Abbreviations: RCT: randomised controlled trial.

Characteristics of studies awaiting classification

ISRCTN39729827

\begin{tabular}{||l|l||}
\hline Methods & Unavailable. \\
\hline Participants & Unavailable. \\
\hline Interventions & Unavailable. \\
\hline Outcomes & Unavailable. \\
\hline Notes & We are awaiting submission for publication. \\
\hline \hline
\end{tabular}


Physiotherapy for pain and disability in adults with complex regional pain syndrome.26-Feb-2016

\section{Mete-Topcuoglu 2010}

\begin{tabular}{||l|l||}
\hline Methods & Not yet assessed. \\
\hline Participants & Not yet assessed. \\
\hline Interventions & Not yet assessed. \\
\hline Outcomes & Not yet assessed. \\
\hline Notes & This is currently only available as a conference abstract. \\
\hline
\end{tabular}

NCT00625976

\begin{tabular}{||l|l||}
\hline Methods & Unavailable. \\
\hline Participants & Unavailable. \\
\hline Interventions & Unavailable. \\
\hline Outcomes & Unavailable. \\
\hline Notes & We were unable to contact the study authors. \\
\hline
\end{tabular}

Footnotes

\section{Characteristics of ongoing studies}

\section{Barnhoorn 2012}

\begin{tabular}{|c|c|}
\hline Study name & $\begin{array}{l}\text { The effectiveness and cost evaluation of pain exposure physical therapy and } \\
\text { conventional therapy in patients with complex regional pain syndrome type } 1 \text {. } \\
\text { Rationale and design of randomized controlled trial. }\end{array}$ \\
\hline Methods & Parallel-group, 2-arm randomised controlled trial (RCT) (The Netherlands) \\
\hline Participants & $\begin{array}{l}\text { Inclusion criteria: } \\
\text { 1. diagnosis of CRPS I; of upper or lower extremity; and of between } 3 \text { and } 24 \\
\text { months duration; } \\
\text { 2. age } 18 \text { to } 80 \text { years. } \\
\text { Exclusion criteria: } \\
\text { 1. alternative diagnoses that may explain the pain syndrome; } \\
\text { 2. impairments of the contra-lateral extremity; } \\
\text { 3. relapse of CRPS I; } \\
\text { 4. prior sympathectomy of the affected extremity; } \\
\text { 5. pregnancy; lactation. }\end{array}$ \\
\hline Interventions & $\begin{array}{l}\text { Experimental group: 'pain exposure physical therapy', consisting of a } \\
\text { progressive-loading exercise programme, de-sensitising massage and } \\
\text { management of pain-avoidance behaviour. } \\
\text { Conventional group: conventional treatment according to Dutch guidelines; } \\
\text { comprising pharmacological and physical therapy exercise interventions. }\end{array}$ \\
\hline
\end{tabular}




\begin{tabular}{|c|c|}
\hline Outcomes & $\begin{array}{l}\text { Primary outcome measures: } \\
\text { 1. impairment level SumScore (ISS) (restricted version). } \\
\text { Secondary outcome measures: } \\
\text { 1. Disability of Arm, Shoulder and Hand questionnaire; } \\
\text { 2. Lower Limb Tasks Questionnaire; } \\
\text { 3. Fear-Avoidance Beliefs Questionnaire; } \\
\text { 4. SF-36; } \\
\text { 5. muscle force measurements, as measured by a hand-held dynamometer; } \\
\text { 6. } 10 \text { metre walking test; } \\
\text { 7. Timed Up and Go test; } \\
\text { 8. compliance and adherence, as measured by interview, questionnaires (the } \\
\text { Seven Days Physical Activity Recall, International Physical Activity } \\
\text { Questionnaire, Pain Catastrophising Scale, Pain Disability Index) and } \\
\text { accelerometry. }\end{array}$ \\
\hline Starting date & January 2009 \\
\hline Contact information & Jan Paul Frölke MD, PhD; J.Frolke@chir.umcn.nl \\
\hline Notes & http://clinicaltrials.gov/show/NCT00817128 \\
\hline
\end{tabular}

ISRCTN48768534

\begin{tabular}{|c|c|}
\hline Study name & $\begin{array}{l}\text { Transcutaneous electrical nerve stimulation (TENS) for patients with upper limb } \\
\text { complex regional pain syndrome: a feasibility study }\end{array}$ \\
\hline Methods & Parallel-group, 2-arm RCT (UK) \\
\hline Participants & $\begin{array}{l}\text { Inclusion criteria: } \\
\text { 1. } 18 \text { years of age or older; } \\
\text { 2. have had CRPS for } \geq 6 \text { months; } \\
\text { 3. can speak English to a good standard; } \\
\text { 4. no neurological conditions; } \\
\text { 5. capable of making an informed decision to take part or not. } \\
\text { Exclusion criteria: } \\
\text { 1. individuals with a pacemaker, heart disease or epilepsy; } \\
\text { 2. individuals who are pregnant; } \\
\text { 3. abnormal skin sensation in the area below the electrodes. }\end{array}$ \\
\hline Interventions & $\begin{array}{l}\text { Intervention group: transcutaneous electrical nerve stimulation } \\
\text { Placebo group: sham transcutaneous electrical nerve stimulation }\end{array}$ \\
\hline Outcomes & $\begin{array}{l}\text { Primary outcome measures: } \\
\text { 1. pain intensity using a VAS; } \\
\text { 2. medication use; } \\
\text { 3. Disability of Arm, Shoulder and Hand questionnaire; } \\
\text { 4. Hand Laterality Recognition Task; } \\
\text { 5. Bath CRPS Body Perception Disturbances questionnaire. } \\
\text { Secondary outcome measures: } \\
\text { 1. placebo blinding credibility; } \\
\text { 2. adverse reactions; } \\
\text { 3. qualitative interviews. }\end{array}$ \\
\hline
\end{tabular}


Physiotherapy for pain and disability in adults with complex regional pain syndrome.26-Feb-2016

\begin{tabular}{||l|l||}
\hline Starting date & November 2013 \\
\hline Contact information & Dr Cormac Ryan PhD, c.ryan@tees.ac.uk \\
\hline Notes & http://controlled-trials.com/ISRCTN48768534 \\
\hline
\end{tabular}

\section{NCT01915329}

\begin{tabular}{|c|c|}
\hline Study name & $\begin{array}{l}\text { Effects of repetitive electrical sensory stimulation (RSS) as intervention in } \\
\text { complex regional pain syndrome type I (CRPS) }\end{array}$ \\
\hline Methods & Parallel-group, 2-arm RCT (Germany) \\
\hline Participants & $\begin{array}{l}\text { Inclusion criteria: } \\
\text { 1. age } 18 \text { to } 75 \text { years; } \\
\text { 2. diagnosed with CRPS. } \\
\text { Exclusion criteria: } \\
\text { 1. intolerable hyperalgesia; } \\
\text { 2. lesions at the finger tips; } \\
\text { 3. high grade digit contracture; } \\
\text { 4. central neurological disorders; } \\
\text { 5. psychiatric disorders; }\end{array}$ \\
\hline Interventions & $\begin{array}{l}\text { Experimental group: repetitive electrical sensory stimulation } \\
\text { Sham comparator: sham repetitive electrical sensory stimulation }\end{array}$ \\
\hline Outcomes & $\begin{array}{l}\text { Primary outcome measures: } \\
\text { 1. static tactile 2-point discrimination threshold. } \\
\text { Secondary outcome measures: } \\
\text { 1. pain intensity using an 11-point NRS; } \\
\text { 2. somatosensory evoked potentials. }\end{array}$ \\
\hline Starting date & February 2012 \\
\hline Contact information & Christoph Maier MD, PhD; christopp.maier@rub.de \\
\hline Notes & http://clinicaltrials.gov/show/NCT01915329 \\
\hline
\end{tabular}

\section{NCT01944150}

\begin{tabular}{|c|c|}
\hline Study name & $\begin{array}{l}\text { Association of transcutaneous electrical nerve stimulation and hypnosis } \\
\text { (HYPTENS) }\end{array}$ \\
\hline Methods & Parallel-group, 2-arm RCT (France) \\
\hline Participants & $\begin{array}{l}\text { Inclusion criteria: } \\
\text { 1. age } 18 \text { to } 80 \text { years suffering from chronic non-cancer pain of mixed } \\
\text { aetiologies (either nociceptive or neuropathic) including osteoarthritic limb } \\
\text { arthralgia, chronic lumbo radiculalgia, chronic back pain, cervical } \\
\text { radiculopathy, postherpetic neuralgia, postsurgical peripheral neuropathic } \\
\text { pain, post-trauma neuropathic pain, CRPS I or II, tendinopathy; } \\
\text { 2. uninjured skin; } \\
\text { 3. ability to comply with requirements of the trial. } \\
\text { Exclusion criteria: }\end{array}$ \\
\hline
\end{tabular}




\begin{tabular}{|c|c|}
\hline & $\begin{array}{l}\text { 1. participants with fibromyalgia; } \\
\text { 2. participants receiving relaxation therapy, acupuncture or } \\
\text { cognitive/behavioural therapies; } \\
\text { 3. participants with cognitive disorders, unaided hearing loss, a major hearing } \\
\text { impairment, a pace maker, allodynia or complete anaesthesia of the painful } \\
\text { territory or already been treated by TENS or hypnosis, or both; } \\
\text { 4. pregnancy. }\end{array}$ \\
\hline Interventions & $\begin{array}{l}\text { Experimental group: transcutaneous electrical nerve stimulation and hypnosis. } \\
\text { Active comparator group: transcutaneous electrical nerve stimulation. }\end{array}$ \\
\hline Outcomes & $\begin{array}{l}\text { Primary outcome measures: } \\
\text { 1. pain intensity using a VAS (0 to } 100 \mathrm{~mm}) \text {. } \\
\text { Secondary outcome measures: } \\
\text { 1. analgesic consumption; } \\
\text { 2. SF36; } \\
\text { 3. patient global impression of change (PGIC). }\end{array}$ \\
\hline Starting date & September 2013 \\
\hline Contact information & Louise Geoffroy, ide.emdsp@sat.aphp.fr \\
\hline Notes & http://clinicaltrials.gov/show/NCT01944150 \\
\hline
\end{tabular}

\section{UKCRN ID 12602}

\begin{tabular}{|c|c|}
\hline Study name & $\begin{array}{l}\text { Development of an Electrical Sensory Discrimination Therapies device (ESDT) } \\
\text { for the relief of chronic pain in Complex Regional Pain Syndrome. A proof of } \\
\text { concept study. }\end{array}$ \\
\hline Methods & Parallel-group, 2-arm RCT (UK) \\
\hline Participants & $\begin{array}{l}\text { Inclusion criteria: } \\
\text { 1. diagnosed with CRPS type I. } \\
\text { Exclusion criteria: } \\
\text { 1. diagnosed with any other neurological, psychopathologic, motor disorder or } \\
\text { major nerve damage (CRPS II); } \\
\text { 2. the presence of any other limb pathology or pain on the affected CRPS limb; } \\
\text { 3. cutaneous damage on the area to be stimulated; } \\
\text { 4. receiving intensive CRPS-specific MDT rehabilitation in an inpatient setting } \\
\text { during the time course of the study or within the previous month; } \\
\text { 5. unable to understand written or verbal English and give informed consent. }\end{array}$ \\
\hline Interventions & $\begin{array}{l}\text { Intervention group: ESDT and de-sensitisation tasks. } \\
\text { Control group: routine care, including de-sensitisation tasks. }\end{array}$ \\
\hline Outcomes & $\begin{array}{l}\text { 1. Short form McGill Pain Questionnaire; } \\
\text { 2. Brief Pain Inventory questionnaire; } \\
\text { 3. Disability of Arm, Shoulder and Hand questionnaire (upper limb CRPS); } \\
\text { 4. Lower Extremity Functional Scale questionnaire (lower limb CRPS); } \\
\text { 5. Hospital Anxiety and Depression Scale; } \\
\text { 6. adverse events. }\end{array}$ \\
\hline
\end{tabular}


Physiotherapy for pain and disability in adults with complex regional pain syndrome.26-Feb-2016

\begin{tabular}{||l|l||}
\hline Starting date & 2012 \\
\hline Contact information & Prof CS McCabe PhD, Candy; Mccabe@uwe.ac.uk \\
\hline Notes & \\
\hline
\end{tabular}

Footnotes

Abbreviations: ESDT: electrical sensory discrimination therapies; PGIC: patient global impression of change; RCT: randomised controlled trial; RSS: repetitive electrical sensory discrimination; TENS: transcutaneous electrical nerve stimulation; UK: United Kingdom; VAS: visual analogue scale.

\section{Summary of findings tables}

\section{Additional tables}

\section{References to studies}

\section{Included studies}

\section{Askin 2014}

Askin A, Savas S, Koyuncuoglu HR, Baloglu HH, Inci MF. Low dose high frequency ultrasound therapy for stellate ganglion blockade in complex regional pain syndrome type I: a randomised placebo controlled trial. International Journal of Clinical and Experimental Medicine 2014;7(12):5603-11.

\section{Aydemir 2006}

Aydemir K, Taşkaynatan MA, Yaziicioğlu K, Özgül A. The effects of stellate ganglion block with Lidocaine and ultrasound in complex regional pain syndrome: a randomized, double blind, placebo controlled study [Kompleks bölgesel ağri sendromunda Lydokane ultrason ile yapilan stellat ganglyon blokajinin etkinliği: çift kör randomize plasebo kontrollü çalişma]. Journal of Rheumatology and Medical Rehabilitation 2006;17(3):193-200.

\section{Cacchio 2009a}

Cacchio A, De Blasis E, De Blasis V, Santilli V, Spacca G. Mirror therapy in complex regional pain syndrome type 1 of the upper limb in stroke patients. Neurorehabilitation and Neural Repair 2009;23(8):792-9.

\section{Cacchio 2009b}

Cacchio A, De Blasis E, Necozione S, di Orio F, Santilli V. Mirror therapy for chronic complex regional pain syndrome type 1 and stroke. New England Journal of Medicine 2009;361(6):634-6.

\section{Dimitrijevic 2014}

Dimitrijevic IM, Lazovic MP, Kocic MN, Dimitrijevic LR, Mancic DD, Stankovic AM. Effects of low-level laser therapy and interferential current therapy in the treatment of complex regional pain syndrome. Turkiye Fiziksel Tip ve Rehabilitasyon Dergisi [Turkish Journal of Physical Medicine and Rehabilitation] 2014;60(2):98-105.

\section{Duman 2009}

Duman I, Ozdemir A, Kenan Tan A, Dincer K. The efficacy of manual lymphatic drainage therapy in the management of limb edema secondary to reflex sympathetic dystrophy. Rheumatology International 2009;29(7):759-63. 


\section{Durmus 2004}

Durmus A, Cakmak A, Disci R, Muslumanoglu L. The efficiency of electromagnetic field treatment in Complex Regional Pain Syndrome Type 1. Disability and Rehabilitation 2004;26(9):537-45.

\section{Hazneci 2005}

Hazneci B, Tan AK, Özdem T, Dinçer K, Kalyon TA. The effects of transcutaneous electroneurostimulation and ultrasound in the treatment of reflex sympathetic dystrophy syndrome [Refleks sempatik distrofi sendromu tedavisinde transkutanöz elektronörostimülasyon ve ultrasonun etkileri]. Turkiye Fiziksel Tip ve Rehabilitasyon Dergisi [Turkish Journal of Physical Medicine and Rehabilitation] 2005;51(3):83-9.

\section{Jeon 2014}

Jeon B, Cho S, Lee J-H. Application of virtual body swapping to patients with complex regional pain syndrome: a pilot study. Cyberpsychology, Behavior and Social Networking 2014;17(6):366-70.

\section{Li 2012}

Li N, Tian F, Wang C, Yu P, Zhou X, Wen Q, et al. Therapeutic effect of acupuncture and massage for shoulder hand syndrome in hemiplegia patients: a clinical two-centre randomized controlled trial. Journal of Traditional Chinese Medicine 2012;32(3):343-9.

\section{Moseley 2004}

Moseley GL. Graded motor imagery is effective for long-standing complex regional pain syndrome: a randomised controlled trial. Pain 2004;108(1-2):192-8.

\section{Moseley 2005}

Moseley GL. Is successful rehabilitation of complex regional pain syndrome due to sustained attention to the affected limb? A randomised clinical trial. Pain 2005;114(1-2):54-61.

\section{Moseley 2006}

Moseley GL. Graded motor imager for pathologic pain: a randomised controlled trial. Neurology 2006;67(12):2129-34.

\section{Moseley 2009}

Moseley GL, Wiech K. The effect of tactile discrimination training is enhanced when patients watch the reflected image of their unaffected limb during training. Pain 2009;144(3):314-9.

\section{Mucha 1992}

Mucha C. Effects of $\mathrm{CO}_{2}$-baths in the combined concept of the early functional therapy in cases of algodystrophy [Einflub von $\mathrm{CO}_{2}$-Badern im fruhfunktionellen Therapiekonzept der Algodystrophie]. Physikalische Medizin und Kur Medizin 1992;2:173-8.

\section{Oerlemans 1999}

Oerlemans HM, Goris RJA, de Boo T, Oostendorp RAB. Do physical therapy and occupational therapy reduce the impairment percentage in reflex sympathetic dystrophy? American Journal of Physical Medicine and Rehabilitation 1999;78(6):533-9.

* Oerlemans HM, Oostendorp RAB, de Boo T, Goris RJA. Pain and reduced mobility in complex regional pain syndrome I: outcome of a prospective randomised controlled trial of adjuvant physical therapy versus occupational therapy. Pain 1999;83(1):77-83. 
Oerlemans HM, Oostendorp RAB, de Boo T, van der Laan L, Severens JL, Goris RJA. Adjuvant physical therapy versus occupational therapy in patients with reflex sympathetic dystrophy/complex regional pain syndrome type I. Archives of Physical Medicine and Rehabilitation 2000;81(1):49-56.

Severens JL, Oerlemans HM, Weegels JPG, van 't Hof MA, Oostendorp RAB, Goris RJA. Cost-effectiveness analysis of adjuvant physical therapy or occupational therapy for patients with reflex sympathetic dystrophy. Archives of Physical Medicine and Rehabilitation 1999;80(9):1038-43.

\section{Schreuders 2014}

Unpublished data only

Schreuders TAR, Tichelaar R, Huygen FJPM, Hitters MWMGC, Stam HJ, Selles RW. Effects of a graded motor imagery program in patients with longstanding complex regional pain syndrome I (as supplied 29 May 2014). Data on file.

\section{Uher 2000}

Uher EM, Vacariu G, Schneider B, Fialka V. Comparison of manual lymph drainage with physical therapy in the complex regional pain syndrome I. A comparative randomised controlled therapy study [Manuelle Lymphdrainage im Vergleich zur Physiotherapie bei Complex Regional Pain Syndrom Typ I. Randomisierte kontrollierte Therapievergleichsstudie]. Wiener Klinische Wochenschrift 2000;112(3):133-7.

\section{Excluded studies}

\section{Bolel 2006}

Bolel K, Hizmetli S, Akyüz A. Sympathetic skin responses in reflex sympathetic dystrophy. Rheumatology International 2006;26(9):788-91.

\section{Fialka 1992}

Fialka VV, Wickenhauser J, Engel A, Schneider B. Sympathetic reflex dystrophy. Effectiveness of physical therapy treatment of Sudek's syndrome [Sympathische Reflexdystrophie. Wirksamkeit physiotherapeutischer Behandlungsmaßnahmen des Sudeksyndrom]. Fortschritte der Medzin 1992;110(9):146-8.

\section{Fialka 1996}

Fialka V, Korpan M, Saradeth T, Paternostro-Slugo T, Hexel O, Frischenschlager O, et al. Autogenic training for reflex sympathetic dystrophy: a pilot study. Complementary Therapies in Medicine 1996;4(2):103-5.

\section{Field 1993}

Field J, Atkins RM. Effect of guanethidine on the natural history of post-traumatic algodystrophy. Annals of the Rheumatic Diseases 1993;52(6):467-9.

\section{Gromo 1974}

Gromo G, Ceroni P, Sosso A. Iontophoresis with a diffuser enzyme (Thiomucase) associated with diadynamic currents in the physiokinetictherapy management of post-traumatic algodystrophic edematous syndromes of the limbs [La ionoforesi con enzima diffusore (Thiomucase) associata alle correnti diadinamiche nel trattamento fisiokinesiterapico delle sindromi edematose algodistrofiche post-traumatiche degli arti]. Minerva Medica 1974;65(77):4015-25.

\section{Jasmina 2012}

Jasmina T, Genchev G, Savova A, Dantchev N, Petrova G. Cost-effectiveness and activities of daily living in patients with complex regional pain syndrome type I. International Journal of Pharmaceutical Sciences Review and Research 2012;17(1):16-21. 


\section{Karabegović 2009}

Karabegović A, Kapidžić-Duraković S, Ljuca F. Laser therapy of painful shoulder and shoulder-hand syndrome in treatment of patients after the stroke. Bosnian Journal of Basic Medical Sciences 2009;9(1):59-65.

\section{Kocić 2010}

Kocić M, Lazović M, Dimitrijević I, Mančić D, Stanković A. Evaluation of low level laser and interferential current in the therapy of complex regional pain syndrome by infrared thermographic camera [Procena terapijskog efekta lasera male snage i interferenthih struja kod bolesnika sa kompleksnim regionalnim bolnim sindromom primenom infracrvene termovizijske kamere]. Vojnosanitetski Pregled 2010;67(9):755-60.

\section{Perrigot 1982}

Perrigot M, Bergego C, Hocini A, Pierrot-Deseilligny E. Algodystrophic syndrome in hemiplegia. Clinical and therapeutic study [Le syndrome algodystrophique chez l'hémiplégique. Étude clinique et thérapeutique]. Annales de Médecine Interne 1982;133(8):544-8.

\section{Toth 2014}

Toth C, Brady S, Gagnon F, Wigglesworth K. A randomized, single-blind, controlled, parallel assignment study of exercise versus education as adjuvant in the treatment of peripheral neuropathic pain. Clinical Journal of Pain 2014;30(2):111-8.

\section{Tulgar 1991}

Tulgar M, McGlone F, Bowsher D, Miles JB. Comparative effectiveness of different stimulation modes in relieving pain. Part I. A pilot study. Pain 1991;47(2):151-5.

\section{Wu 1999}

Wu W, Bandilla E, Ciccone DS, Yang J, Cheng SC, Carner N, et al. Effects of Qigong on late-stage complex regional pain syndrome. Alternative Therapies in Health and Medicine 1999;5(1):45-54.

\section{Zyluk 1994}

Zyluk A. Clinical estimation of late treatment results in posttraumatic Sudeck's Dystrophy treated with mannitol, calcitonin and exercise therapy [Kliniczna ocena odległych wynikow leczenia pourazowej dystrofii sudecka za pomocą mannitolu, kalcytoniny I terapii ruchowej]. Annales Academiae Medicae Stetinensis 1994;40:133-44.

\section{Studies awaiting classification ISRCTN39729827}

[ISRCTN: 39729827]

ISRCTN39729827. Investigation of the effectiveness of BioFeedBack therapy on Complex Regional Pain Syndrome (CRPS) of the upper limb. http://www.isrctn.com/ISRCTN39729827 Accessed 08 February 2014.

\section{Mete-Topcuoglu 2010}

Mete-Topcuoglu A, Ordu-Gokkaya NK, Karakus D, Ucan H. The effect of upper extremity aerobic exercise in complex regional pain syndrome type I: randomized controlled study in subacute stroke. European Journal of Pain Supplements 2010;4(S1):133.

\section{NCT00625976}


[ClinicalTrials.gov: NCT00625976]

NCT00625976. Graded Exposure (GEXP) in Vivo Versus Physiotherapy in Complex Regional Pain Syndrome Type I (CRPS-I). https://clinicaltrials.gov/ct2/show/NCT00625976 Accessed 08 February 2014.

\section{Ongoing studies}

\section{Barnhoorn 2012}

Barnhoorn KJ, Oostendorp RAB, van Dongen RTM, Klomp FP, Samwel H, van der Wilt GJ, et al. The effectiveness and cost evaluation of pain exposure physical therapy and conventional therapy in patients with complex regional pain syndrome type 1 . Rationale and design of a randomized controlled trial. BMC Musculoskeletal Disorders 2012;13:58.

\section{ISRCTN48768534}

[ISRCTN: 48768534]

ISRCTN48768534. Transcutaneous electrical nerve stimulation (TENS) for patients with upper limb complex regional pain syndrome: a feasibility study.

http://www.isrctn.com/ISRCTN48768534?q=\&filters=conditionCategory:Nervous\%20System\%20Diseases, recr uitmentCountry:United\%20Kingdom\&sort=\&offset=43\&totalResults=310\&page=1\&pageSize=100\&searchType =basic-search Accessed 08 February 2014.

\section{NCT01915329}

[ClinicalTrials.gov: NCT01915329]

NCT01915329. Effects of Repetitive Electric Sensory Stimulation (RSS) as Intervention in Complex-regional-pain-syndrome Type I (CRPS). https://clinicaltrials.gov/ct2/show/NCT01915329 Accessed 08 February 2014.

\section{NCT01944150}

[ClinicalTrials.gov: NCT01944150]

NCT01944150. Association of Transcutaneous Electrical Nerve Stimulation and Hypnosis (HYPTENS). https://clinicaltrials.gov/ct2/show/NCT01944150 Accessed 08 February 2014.

\section{UKCRN ID 12602}

[Other: UKCRN ID 12602]

UKCRN ID 12602. Development of an Electrical Sensory Discrimination Therapies device (ESDT) for the relief of chronic pain in Complex Regional Pain Syndrome. A proof of concept study.

http://public.ukcrn.org.uk/search/StudyDetail.aspx?StudyID=12602 Accessed 08 February 2014.

\section{Other references}

\section{Additional references}

\section{Anderson 2002}

Anderson DM. Mosby's Medical, Nursing \& Allied Health Dictionary. 6th edition. St. Louis: Mosby, 2002.

\section{Atamaz 2012}

Atamaz FC, Durmaz B, Baydar M, Demircioglu OY, Iyiyapici A, Kuran B, et al. Comparison of the efficacy of transcutaneous electrical nerve stimulation, interferential currents, and shortwave diathermy in knee osteoarthritis: a double-blind, randomized, controlled, multicenter study. Archives of Physical Medicine and 
Rehabilitation 2012;93(5):748-56.

\section{Atkins 2010}

Atkins RM. Principles of complex regional pain syndrome. In: Buscholz RW, Heckman JD, Court-Brown CM, Tornetta P, editor(s). Rockwood and Green's Fractures in Adults. 7th edition. Vol. 1. Philadelphia: Lippincott Williams \& Wilkins, 2010:602-14.

\section{Balshem 2011}

Balshem H, Helfand M, Schünemann HJ, Oxman AD, Kunz R, Brozek J et al. GRADE guidelines: 3. Rating the quality of evidence. Journal of Clinical Epidemiology 2011;64(4):401-6.

\section{Beerthuizen 2009}

Beerthuizen A, van 't Spijker A, Huygen FJPM, Klein J, de Wit R. Is there an association between psychological factors and the Complex Regional Pain Syndrome type 1 (CRPS1) in adults? A systematic review. Pain 2009;145(1-2):52-9.

\section{Beerthuizen 2012}

Beerthuizen A, Stronks DL, Van't Spijker A, Yaksh A, Hanraets BM, Klein J, et al. Demographic and medical parameters in the development of complex regional pain syndrome type 1 (CRPS1): prospective study on 596 patients with a fracture. Pain 2012;153(6):1187-92.

\section{Bialosky 2009}

Bialosky JE, Bishop MD, Price DD, Robinson ME, George SZ. The mechanisms of manual therapy in the treatment of musculoskeletal pain: a comprehensive model. Manual Therapy 2009;14(5):531-8.

\section{Bowering 2013}

Bowering KJ, O'Connell NE, Tabor A, Catley MJ, Leake HB, Moseley GL, et al. The effects of graded motor imagery and its components on chronic pain: a systematic review and meta-analysis. The Journal of Pain 2013;14(1):3-13.

\section{Bruehl 1999}

Bruehl S, Harden RN, Galer BS, Saltz S, Bertram M, Backonja M, et al. External validation of IASP diagnostic criteria for Complex Regional Pain Syndrome and proposed research diagnostic criteria. International Association for the Study of Pain. Pain 1999;81(1-2):147-54.

\section{Bruehl 2010}

Bruehl S. An update on the pathophysiology of complex regional pain syndrome. Anesthesiology 2010;113(3):713-25.

\section{Bruehl 2015}

Bruehl S. Complex regional pain syndrome. BMJ 2015;350:h2730. [DOI: 10.1136/bmj.h.2730]

\section{Busse 2015}

Busse JW, Bartlett SJ, Dougados M, Johnston BC, Guyatt GH, Kirwan JR, et al. Optimal Strategies for Reporting Pain in Clinical Trials and Systematic Reviews: Recommendations from an OMERACT 12 Workshop. Journal of Rheumatology 2015 May 15 [Epub ahead of print]. [DOI: 10.3899/jrheum.141440]

\section{Button 2013}

Button KS, loanidis JPA, Mokrysz C, Nosek BA, Flint J, Robinson ESJ, et al. Power failure: why small sample 
size undermines the reliability of neuroscience. Nature Reviews Neuroscience 2013;14(5):365-76.

\section{Coderre 2011}

Coderre TJ. Complex regional pain syndrome: what's in a name? The Journal of Pain 2011;12(1):2-12.

\section{Cossins 2013}

Cossins L, Okell RW, Cameron H, Simpson B, Poole HM, Goebel A. Treatment of complex regional pain in adults: a systematic review of randomized controlled trials published from June 2000 to February 2012. European Journal of Pain 2013;17(2):158-73.

\section{Daly 2009}

Daly AE, Bialocerkowski AE. Does evidence support physiotherapy management of adult Complex Regional Pain Syndrome Type One? A systematic review. European Journal of Pain 2009;13(4):339-53.

\section{de Mos 2009}

de Mos M, Huygen FJ, van der Hoeven-Borgman M, Dieleman JP, Ch Stricker BH, Sturkenboom MCJM. Outcome of the complex regional pain syndrome. Clinical Journal of Pain 2009;25(7):590-7.

\section{de Rooij 2009}

de Rooij AM, de Mos M, Sturkenboom MC, Marinus J, van den Maagdenberg AM, van Hilten JJ. Familial occurrence of complex regional pain syndrome. European Journal of Pain 2009;13(2):171-7.

\section{Dechartres 2013}

Dechartres A, Trinquart L, Boutron I, Ravaud P. Influence of trial sample size on treatment effect estimates: meta-epidemiological study. BMJ 2013;346:f2304.

\section{Dworkin 2008}

Dworkin RH, Turk DC, Wyrwich KW, Beaton D, Cleeland CS, Farrar JT, et al. Interpreting the clinical importance of treatment outcomes in chronic pain clinical trials: IMMPACT recommendations. The Journal of Pain 2008;9(2):105-21.

\section{Dworkin 2009}

Dworkin RH, Turk DC, McDermott MP, Peirce-Sandner S, Burke LB, Cowan P, et al. Interpreting the clinical importance of group differences in chronic pain clinical trials: IMMPACT recommendations. Pain 2009;146(3):238-44.

\section{Dworkin 2010}

Dworkin RH, Turk DC, Peirce-Sandner S, Baron R, Bellamy N, Burke LB, et al. Research design considerations for confirmatory chronic pain clinical trials: IMMPACT recommendations. Pain 2010;149(2):177-93.

\section{Galer 2000}

Galer BS, Henderson J, Perander J, Jensen MP. Course of symptoms and quality of life measurement in Complex Regional Pain Syndrome: a pilot survey. Journal of Pain and Symptom Management 2000;20(4):286-92.

\section{Geertzen 1998}

Geertzen JHB, Dijkstra PU, van Sonderen ELP, Groothoff JW, ten Duis HJ, Eisma WH. Relationship between impairments, disability and handicap in reflex sympathetic dystrophy patients: a long-term follow-up study. 
Clinical Rehabilitation 1998;12(5):402-12.

\section{Goats 1994}

Goats GC. Massage - the scientific basis of an ancient art: Part 2. physiological and therapeutic effects. British Journal of Sports Medicine 1994;28(3):153-6.

\section{Goebel 2011}

Goebel A. Complex regional pain syndrome in adults. Rheumatology (Oxford, England) 2011;50(10):1739-50.

\section{Goebel 2012}

Goebel A, Barker CH, Turner-Stokes L, Cossins L, Okell R, Atkins RM, et al. Complex Regional Pain Syndrome in Adults: UK Guidelines for Diagnosis, Referral and Management in Primary and Secondary Care. London: Royal College of Physicians, 2012.

\section{Guyatt 2011a}

Guyatt G, Oxman AD, Akl EA, Kunz R, Vist G, Brozek J, et al. GRADE guidelines: 1. Introduction - GRADE evidence profiles and summary of findings table. Clinical Journal of Clinical Epidemiology 2011a;64(4):383-94.

\section{Guyatt 2011b}

Guyatt GH, Oxman AD, Vist G, Kunz R, Brozek J, Alonso-Coello P, et al. GRADE guidelines: 4. Rating the quality of evidence--study limitations (risk of bias). Journal of Clinical Epidemiology 2011;64(4):407-15.

\section{Harden 2005}

Harden RN, Bruehl SP. Diagnostic criteria: the statistical derivation of the four criterion factors. In: Wilson P, Stanton-Hicks M, Harden RN, editor(s). CRPS: Current Diagnosis and Therapy. Progress in Pain Research and Management. Vol. 32. Seattle: IASP Press, 2005:45-58.

\section{Harden 2007}

Harden RN, Bruehl S, Stanton-Hicks M, Wilson PR. Proposed new diagnostic criteria for complex regional pain syndrome. Pain Medicine 2007;8(4):326-31.

\section{Harden 2010}

Harden RN, Bruehl S, Perez RSGM, Birklein F, Marinus J, Maihofner C, et al. Validation of proposed diagnostic criteria (the "Budapest Criteria") for complex regional pain syndrome. Pain 2010;150(2):268-74.

\section{Harden 2013}

Harden RN, Oaklander AL, Burton AW, Perez RSGM, Richardson K, Swan M, et al. Complex regional pain syndrome: practical diagnostic and treatment guidelines, 4th edition. Pain Medicine 2013;14(2):180-229.

\section{Higgins 2011a}

Higgins JPT, Altman DG, Sterne JAC. Chapter 8: Assessing risk of bias in included studies. In: Higgins JPT, Green S (editors). Cochrane Handbook for Systematic Reviews of Interventions Version 5.1.0 [updated March 2011]. The Cochrane Collaboration, 2011. Available from www.cochrane-handbook.org.

\section{Higgins 2011b}

Higgins JPT, Deeks JJ, Altman DG. Chapter 16: Special topics in statistics. In: Higgins JPT, Green S (editors). Cochrane Handbook for Systematic Reviews of Interventions Version 5.1.0 [updated March 2011]. The Cochrane Collaboration, 2011. Available from www.cochrane-handbook.org. 


\section{Kemler 2000}

Kemler MA, de Vet HC. Health-related quality of life in chronic refractory reflex sympathetic dystrophy (complex regional pain syndrome type I). Journal of Pain and Symptom Management 2000;20(1):68-76.

\section{Kisner 2002}

Kisner C, Colby LA. Therapeutic Exercise: Foundations and Techniques. 4th edition. Philadelphia: F.A. Davis Company, 2002.

\section{Kozin 1992}

Kozin F. Reflex sympathetic dystrophy syndrome: a review. Clinical and Experimental Rheumatology 1992;10(4):401-9.

\section{Lohnberg 2013}

Lohnberg JA, Altmaier EM. A review of psychosocial factors in complex regional pain syndrome. Journal of Clinical Psychology in Medical Settings 2013;20(2):247-54.

\section{Louw 2011}

Louw A, Diener I, Butler DS, Puentedura EJ. The effect of neuroscience education on pain, disability, anxiety, and stress in chronic musculoskeletal pain. Archives of Physical Medicine and Rehabilitation 2011;92(12):2041-56.

\section{Marinus 2011}

Marinus J, Moseley GL, Birklein F, Baron R, Maihöfner C, Kingery WS, et al. Clinical features and pathophysiology of complex regional pain syndrome. Lancet Neurology 2011;10(7):637-48.

\section{Melendez-Torres 2015}

Melendez-Torres GJ, Bonell C, Thomas J. Emergent approaches to the meta-analysis of multiple heterogeneous complex interventions. BMC Medical Research Methodology 2015;15:47. [DOI: $10.1186 / \mathrm{s} 12874-015-0040-z]$

\section{Merskey 1994}

Merskey H, Bogduk N. Classification of Chronic Pain: Descriptions of Chronic Pain Syndromes and Definitions of Pain Terms. 2nd edition. Seattle: IASP Press, 1994.

\section{Moore 2008}

Moore RA, Barden J, Derry S, McQuay HJ. Managing potential publication bias. In: McQuay HJ, Kalso E, Moore RA, editor(s). Systematic Reviews in Pain Research: Methodology Refined. Seattle: IASP Press, 2008:15-23.

\section{Moore 2010}

Moore RA, Eccleston C, Derry S, Wiffen P, Bell RF, Straube S, et al. "Evidence" in chronic pain--establishing best practice in the reporting of systematic reviews. Pain 2010;150(3):386-9.

\section{Moore 2012}

Moore RA, Derry S, Aldington D, Cole P, Wiffen PJ. Amitriptyline for neuropathic pain and fibromyalgia in adults. Cochrane Database of Systematic Reviews 2012, Issue 12. Art. No.: CD008242. DOI:

10.1002/14651858.CD008242.pub2. 


\section{Moore 2013}

Moore A, Derry S, Eccleston C, Kalso E. Expect analgesic failure; pursue analgesic success. BMJ 2013;346:f2690.

\section{Moore 2014a}

Moore RA, Derry S, Simon LS, Emery P. Nonsteroidal anti-inflammatory drugs, gastroprotection, and benefit-risk. Pain Practice 2014;14(4):378-95.

\section{Moore 2014b}

Moore RA, Cai N, Skljarevski V, Tölle TR. Duloxetine use in chronic painful conditions--individual patient data responder analysis. European Journal of Pain 2014;18(1):67-75.

\section{Moseley 2012}

Moseley GL, Flor H. Targeting cortical representations in the treatment of chronic pain: a review. Neurorehabilitation and Neural Repair 2012;26(6):646-52.

\section{Möhler 2015}

Möhler R, Köpke S, Meyer G. Criteria for Reporting the Development and Evaluation of Complex Interventions in healthcare: revised guideline (CReDECI 2). Trials 2015;16:204.

\section{Nijs 2012}

Nijs J, Kosek E, Van Oosterwijck J, Meeus M. Dysfunctional endogenous analgesia during exercise in patients with chronic pain: to exercise or not to exercise? Pain Physician 2012;15(3 Suppl):ES205-13.

\section{Nüesch 2010}

Nüesch E, Trelle S, Reichenbach S, Rutjes AWS, Tschannen B, Altman DG, et al. Small study effects in meta-analyses of osteoarthritis trials: Meta-epidemiological study. BMJ 2010;341:c3515.

\section{O'Connell 2013}

O'Connell NE, Wand BM, McAuley J, Marston L, Moseley GL. Interventions for treating pain and disability in adults with complex regional pain syndrome- an overview of systematic reviews. Cochrane Database of Systematic Reviews 2013, Issue 4. Art. No.: CD009416. DOI: 10.1002/14651858.CD009416.pub2.

\section{Parkitny 2013}

Parkitny L, McAuley JH, Di Pietro F, Stanton TR, O'Connell NE, Marinus J, et al. Inflammation in complex regional pain syndrome: a systematic review and meta-analysis. Neurology 2013;80(1):106-17.

\section{Perez 2010}

Perez RS, Zollinger PE, Dijkstra PU, Thomassen-Hilgersom IL, Zuurmond WW, Rosenbrand KCL, et al. Evidence based guidelines for complex regional pain syndrome type 1. BMC Neurology 2010;10:20.

\section{Plumbe 2013}

Plumbe L, Peters S, Bennett S, Vicenzino B, Coppieters MW. Mirror therapy, graded motor imagery and virtual illusion for the management of chronic pain [Protocol]. Cochrane Database of Systematic Reviews 2013, Issue 1. Art. No.: CD010329. DOI: 10.1002/14651858.CD010329.

\section{Reinders 2002}

Reinders MF, Geertzen JHB, Dijkstra PU. Complex regional pain syndrome type I: use of the International 
Association for the Study of Pain diagnostic criteria defined in 1994. Clinical Journal of Pain 2002;18(4):207-15.

\section{RevMan 2014}

Review Manager [Computer program]. Version 5.3. Copenhagen: The Nordic Cochrane Centre; The Cochrane Collaboration, 2014.

\section{Robertson 2006}

Robertson V, Ward A, Low J, Reed A. Electrotherapy Explained. Principles and Practice. 4th edition. London: Butterworth-Heinemann, 2006.

\section{Sandroni 2003}

Sandroni P, Benrud-Larson LM, McClelland RL, Low PA. Complex regional pain syndrome type I: incidence and prevalence in Olmsted county, a population-based study. Pain 2003;103(1-2):199-207.

\section{Sharma 2009}

Sharma A, Agarwal S, Broatch J, Raja SN. A web-based cross-sectional epidemiological survey of complex regional pain syndrome. Regional Anesthesia and Pain Medicine 2009;34(2):110-5.

\section{Shipton 2009}

Shipton EA. Complex regional pain syndrome - Mechanisms, diagnosis, and management. Current Anaesthesia \& Critical Care 2009;20(5-6):209-14.

\section{Smith 2005}

Smith TO. How effective is physiotherapy in the treatment of complex regional pain syndrome type I? A review of the literature. Musculoskeletal Care 2005;3(4):181-200.

\section{Smith 2015}

Smith SM, Hunsinger M, McKeown A, Parkhurst M, Allen R, Kopko S, et al. Quality of pain intensity assessment reporting: ACTTION systematic review and recommendations. The Journal of Pain 2015;16(4):299-305.

\section{Stanton-Hicks 2002}

Stanton-Hicks MD, Burton AW, Bruehl SP, Carr DB, Harden RN, Hassenbusch SJ, et al. An updated interdisciplinary clinical pathway for CRPS: report of an expert panel. Pain Practice 2002;2(1):1-16.

\section{Steinbrocker 1948}

Steinbrocker O, Spitzer N, Friedman $\mathrm{HH}$. The shoulder-hand syndrome in reflex dystrophy of the upper extremity. Annals of Internal Medicine 1948;29(1):22-52.

\section{Todorova 2013}

Todorova J, Dantchev N, Petrova G. Complex regional pain syndrome acceptance and the alternative denominations in the medical literature. Medical Principles and Practice 2013;22(3):295-300.

\section{Turk 2008a}

Turk DC, Dworkin RH, McDermott MP, Bellamy N, Burke LB, Chandler JM, et al. Analyzing multiple endpoints in clinical trials of pain treatments: IMMPACT recommendations. Initiative on Methods, Measurement, and Pain Assessment in Clinical Trials. Pain 2008;139(3):485-93. 


\section{Turk 2008b}

Turk DC, Dworkin RH, Revicki D, Harding G, Burke LB, Cella D, et al. Identifying important outcome domains for chronic pain clinical trials: an IMMPACT survey of people with pain. Pain 2008;137(2):276-85.

\section{van Rijn 2011}

van Rijn MA, Marinus J, Putter H, Bosselaar SRJ, Moseley GL, van Hilten JJ. Spreading of complex regional pain syndrome: not a random process. Journal of Neural Transmission 2011;118(9):1301-9.

\section{Vaneker 2006}

Vaneker M, Wilder-Smith OH, Schrombges P, Oerlemans HM. Impairments as measured by ISS do not greatly change between one and eight years after CRPS 1 diagnosis. European Journal of Pain 2006;10(7):639-44.

\section{Veldman 1993}

Veldman PH, Reynen HM, Arntz IE, Goris RJ. Signs and symptoms in reflex sympathetic dystrophy: prospective study of 829 patients. Lancet 1993;342(8878):1012-6.

\section{Zyluk 1998}

Zyluk A. The natural history of post-traumatic reflex sympathetic dystrophy. Journal of Hand Surgery (Edinburgh, Scotland) 1998;23(1):20-3.

\section{Other published versions of this review}

\section{Smart 2013}

Smart KM, Wand BW, O'Connell NE. Physiotherapy for pain and disability in adults with complex regional pain syndrome (CRPS) types I and II [Protocol]. Cochrane Database of Systematic Reviews 2013, Issue 11. Art. No.: CD010853. DOI: 10.1002/14651858.CD010853.

\section{Data and analyses}

\section{Graded motor imagery versus usual care}

\begin{tabular}{||l|l|l|l|l||}
\hline Outcome or Subgroup & Studies & $\begin{array}{l}\text { Participa } \\
\text { nts }\end{array}$ & Statistical Method & Effect Estimate \\
\hline \hline $\begin{array}{l}1.1 \text { Pain intensity } \\
\text { (post-treatment) }\end{array}$ & 2 & 49 & $\begin{array}{l}\text { Mean Difference (IV, Random, } \\
95 \% \text { CI) }\end{array}$ & $-14.45[-23.02,-5.87]$ \\
\hline \hline $\begin{array}{l}1.2 \text { Function (0 to 11 patient } \\
\text { specific functional scale) } \\
\text { (post-treatment) }\end{array}$ & 2 & 49 & $\begin{array}{l}\text { Mean Difference (IV, Random, } \\
95 \% \text { Cl) }\end{array}$ & $1.87[1.03,2.71]$ \\
\hline \hline
\end{tabular}

\section{Figures}

\section{Figure 1}




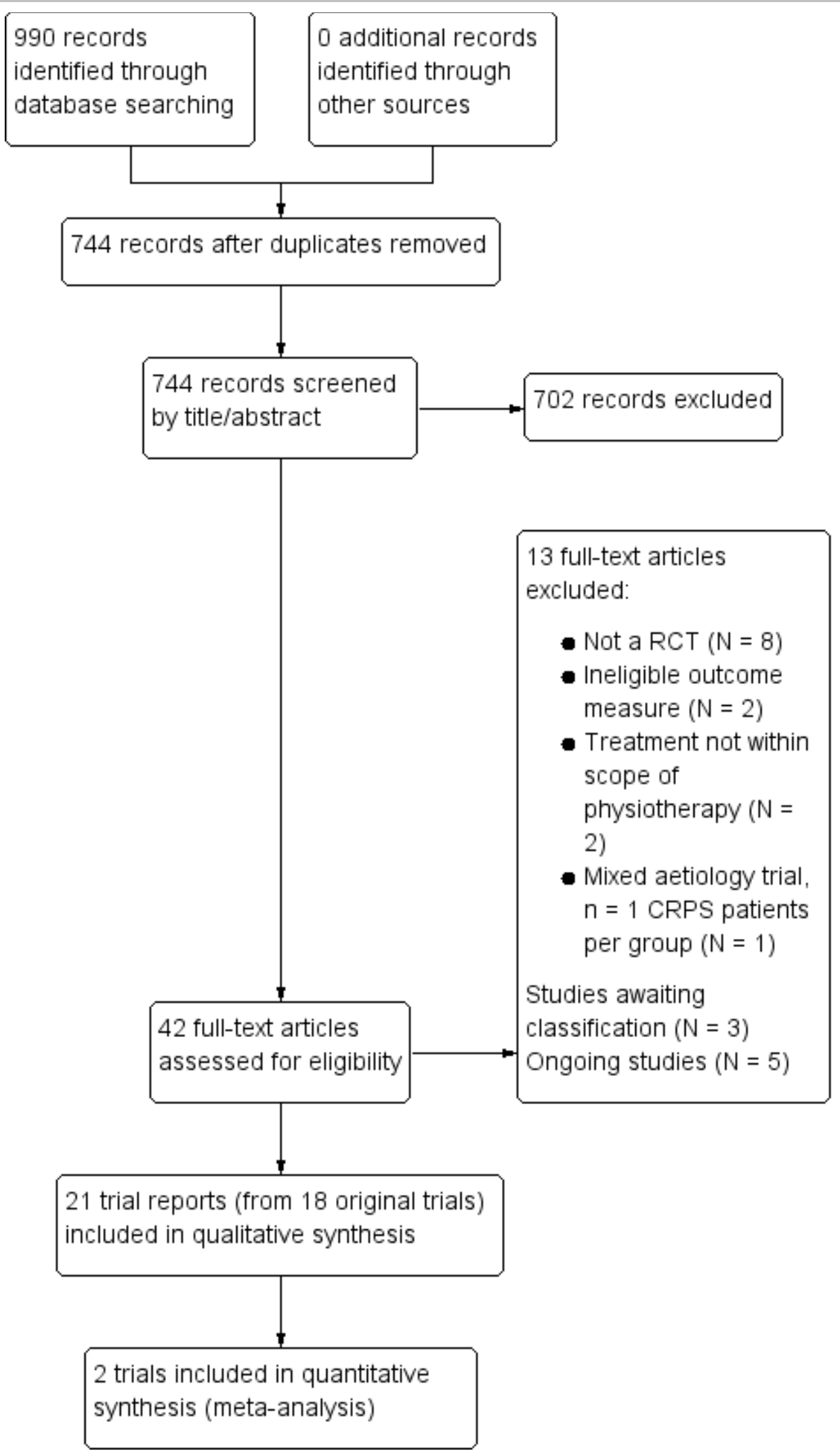

Study flow diagram. 


\section{Figure 2}

Random sequence generation (selection bias)
Allocation concealment (selection bias)
Blinding of participants and personnel (performance bias)
Blinding of outcome assessment (detection bias): Self-reported outcomes
Blinding of outcome assessment (detection bias): Investigator-administered outcomes
Incomplete outcome data (attrition bias): Drop-out rate described and acceptable
Incomplete outcome data (attrition bias): Participants analysed in the group to which they were allocated
Selective reporting (reporting bias)
Sample size
Dunclear risk of bias
OLw risk of bias

'Risk of bias' graph: review authors' judgements about each 'Risk of bias' item presented as percentages across all included trials.

\section{Figure 3}

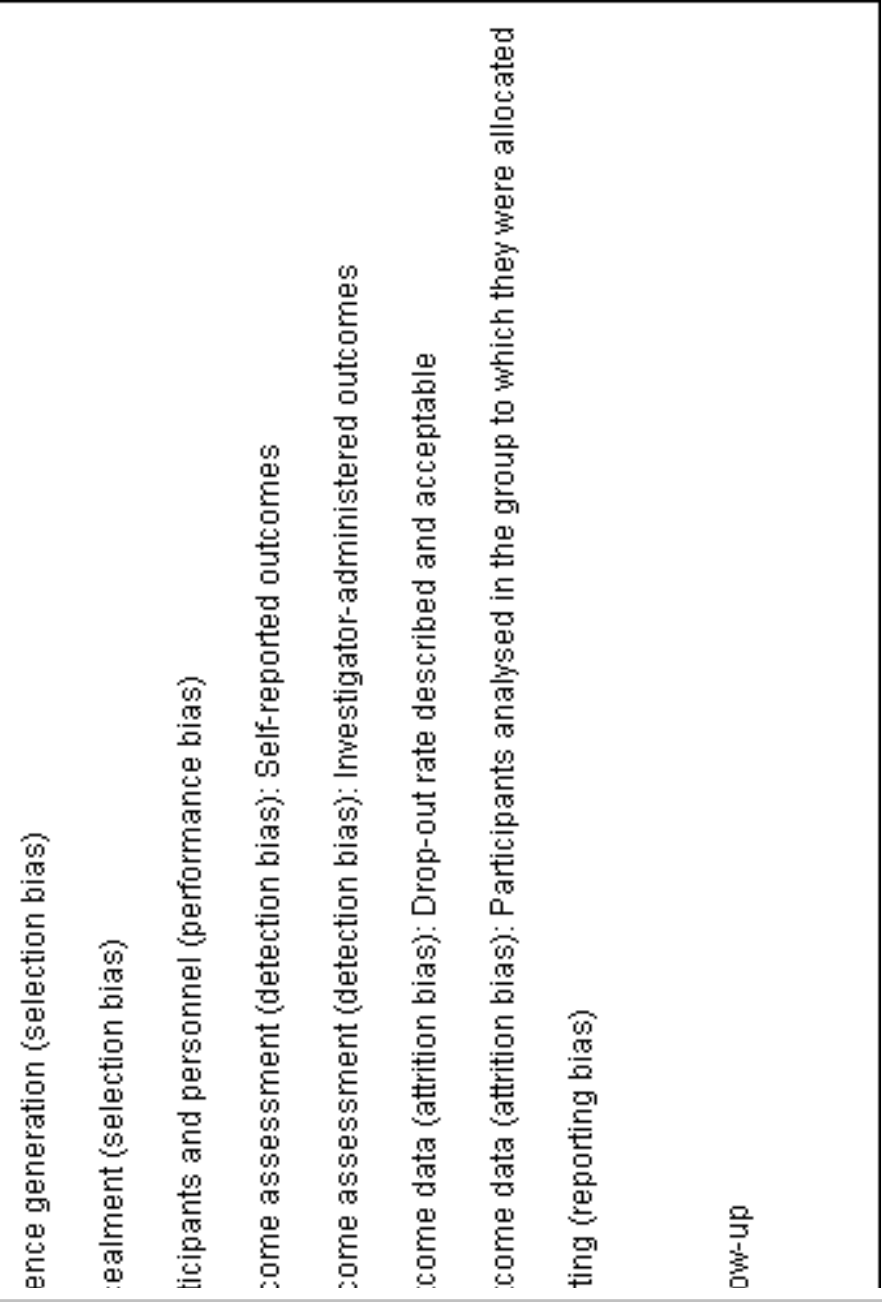


Physiotherapy for pain and disability in adults with complex regional pain syndrome.26-Feb-2016

\begin{tabular}{|c|c|c|c|c|c|c|c|c|c|c|c|}
\hline & 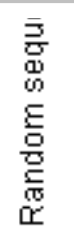 & 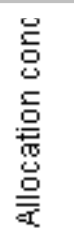 & 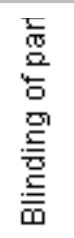 & $\begin{array}{l}\bar{\Xi} \\
\text { 言 } \\
\text { 吾 } \\
\text { 言 } \\
\text { 言 }\end{array}$ & 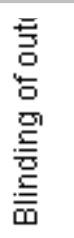 & 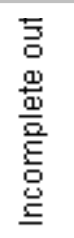 & 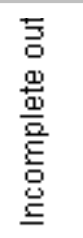 & 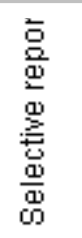 & 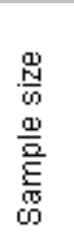 & 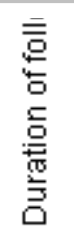 & 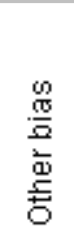 \\
\hline Askin 2014 & $\Theta$ & $\odot$ & $\odot$ & $\odot$ & $\odot$ & $\odot$ & - & $\odot$ & 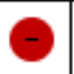 & $\theta$ & $\odot$ \\
\hline Aydemir 2006 & $\odot$ & $\odot$ & $\odot$ & $\odot$ & $\odot$ & $?$ & $?$ & $\odot$ & - & $?$ & + \\
\hline Cacchio 2009a & $?$ & $?$ & $?$ & $?$ & + & $?$ & $\odot$ & $\odot$ & $\odot$ & $\odot$ & $\odot$ \\
\hline Cacchio 2009b & $?$ & $?$ & $?$ & $?$ & + & + & $\odot$ & ○ & $\odot$ & $\odot$ & $?$ \\
\hline Dimitrijevic 2014 & $\odot$ & $\odot$ & $\odot$ & $\odot$ & $?$ & $?$ & - & $\odot$ & $\odot$ & $\Theta$ & + \\
\hline Duman 2009 & $?$ & $?$ & $\Theta$ & - & $?$ & $\odot$ & $\odot$ & $\odot$ & - & + & + \\
\hline Durmus 2004 & $\odot$ & $?$ & + & $\odot$ & + & $\odot$ & $\odot$ & $\odot$ & $\odot$ & $\odot$ & + \\
\hline Hazneci 2005 & $?$ & $?$ & + & + & $?$ & $?$ & $?$ & $\odot$ & $\odot$ & $\odot$ & + \\
\hline Jeon 2014 & $?$ & $?$ & $?$ & $?$ & + & $\odot$ & $\odot$ & - & $\odot$ & $\odot$ & $?$ \\
\hline Li 2012 & $\odot$ & + & $\odot$ & $\odot$ & $?$ & + & $\odot$ & + & $?$ & + & + \\
\hline Moseley 2004 & $\odot$ & + & $\odot$ & $\odot$ & + & $\odot$ & $\odot$ & $\odot$ & $\odot$ & $?$ & $?$ \\
\hline Moseley 2005 & $\odot$ & $\odot$ & $\odot$ & $\odot$ & $?$ & $\odot$ & $\theta$ & - & - & + & $?$ \\
\hline Moseley 2006 & $\odot$ & + & $\odot$ & $\odot$ & + & $\odot$ & $\odot$ & $\odot$ & $\odot$ & $\odot$ & $?$ \\
\hline Moseley 2009 & $?$ & + & $?$ & $?$ & $?$ & $\odot$ & + & - & - & $\theta$ & $?$ \\
\hline Mucha 1992 & $?$ & $?$ & $\odot$ & $\odot$ & $?$ & $\odot$ & + & ○ & $\odot$ & $\Theta$ & + \\
\hline Oerlemans 1999 & $\odot$ & $?$ & $\odot$ & $\odot$ & $?$ & $?$ & + & $\odot$ & $\odot$ & + & $\theta$ \\
\hline Schreuders 2014 & $\odot$ & $\odot$ & $\ominus$ & $\ominus$ & + & $\odot$ & $\theta$ & $\odot$ & $\odot$ & $?$ & - \\
\hline Uher & $?$ & + & $\odot$ & $\odot$ & + & $\odot$ & $\odot$ & $\odot$ & $\odot$ & $\odot$ & + \\
\hline
\end{tabular}

'Risk of bias' summary: review authors' judgements about each 'Risk of bias' item for each included trial.

\section{Sources of support}

\section{Internal sources}

- No sources of support provided

\section{External sources}

- No sources of support provided

\section{Feedback}

\section{Appendices}




\section{Search strategies}

\section{CENTRAL, DARE and HTA search strategies}

\#1 MeSH descriptor: [Complex Regional Pain Syndromes] explode all trees

\#2 "complex regional pain syndrome*":ti,ab,kw (Word variations have been searched)

\#3 crps:ti,ab,kw (Word variations have been searched)

\#4 (Post traumatic near/1 (algodystrophy or dystrophy or neurodystrophy or osteoporosis or pain syndrome)):ti,ab,kw (Word variations have been searched)

\#5 "Minor causalgia":ti,ab,kw (Word variations have been searched)

\#6 "Transient migratory osteoporosis":ti,ab,kw (Word variations have been searched)

\#7 "Peripheral trophneurosis":ti,ab,kw (Word variations have been searched)

\#8 ((Major or mitchell*) near/1 causalgia):ti,ab,kw (Word variations have been searched)

\#9 "Neurovascular dystrophy":ti,ab,kw (Word variations have been searched)

\#10 "Sudecks Osteodystrophy":ti,ab,kw (Word variations have been searched)

\#11 Sympathalgia:ti,ab,kw (Word variations have been searched)

\#12 Chronic traumatic oedema:ti,ab,kw (Word variations have been searched)

\#13 Sympathetic dystrophy syndrome:ti,ab,kw (Word variations have been searched)

$\# 14 \# 1$ or \#2 or \#3 or \#4 or \#5 or \#6 or \#7 or \#8 or \#9 or \#10 or \#11 or \#12 or \#13

\#15 MeSH descriptor: [Physical Therapy Modalities] explode all trees

\#16 physiotherap*:ti,ab,kw (Word variations have been searched)

\#17 "physical therap*":ti,ab,kw (Word variations have been searched)

\#18 manual therapy:ti,ab,kw (Word variations have been searched)

\#19 manipulative therapy:ti,ab,kw (Word variations have been searched)

\#20 ((therapeutic or therapy) near/2 exercise):ti,ab,kw (Word variations have been searched)

\#21 MeSH descriptor: [Electric Stimulation Therapy] explode all trees

\#22 (electrotherapy or TENS or "transcutaneous electrical nerve stimulation" or "therapeutic ultrasound" or interferential or "shortwave diathermy" or "laser therapy " or "heat therapy" or cryotherapy):ti,ab,kw (Word variations have been searched)

\#23 graded motor imagery:ti,ab,kw (Word variations have been searched)

\#24 mirror therapy:ti,ab,kw (Word variations have been searched)

\#25 MeSH descriptor: [Musculoskeletal Manipulations] explode all trees

\#26 tactile sensory discriminatory training:ti,ab,kw (Word variations have been searched)

\#27 sensory-motor integration:ti,ab,kw (Word variations have been searched)

\#28 sensory-motor re-tuning:ti,ab,kw (Word variations have been searched)

\#29 hydrotherapy:ti,ab,kw (Word variations have been searched) 
Physiotherapy for pain and disability in adults with complex regional pain syndrome.26-Feb-2016 \#30 (pain near/3 (advice or education)):ti,ab,kw (Word variations have been searched)

\#31 (manipulation or massage or de-sensiti?ation or mobili?ation):ti,ab,kw (Word variations have been searched)

$\# 32 \# 15$ or \#16 or \#17 or \#18 or \#19 or \#20 or \#21 or \#22 or \#23 or \#24 or \#25 or \#26 or \#27 or \#28 or \#29 or \#30 or \#31

\#33 \#14 and \#32

\section{MEDLINE search strategy}

1. exp Complex Regional Pain Syndromes/

2. "complex regional pain syndrome*".tw.

3. crps.tw.

4. (Post traumatic adj1 (algodystrophy or dystrophy or neurodystrophy or osteoporosis or pain syndrome)).tw.

5. "Minor causalgia".tw.

6. "Transient migratory osteoporosis".tw.

7. "Peripheral trophneurosis".tw.

8. "Sudeck's Osteodystrophy".tw.

9. "Neurovascular dystrophy".tw.

10. ((Major or mitchell $\left.{ }^{\star}\right)$ adj1 causalgia).tw.

11. Sympathalgia.tw.

12. Chronic traumatic oedema.tw.

13. Sympathetic dystrophy syndrome.tw.

14. or $/ 1-13$

15. exp Physical Therapy Modalities/

16. physiotherap*.tw.

17. "physical therap*".tw.

18. manual therapy.tw.

19. manipulative therapy.tw.

20. ((therapeutic or therapy) adj2 exercise).tw.

21. exp Electric Stimulation Therapy/

22. (electrotherapy or TENS or "transcutaneous electrical nerve stimulation" or "therapeutic ultrasound" or interferential or "shortwave diathermy" or "laser therapy " or "heat therapy" or cryotherapy).tw.

23. graded motor imagery.tw.

24. mirror therapy.tw.

25. exp Musculoskeletal Manipulations/

26. tactile sensory discriminatory training.tw. 
27. sensory-motor integration.tw.

28. sensory-motor re-tuning.tw.

29. hydrotherapy.tw.

30. (pain adj3 (advice or education)).tw.

31. (manipulation or massage or de-sensiti\#ation or mobili\#ation).tw.

32. or/15-31

33. 14 and 32

34. randomized controlled trial.pt.

35. controlled clinical trial.pt.

36. randomized.ab.

37. placebo.ab.

38. drug therapy.fs.

39. randomly.ab.

40. trial.ab.

41. or/34-40

42. exp animals/ not humans.sh.

43. 41 not 42

44. 33 and 43

\section{EMBASE search strategy}

1. exp Complex Regional Pain Syndromes/

2. "complex regional pain syndrome*".tw.

3. crps.tw.

4. (Post traumatic adj1 (algodystrophy or dystrophy or neurodystrophy or osteoporosis or pain syndrome)).tw.

5. "Minor causalgia".tw.

6. "Transient migratory osteoporosis".tw.

7. "Peripheral trophneurosis".tw.

8. "Sudeck's Osteodystrophy".tw.

9. "Neurovascular dystrophy".tw.

10. ((Major or mitchell $\left.{ }^{\star}\right)$ adj1 causalgia).tw.

11. Sympathalgia.tw.

12. Chronic traumatic oedema.tw.

13. Sympathetic dystrophy syndrome.tw.

14. or $/ 1-13$ 
15. exp Physical Therapy Modalities/

16. physiotherap*.tw.

17. "physical therap*".tw.

18. manual therapy.tw.

19. manipulative therapy.tw.

20. ((therapeutic or therapy) adj2 exercise).tw.

21. exp Electric Stimulation Therapy/

22. (electrotherapy or TENS or "transcutaneous electrical nerve stimulation" or "therapeutic ultrasound" or interferential or "shortwave diathermy" or "laser therapy " or "heat therapy" or cryotherapy).tw.

23. graded motor imagery.tw.

24. mirror therapy.tw.

25. exp Musculoskeletal Manipulations/

26. tactile sensory discriminatory training.tw.

27. sensory-motor integration.tw.

28. sensory-motor re-tuning.tw.

29. hydrotherapy.tw.

30. (pain adj3 (advice or education)).tw.

31. (manipulation or massage or de-sensiti\#ation or mobili\#ation).tw.

32. or/15-31

33. 14 and 32

34 random $\$ . t w$.

35 factorial\$.tw.

36 crossover $\$ . t w$.

37 cross over $\$$.tw.

38 cross-over $\$ . t w$.

39 placebo\$.tw.

40 (doubl\$ adj blind\$).tw.

41 (singl\$ adj blind\$).tw.

42 assign $\$ . t w$.

43 allocat\$.tw.

44 volunteer\$.tw.

45 Crossover Procedure/

46 double-blind procedure.tw.

47 Randomized Controlled Trial/ 
48 Single Blind Procedure/

49 or/34-48 (1433702)

50 (animal/ or nonhuman/) not human/

5149 not 50

5233 and 51

\section{PsycINFO search strategy}

1. exp "Complex Regional Pain Syndrome (Type I)"/

2. "complex regional pain syndrome ${ }^{*}$. .tw.

3. crps.tw.

4. (Post traumatic adj1 (algodystrophy or dystrophy or neurodystrophy or osteoporosis or pain syndrome)).tw.

5. "Minor causalgia".tw.

6. "Transient migratory osteoporosis".tw.

7. "Peripheral trophneurosis".tw.

8. "Sudeck's Osteodystrophy".tw.

9. "Neurovascular dystrophy".tw.

10. ((Major or mitchell $\left.{ }^{\star}\right)$ adj1 causalgia).tw.

11. Sympathalgia.tw.

12. Chronic traumatic oedema.tw.

13. Sympathetic dystrophy syndrome.tw.

14. or $/ 1-13$

15. exp Physical Therapy/

16. physiotherap*.tw.

17. "physical therap*".tw.

18. manual therapy.tw.

19. manipulative therapy.tw.

20. ((therapeutic or therapy) adj2 exercise).tw.

21. exp Electrical Stimulation/

22. (electrotherapy or TENS or "transcutaneous electrical nerve stimulation" or "therapeutic ultrasound" or interferential or "shortwave diathermy" or "laser therapy " or "heat therapy" or cryotherapy).tw.

23. graded motor imagery.tw.

24. mirror therapy.tw.

25. tactile sensory discriminatory training.tw.

26. sensory-motor integration.tw. 
27. sensory-motor re-tuning.tw.

28. hydrotherapy.tw.

29. (pain adj3 (advice or education)).tw.

30. (manipulation or massage or de-sensiti\#ation or mobili\#ation).tw.

31. or $/ 15-30$

32. 14 and 31

33. clinical trials/

34. (randomis* ${ }^{*}$ or randomiz*).tw.

35. (random $\$$ adj3 (allocat $\$$ or assign $\$)$ ).tw.

36. ((clinic $\$$ or control\$) adj trial\$).tw.

37. ((singl\$ or doubl\$ or trebl\$ or tripl\$) adj3 (blind $\$$ or mask $\$)$ ).tw.

38. (crossover\$ or "cross over\$").tw.

39. random sampling/

40. Experiment Controls/

41. Placebo/

42. placebo\$.tw.

43. exp program evaluation/

44. treatment effectiveness evaluation/

45. ((effectiveness or evaluat\$) adj3 (stud\$ or research\$)).tw.

46. or/33-45

47. 32 and 46

\section{CINAHL search strategy}

S43 S33 AND S42

S42 S34 OR S35 OR S36 OR S37 OR S38 OR S39 OR S40 OR S41

S41 (allocat ${ }^{\star}$ random*)

S40 (MH "Quantitative Studies")

S39 (MH "Placebos")

S38 placebo*

S37 (random* allocat ${ }^{*}$ )

S36 (MH "Random Assignment")

S35 (Randomi?ed control* trial* $^{\star}$ )

S34 (singl ${ }^{*}$ blind $^{*}$ ) or $\left(\right.$ doubl $^{*}$ blind $^{*}$ ) or (tripl ${ }^{*}$ blind $^{*}$ ) or (trebl* blind ${ }^{*}$ ) or (trebl* mask ${ }^{*}$ ) or (tripl mask $^{*}$ ) or (doubl $^{\star}$ mask $^{*}$ ) or (singl ${ }^{\star}$ mask $^{*}$ ) 
S33 S14 AND S32

S32 S15 OR S16 OR S17 OR S18 OR S19 OR S20 OR S21 OR S22 OR S23 OR S24 OR S25 OR S26 OR S27 OR S28 OR S29 OR S30 OR S31

S31 (manipulation or massage or de-sensiti?ation or mobili?ation)

S30 (pain N3 (advice or education))

S29 hydrotherapy

S28 sensory-motor re-tuning

S27 sensory-motor integration

S26 tactile sensory discriminatory training

S25 (MH "Manual Therapy+")

S24 mirror therapy

S23 graded motor imagery

S22 (electrotherapy or TENS or "transcutaneous electrical nerve stimulation" or "therapeutic ultrasound" or interferential or "shortwave diathermy" or "laser therapy " or "heat therapy" or cryotherapy)

S21 (MH "Transcutaneous Electrical Nerve Stimulation (lowa NIC)")

S20 ((therapeutic or therapy) N2 exercise)

S19 manipulative therapy

S18 manual therapy

S17 "physical therap*"

S16 physiotherap*

S15 (MH "Physical Therapy+")

S14 S1 OR S2 OR S3 OR S4 OR S5 OR S6 OR S7 OR S8 OR S9 OR S10 OR S11 OR S12 OR S13

S13 Sympathetic dystrophy syndrome

S12 Chronic traumatic oedema

S11 Sympathalgia

S10 ((Major or mitchell $\left.{ }^{\star}\right)$ N1 causalgia)

S9 "Neurovascular dystrophy"

S8 "Sudeck's Osteodystrophy"

S7 "Peripheral trophneurosis"

S6 "Transient migratory osteoporosis"

S5 "Minor causalgia"

S4 (Post traumatic N1 (algodystrophy or dystrophy or neurodystrophy or osteoporosis or pain syndrome))

S3 crps

S2 "complex regional pain syndrome*" 
S1 (MH "Complex Regional Pain Syndromes+")

\section{LILACS search strategy}

1. "crps"

2. "physiotherapy"

3. "clinical trial"

\section{PEDro search strategy}

1. "complex regional pain syndrome"

2. "reflex sympathetic dystrophy"

3. "causalgia"

4. "sudeks'"

5. "sympathetic pain"

6. "clinical trial"

\section{Web of Science search strategy}

1. "crps"

2. "physiotherapy"

3. "orthopaedic rehabilitation"

4. "articles" 